Running Head: Pathways to Literacy

\title{
Pathways to Literacy: A Study of Invented Spelling and Its Role in Learning to Read
}

\author{
Gene P. Ouellette \\ Carleton University \\ Ottawa, Ontario
}

\begin{abstract}
A thesis submitted to the Faculty of Graduate Studies and Research In partial fulfillment of the requirements for the degree of Doctor of Philosophy in Psychology
\end{abstract}

August 2006

(C) Gene Ouellette 2006 


$\begin{array}{ll}\begin{array}{l}\text { Library and } \\ \text { Archives Canada }\end{array} & \begin{array}{l}\text { Bibliothèque et } \\ \text { Archives Canada }\end{array} \\ \begin{array}{l}\text { Published Heritage } \\ \text { Branch }\end{array} & \begin{array}{l}\text { Direction du } \\ \text { Patrimoine de l'édition }\end{array} \\ \begin{array}{l}\text { 395 Wellington Street } \\ \text { Ottawa ON K1A ON4 }\end{array} & \begin{array}{l}\text { 395, rue Wellington } \\ \text { Ottawa ON K1A ON4 } \\ \text { Canada }\end{array}\end{array}$

Your file Votre référence ISBN: 978-0-494-18229-1 Our file Notre référence ISBN: 978-0-494-18229-1

NOTICE:

The author has granted a nonexclusive license allowing Library and Archives Canada to reproduce, publish, archive, preserve, conserve, communicate to the public by telecommunication or on the Internet, loan, distribute and sell theses worldwide, for commercial or noncommercial purposes, in microform, paper, electronic and/or any other formats.

The author retains copyright ownership and moral rights in this thesis. Neither the thesis nor substantial extracts from it may be printed or otherwise reproduced without the author's permission.
AVIS:

L'auteur a accordé une licence non exclusive permettant à la Bibliothèque et Archives Canada de reproduire, publier, archiver, sauvegarder, conserver, transmettre au public par télécommunication ou par l'Internet, prêter, distribuer et vendre des thèses partout dans le monde, à des fins commerciales ou autres, sur support microforme, papier, électronique et/ou autres formats.

L'auteur conserve la propriété du droit d'auteur et des droits moraux qui protège cette thèse. $\mathrm{Ni}$ la thèse ni des extraits substantiels de celle-ci ne doivent être imprimés ou autrement reproduits sans son autorisation.
In compliance with the Canadian

Privacy Act some supporting forms may have been removed from this thesis.

While these forms may be included in the document page count, their removal does not represent any loss of content from the thesis.
Conformément à la loi canadienne sur la protection de la vie privée, quelques formulaires secondaires ont été enlevés de cette thèse.

Bien que ces formulaires aient inclus dans la pagination, il n'y aura aucun contenu manquant.

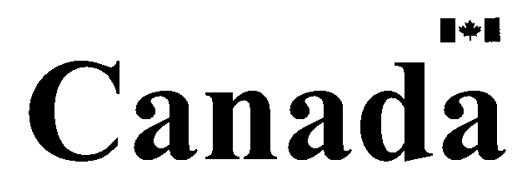




\begin{abstract}
This paper presents a detailed consideration of young children's attempts at spelling, referred to as invented spelling, and considers both the component processes that underlie this literacy activity, and the role that invented spelling may play in subsequent literacy acquisition. The present research is presented here as two distinct studies. The first study investigated the component cognitive-linguistic skills that underlie invented spelling sophistication in non-readers. Skill areas hypothesized to be important were evaluated in a sample $(\mathrm{N}=115)$ of 5-year old kindergarten students. Results indicated important roles of phonological working memory, letter-sound knowledge, phonemic awareness, other areas of oral language, and orthographic awareness, to invented spelling. These results are discussed in relation to previous research as well as to a proposed conceptualization of invented spelling as a complex developmental skill that integrates representations from phonological and orthographic domains. The second study evaluated the utility of training 5-year olds to be better invented spellers. In particular, the effects of training invented spelling on subsequent phonemic awareness, orthographic knowledge, and learning to read were evaluated. The present results offer the first direct training evidence that practice in invented spelling helps children hone phonemic and orthographic awareness, and importantly, helps them learn how to read. These important findings are discussed in the context of the relations between spelling and reading in early literacy acquisition.
\end{abstract}




\section{Acknowledgements}

Seldom is a journey undertaken in complete isolation; the journey that has led to the completion of this document is certainly no exception. This research could not have been completed without the support of many. The professional and thorough supervision of Dr. Monique Sénéchal has been greatly appreciated, and for her guidance and support I will always be grateful. I am also thankful for the guidance and encouragement offered by Dr. Jo-Anne LeFevre and Dr. John Logan over the past few years. Research of this scope would not have been possible without tremendous help with stimuli preparation and data collection, and for that I sincerely thank Tina Leclaire and Kristen Pretruska, as well as all others who contributed time to this project. Financial support through Doctoral Fellowships from the Natural Sciences and Engineering Research Council of Canada and the Ontario Graduate Scholarship program, made the journey possible. I also thank Carleton University and the Department of Psychology for additional scholarship support. Finally, I extend my appreciation and love to my family, as without their support, I would never had been able to start the journey in the first place. 


\section{Table of Contents}

I. Introduction: Research Problems and Importance 1

II. Literature Review: An Introduction to Early Spelling 4

An Overview of Invented Spelling:

Children Attempt to Represent What They Hear 4

An Overview of Invented Spelling: Stages/Phases of Acquisition 5

III. Literature Review: Component Processes of Invented Spelling 9

Invented Spelling: More Than a Reflection of Phonemic Awareness? 9

The Importance of Letter-Sound Knowledge $\quad 12$

$\begin{array}{lr}\text { Working Memory } & 14\end{array}$

Orthographic Awareness: Skills Beyond Phonemic Awareness and Letter-Sound Knowledge $\quad 15$

$\begin{array}{lr}\text { Oral Language } & 18\end{array}$

$\begin{array}{ll}\text { Vocabulary } & 18\end{array}$

$\begin{array}{ll}\text { Morphological Processing } & 19\end{array}$

Component Processes of Invented Spelling:

A Summary and Proposed Research 20

IV. Study 1: Component Processes of Invented Spelling 21

$\begin{array}{ll}\text { Hypotheses } & 21\end{array}$ 
$\begin{array}{ll}\text { Method } & 22\end{array}$

$\begin{array}{ll}\text { Participants } & 22\end{array}$

$\begin{array}{ll}\text { Tests and Measures } & 23\end{array}$

$\begin{array}{ll}\text { Procedure } & 30\end{array}$

Results 31

Data Reduction 31

$\begin{array}{ll}\text { Descriptive Statistics } & 32\end{array}$

$\begin{array}{ll}\text { Regression Analyses } & 34\end{array}$

Mediation Models $\quad 42$

Interim Discussion 48

Towards a Cognitive Model of Invented Spelling:

The Role of Internal Representations $\quad 50$

V. Literature Review: The Connection Between Spelling and Reading 53

Parallels in Development $\quad 53$

Coordination in Development: Directions of Influence 55

$\begin{array}{lr}\text { Training Studies } & 59\end{array}$

The Connection Between Spelling and Reading:

Summary and the Present Research

VI. Study 2: An Invented Spelling Training Study 64

$\begin{array}{ll}\text { Method } & 64\end{array}$ 
$\begin{array}{ll}\text { Participants } & 64\end{array}$

Experimental Design $\quad 66$

Intervention Groups $\quad 66$

$\begin{array}{ll}\text { Procedure } & 71\end{array}$

$\begin{array}{ll}\text { Post-Test Measures } & 71\end{array}$

$\begin{array}{ll}\text { Hypotheses } & 76\end{array}$

$\begin{array}{ll}\text { Results } & 76\end{array}$

$\begin{array}{ll}\text { Post-Test Measures } & 76\end{array}$

Facilitative effects: A word-learning task 84

$\begin{array}{lr}\text { Supplementary Analyses } & 85\end{array}$

Interim Discussion $\quad 86$

VII. General Discussion and Conclusions 92

$\begin{array}{ll}\text { Future Research } & 96\end{array}$

$\begin{array}{ll}\text { VIII. References } & 98\end{array}$ 


\section{List of Tables}

Table 1.Component Loadings of Letter-Sound and Orthographic Awareness Tasks From Principal Components Analysis

Table 2. Zero-Order Correlations Among Variables, With Means and Standard Deviations

Table 3. Hierarchical Regression Analyses With Phonemic Awareness and Letter-Sound Knowledge

Table 4. Hierarchical Regression Analyses With Working Memory

Table 5. Hierarchical Regression Analyses With Orthographic Awareness Measures

Table 6. Hierarchical Regression Analyses With Oral Language Measures

Table 7. Word-Learning Task:

Results and Orthogonal (Helmert) Contrasts By Trial 
Figure 1.Mediation Model of Working Memory, Phonemic Awareness, and Invented Spelling

Figure 2.Mediation Model of Oral Language, Phonemic Awareness, and Invented Spelling

Figure 3.Mediation Model of Parental Education, Child Oral Language, and Invented Spelling

Figure 4. Mean performance (and standard deviation) of each training group on invented spelling

Figure 5. Mean performance (and standard deviation) of each training group on phonemic awareness

Figure 6. Mean performance (and standard deviation) of each training group on letter-sound knowledge

Figure 7. Mean performance (and standard deviation) of each training group on orthographic awareness measures

Figure 8. Mean performance (and standard deviation) of each training group on word reading measures

Figure 9. Mean performance on each trial of the word-learning task 
List of Appendices

$\begin{array}{ll}\text { Appendix A. Assessment Stimuli } & 110\end{array}$

$\begin{array}{ll}\text { Appendix B. Invented Spelling Scoring Key } & 114\end{array}$

Appendix C. Pre-Test Scores and Univariate Tests For All Training Groups $\quad 121$



Appendix E. Study 2 Training Stimuli For All Groups

and Sequence of Presentation 123

Appendix F. Feedback Guidelines for Invented Spelling Training 125

Appendix G. Pre- and Post- Test Means by School 132 
Pathways to Literacy: A Study of Invented Spelling and Its Role in Learning to Read

I. Introduction: Research Problems and Importance

It is now well established that individual differences in literacy skill acquisition emerge early and are stable over time (e.g., Scarborough, 1998). Early literacy can be defined in basic terms as reading and spelling (Fletcher-Flinn, Shankweiler, \& Frost, 2004), although early spelling acquisition is often overlooked in literacy research and instruction. Yet, before children are exposed to formal teaching they often attempt to represent words in print. These early pre-conventional spellings are referred to as invented spelling and may offer a window into the development of cognitive and linguistic skills that are critical for future literacy skill acquisition. At present, the component processes underlying this potentially important area of early literacy are not well established. Further, from an applied perspective there remains little consensus as to whether invented spelling is a precursor to early word reading and hence should be incorporated into early literacy programs. The present research has two goals: to explore the component processes pertinent to invented spelling, and to evaluate the potential beneficial effects of including practice in invented spelling with kindergarten children on their subsequent ability to learn how to read words.

When children first begin experimenting with the written code their spelling attempts may bear little resemblance to conventional spellings. Over time, invented spellings increase in complexity and accuracy as children become more adept at capturing words in print, typically without any direct instruction. Phases of acquisition have been described to capture this developmental progression in early spelling. These developmental phases reflect a growing ability to represent sounds within words in print 
and can be used to describe and evaluate the sophistication of young children's spellings. Although qualitative research has offered detailed descriptions of invented spelling, the component processes have not been fully explored. Where previous efforts have been directed at describing what children do, few have considered how they do it. An understanding of the component processes involved in early spelling is important to models of early literacy acquisition and to explain individual differences in early childhood. This is the focus of the first part of the present research.

Invented spelling emerges before children can read (Gentry \& Gillet, 1993). This observation may have important implications for the coordination of spelling and reading in early skill acquisition. In this respect, there are different theoretical conceptualizations of how spelling and reading relate to each other across development, in particular with respect to pathways of influence from one area to the other. From an applied perspective, there also remains little consensus as to the sequence and/or integration of instruction in spelling and reading. The picture is complicated by transient relations across development and inconsistent definitions of the constructs. A better understanding of the causal relations between spelling and reading can contribute to both models of early literacy acquisition and empirically sound approaches to early childhood education aimed at optimizing literacy. This is the focus of the latter part of the present research.

The present research is thus presented here as two distinct studies. The first study is concerned with exploring the component processes pertinent to invented spelling. I begin with an overview of invented spelling that describes the increasing sophistication of young children's attempts at representing words in print. This overview leads into an exploration of cognitive-linguistic skills hypothesized here to be relevant components of 
invented spelling: phonemic awareness, letter-sound knowledge, working memory, orthographic awareness, and oral language. These constructs are all defined and a critical evaluation of related research is offered to provide a rationale for their inclusion here. The methodology, results, and discussion are then presented for this component of the present research.

The second study of the present research involved a training paradigm designed to evaluate the influence of invented spelling practice on learning to read words. This study is introduced with a critical evaluation of correlation and training evidence concerning the links between spelling and reading. It is argued that the relation between spelling and reading is best understood if invented spelling is acknowledged as an early phase of spelling acquisition. It is then hypothesized that a pathway of influence from invented spelling to early word reading can be identified in early literacy acquisition. The need for direct training studies is established and the methodology is presented in detail, along with the results and discussion. A general discussion concludes this written document. 


\section{Literature Review: An Introduction to Early Spelling An Overview of Invented Spelling: Children Attempt to Represent What They Hear}

Before children are formally taught to read or spell, they often experiment with the written code. They may begin by drawing and scribbling, but once writings are differentiated from drawings, children attempt to represent in print, words that they hear. This process is referred to as invented spelling. It has been proposed that children start the writing process with invented spelling, wherein they experiment with representing spoken language in print and refine their productions over time (Chomsky, 1971; Read, 1971). According to this view, invented spelling represents a very early aspect of literacy acquisition, one that surfaces before children are able to read. Invented spelling then may offer a window into developing cognitive and linguistic skills involved in early literacy skill acquisition, and is thus of considerable interest to the study of literacy.

Children's early attempts to represent words in print prior to any direct instruction in spelling have been of interest to both researchers and clinicians alike since the topic was brought to the forefront by Read (1971, 1975), Chomsky (1971) and Clay (1972). Read qualitatively described spelling attempts made by 20 preschoolers selected on the basis of demonstrating spontaneous invented spellings. His descriptions focused on the consistency of the children's errors and led to the conclusion that the children were attempting to represent what they heard in predictable ways. For instance, Read noted that an early and frequent strategy used by the preschool children was to represent words with letter names (for example, writing $U$ for "you"). Read considered such consistent patterns as evidence that children were analyzing the phonological structure of spoken 
language, and concluded that children initially try to spell by representing what they hear, rather than by reproducing memorized strings of letters.

Further support for the premise that children's early spellings represent attempts at translating what is heard into print comes from extensive qualitative analyses of over 5000 invented spelling attempts documented by Treiman (1993). For instance, Treiman described many common patterns evident in invented spellings that suggest children choose letters based upon articulation and acoustic similarity among sounds. As an example, children often represent the orthography for a /tr/ consonant cluster as $J$, which can be explained by the acoustic, not visual, similarity between the target and letters chosen.

\section{An Overview of Invented Spelling: Stages/Phases of Acquisition}

An important premise originally put forth in Read's influential writings (1971, 1975) was that invented spelling reflects a developmental progression of increasing sophistication as children become more adept at representing sounds within words in print. Read's writings were influential in relating early spelling to phonology, as reflected in the subsequent descriptions of developmental stages proposed by several researchers and educators (Ferreiro, 1991; Gentry, 1982; Gentry \& Gillet, 1993; Henderson, 1981; Treiman, 1993). Gentry and Gillet arguably offered the most detailed description, and thus it is these writers' schema that will be outlined here.

Based on qualitative analyses of the transcriptions of invented spellings offered by Read (1971, 1975), as well as those of another single case study, Gentry (1982) and Gentry and Gillet (1993) proposed 5 stages of early spelling acquisition. The first level is referred to as the pre-communication stage and is characterized by non-alphabetic 
markings or scribbles, then random strings of letters and/or numbers. These initial attempts at printing have been further analyzed and broken down into more detail by Levin and colleagues (e.g., Levin, Share, \& Shatil, 1996) as well as Ferreiro (Ferreiro \& Teberosky, 1982; Ferreiro, 1988, as cited in Silva \& Martins, 2003). Children at this level do not make a connection between spoken language and representation in print, choosing rather to focus on attributes of the object. For example, more letters or symbols may be used to represent a word that refers to a large object.

The recognition that letters stand for sounds marks the onset of the semi-phonetic stage of early spelling. Yet the children at this stage can only partially represent what is heard. Initially children may represent the first sound of a word only, and later begin to mark the final sound and eventually the medial sound(s). Stage and Wagner (1992) also reported that young children's accuracy in spelling was best for the initial position in a syllable, next best for final position and worst for medial (vowel) position; this position effect diminished over time, thus confirming the progression of sound representation in the semi-phonetic stage. Further, the first vowels represented are typically those whose names are heard in the words (Ehri, 2000).

When children are using letters to represent all the sounds within a word they have entered into the phonetic stage of early spelling development. This level of spelling is characterized by all sounds being represented phonetically, although choices do not always conform to conventional spellings. Letter names often remain the basis for selection in spelling. For example, "wife" may be spelled as $Y F$ given the phonetic sound of $Y$ ("wie") (Ehri, 1989). Vowels are typically marked here, with vowel names used to represent long vowels (Tangel \& Blachman, 1992). For instance, "boat" may be spelled 
BOT. Following the developmental progression of these stages then, early spelling appears to be characterized by phonological analysis of spoken language (Caravolas, Bruck, \& Genese, 2003).

The final proposed stages of early spelling are the transitional and conventional stages. The transitional level is appropriately described as a time of transition between invented - and conventional - spelling. The child is spelling phonetically yet begins to show awareness of word specific features (orthographic awareness) and morphology. The conventional stage is marked by a reliance on memorized word-specific orthography. Alternate accounts (eg., Henderson, 1981) propose the same general sequence of acquisition as detailed here.

In summary, these stages of spelling reflect a progression from initial nonalphabetic markings to the emergence of conventional word-specific forms. It has been suggested that once children enter into a semi-phonetic level of spelling, stages become transient periods and may be better described in terms of overlapping waves rather than distinct stages per se (Ehri, 2005; Siegler, 2000). Recently, Ehri as well as Rieben, Ntamakiliro, Gonthier, and Fayol (2005) have argued that spelling acquisition does not necessarily follow a step-by-step progression, but rather occurs with overlap between levels. Spelling acquisition is thus best described in terms of phases rather than stages, to more accurately capture development: stage theory suggests that children master each stage then progress to the next, although the conceptualization of phases in development is consistent with the view that children can exhibit characteristics of different levels at the same point in time. For clarity, I will herein use the term phases when discussing levels of spelling sophistication. A critical evaluation of research exploring the skills 
underlying invented spelling is presented next, together with an argument for considering skills beyond the realm of phonology in early spelling attempts. 
III. Literature Review: Component Processes of Invented Spelling

Invented spelling has been described in terms of a progression of increasing complexity prior to the learning of conventional spellings. Despite the carefully defined phases of acquisition just reviewed, little is known concerning the cognitive and linguistic underpinnings of this area of literacy. From a component processes perspective, the question is which developmental skills are related to the complexity or sophistication of invented spelling. A review of the literature on invented spelling reveals important associations between invented spelling and phonemic awareness and letter-sound knowledge. Other cognitive-linguistic areas have received far less empirical study, although there is tentative empirical and/or theoretical support for a hypothesized relevance of working memory, orthographic awareness, and oral language beyond phonemic awareness. These areas are discussed in detail below along with the rationale for considering their role in invented spelling.

Invented Spelling: More Than a Reflection of Phonemic Awareness?

Phonemic awareness refers to the awareness of, and access to, phonemes within a word (McBride-Chang \& Ho, 2005). Considerable evidence now exists that confirms a relation between phonemic awareness and word reading (see meta-analyses by Bus \& van IJzendoorn, 1999; Ehri et al., 2001). Yet, there has been less attention directed towards the relation between phonemic awareness and early spelling.

On the surface, it would seem reasonable to assume that early spelling involves phonemic awareness so as to allow sublexical segments to be represented in print. That is, an analysis of a word's phonemic structure appears necessary to isolate sounds within words and to store and retain grapheme-phoneme connections in memory (Dixon, Stuart, 
\& Masterson, 2002; Ehri et al., 2001; Rack, Hulme, Snowling, \& Wightman, 1994). Invented spelling may thus reflect developing phonemic analysis proficiency (Mann, 1993; Uhry, 1999). In fact, it has been proposed that phonemic analysis skill is necessary to both segment the speech stream and to allow for letters to be matched with individual phonemes as is being attempted in invented spelling (Ehri et al., 2001; Griffith, 1991; Stahl \& Murray, 1998).

Training studies involving phonemic awareness with invented spelling included as a post-test measure offer direct evidence of a causal connection between phonemic awareness and early spelling acquisition. In this respect, the Ehri et al. (2001) metaanalysis revealed that phonemic awareness training did improve spelling outcomes, with the greatest effect sizes reported for studies involving kindergarten children and experimenter-devised assessment (i.e., not standardized assessment of conventional spelling). Specific phonemic awareness tasks were not evaluated due to relatively few studies examining only a single type of activity.

The impressive training study reported by Tangel and Blachman $(1992,1995)$ offers particularly convincing evidence for the importance of phonemic awareness to invented spelling. These researchers trained 77 low-SES children on phonemic analysis and letter knowledge over an 11-week period in late kindergarten. Training included grouping pictured words on the basis of common onsets or rimes and a say-it-and-moveit activity in which children were taught to move a small disk for each sound they heard in a pictured word. A small group of letters and their sounds was also taught. Relative to a control group that received no intervention $(n=72)$, the trained group was superior in invented spelling sophistication with 5 words dictated at the end of the school year. 
Follow-up assessment late in grade 1 showed an experimental group advantage in both invented and conventional spelling. Similarly, Castiglioni-Spalten and Ehri (2003) reported improvements in both phonemic awareness and invented spelling for senior kindergarten children who were nonreaders (yet at a semi-phonetic level of spelling) after only a brief six-session training regimen with similar phonemic awareness tasks.

A recent study with Portuguese-speaking children highlights that the relation between phonemic awareness and invented spelling appears to be bi-directional. Martins and Silva (2006) trained 5-year-old nonreaders $(\mathrm{N}=45)$ to increase the complexity of their invented spellings, by contrasting each child's attempts with an instructor-created invented spelling that was representative of a more sophisticated token of invented spelling. Following only eight 15 -minute sessions over a two-week period, these children demonstrated superior phonemic awareness and alphabetic skills in comparison to a control group of children. It should be noted, however, that children in the control group were not exposed to the same training stimuli, and thus did not receive the same auditory stimulation as did children in the experimental group. Failure to expose participants in a control group to similar materials used for experimental interventions can threaten internal validity and jeopardize the interpretation of group differences (Troia, 1999).

The bi-directional relation between phonemic awareness and invented spelling reported by Martins and Silva (2006) is in accordance with Treiman (1993), who previously proposed that invented spelling both reflects phonemic awareness and fosters subsequent phonemic awareness growth. That is, phonemic awareness allows children to begin to segment a word and match sounds to letters, and experience with invented spelling further hones these skills making the child more aware of the alphabetic 
principle in the process. Empirical support for this contention is also garnered from results reported by Torgesen and Davis (1996). These investigators examined children's cognitive abilities that predicted response to a 12 -week phonemic-awareness training program for kindergarten children. Growth curve analysis revealed that improvements in phonemic awareness were related to pre-existing invented spelling sophistication. In fact, invented spelling was found to be among the strongest predictors of both analytic (segmenting related tasks) and synthetic (blending tasks) phonemic awareness growth.

There is thus evidence to support a role of phonemic awareness in invented spelling and a role of invented spelling in phonemic awareness growth. In fact, some see invented spelling as a proxy measure of phonemic awareness (Mann, 1993; McBrideChang \& Ho, 2005). Yet, in a sample of 100 kindergarten nonreaders, Mann reported a correlation coefficient of .42 between phonemic awareness and invented spelling, which is far from the magnitude that would suggest that the measures are tapping the same construct. Furthermore, Liberman, Rubin, Duques, and Carlisle (1985) reported a regression model in which phonemic awareness accounted for $67 \%$ of the variance in invented spelling for a small group of kindergarteners, which again indicates substantial unexplained variance in invented spelling beyond phonemic awareness.

\section{The Importance of Letter-Sound Knowledge}

Invented spelling represents a child's attempts at translating spoken language into print. It thus seems reasonable to postulate that this process may be constrained or facilitated by the individual child's letter-sound knowledge. That is, letter-sound knowledge would appear to be necessary albeit not sufficient for invented spelling growth (Ball \& Blachman, 1991), and correlation evidence exists to support this 
contention. For instance, Shatil, Share, and Levin (2000) reported a moderate correlation coefficient of .48 between letter naming in kindergarten and inventive spelling sophistication in grade 1 for a sample of 317 Hebrew speaking children followed longitudinally. Similarly, Caravolas, Hulme, and Snowling (2001) followed 153 British children over the first two years of schooling and reported a concurrent correlation coefficient of .45 between knowledge of letter names and invented spelling sophistication in kindergarten, and a longitudinal correlation coefficient of .31 between letter names in kindergarten and invented spelling in grade 1. Perhaps more interesting, however, was a higher concurrent correlation coefficient of .76 between knowledge of letter sounds and invented spelling in kindergarten and a longitudinal correlation coefficient of .64 between knowledge of letter sounds in kindergarten and invented spelling in grade 1 . This pattern of correlations highlights the importance of letter-sound knowledge and not just knowledge of letter names in early spelling. This observation is in accordance with Burns and Richgels (1989) who reported that 4-year olds with more sophisticated invented spelling were also superior to peers with respect to knowledge of letter sounds (but not necessarily letter names).

Together with the previously reviewed research exploring connections between invented spelling and phonemic awareness, these results suggest that invented spelling reflects both phonemic awareness and letter-sound knowledge. In this respect, Caravolas et al. (2001) reported regression and path analyses in which kindergarten phonemic awareness and letter-sound knowledge together accounted for $64 \%$ of the variance in grade 1 invented spelling. These researchers also reported that phonemic awareness, letter-sound knowledge, and prior spelling were the only variables that predicted invented 
spelling over the first few years of schooling. What remains undefined, however, are the skills that contribute to invented spelling at the start of schooling. It should also be noted that these researchers defined invented spelling as phonological spelling, and thus did not consider accuracy of spelling attempts beyond sound-letter correspondence. That is, these researchers did not consider in their scoring procedure or at any test point, the children's orthographic and morphological knowledge. Yet, invented spelling has been described as a window into both developing phonological and orthographic domains (Stage \& Wagner, 1992). In addition, working memory was not considered in evaluating the skills that contribute to spelling in kindergarten. There thus remains to be a single comprehensive evaluation of the cognitive-linguistic skills that underlie invented spelling at the start of schooling.

\section{Working Memory}

The phonological loop of working memory refers to the active memory system involved in the temporary maintenance and processing of verbal or phonologically encoded information (Baddeley, 1986; Gathercole \& Baddeley, 1993). Following an intervention with grade 4 and 5 students with writing difficulties, Brooks, Vaughan, and Berninger (1999) reported that phonological memory constrained the development of (conventional) spelling. With respect to invented spelling, Caravolas et al. (2001) reported a correlation coefficient of .43 between performance on a verbal memory span task and invented spelling sophistication in kindergarten. Further, Stage and Wagner (1992) proposed that working memory limitations could explain the position effect seen in the semi-phonetic stage of spelling acquisition. That is, as discussed earlier, children are initially most accurate in representing the initial sound of a word, followed by the 
final sound, and least accurate for medial sounds. This positional effect diminishes with time. Stage and Wagner proposed that initial sounds are most accurately coded because there are fewer processing demands on working memory when the initial phoneme is processed, and final phoneme processing reflects a recency effect similar to serial position effects of memory span tasks. This interpretation is in accordance with Gathercole and Baddeley's $(1989,1993)$ original view that working memory is critical in language development, and provides the theoretical grounds to warrant further empirical investigation of the role of working memory in invented spelling acquisition. Working memory is also implicated in phonemic awareness tasks; whether working memory contributes to invented spelling beyond this association with phonemic awareness is not clear.

Given the state of the current literature, it cannot be ascertained if invented spelling is merely a combination of phonemic awareness and letter-sound knowledge, or if there are other potentially relevant cognitive-linguistic skills that have yet to be considered. One such area hypothesized here to be relevant, is orthographic awareness.

Orthographic Awareness: Skills Beyond Phonemic Awareness and Letter-Sound Knowledge

Empirical evidence appears to support the intuitive analysis of invented spelling reflecting phonemic awareness and letter-sound knowledge. Thus the ability to analyze a word's phonology and to then match phonemes with graphemes appropriately requires phonemic awareness and letter-sound knowledge. Yet the process of spelling also requires knowledge of written language form (Lehtonen \& Bryant, 2005), including an awareness of acceptable characters and sequences of characters that are permissible 
within the language. An ability to visually recognize legal symbols and patterns within words (in print) is referred to as orthographic awareness (Mather \& Goildstein, 2001). Note that inherent to this definition is implicit knowledge of rules that govern which characters are legal, and how these characters can be combined. Orthographic awareness is thus seen as a separate construct from letter-sound knowledge.

Orthographic awareness is implicated in translating a temporal stimulus into a spatial response. That is, a spoken word is an auditory stimulus that exists in the auditorytemporal domain, and in spelling this must be converted into print in the spatial domain where a left to right progression (of legal characters and sequences) matches the sequence of sounds as they occur in the temporal domain. Uhry (1999) has suggested that the importance of invented spelling lies in its beneficial impact on this knowledge of how to map a sequence of sounds into a left to right progression to represent what is heard. Orthographic awareness thus goes beyond letter-sound knowledge and encompasses the temporal coding of sounds in print using emerging knowledge concerning the legality of characters, and the letter sequences that may (or may not) occur in a language (Goulandris, 1994; Treiman, 1993). Thus, whereas letter-sound knowledge encompasses the auditory domain in matching graphemes to phonemes, orthographic knowledge pertains to the visual recognition of allowable characters and sequences in print.

Phase theories of early spelling highlight the role of phonologically based skills. Yet the emergence of orthographic awareness and stored orthographic representations may also be important components of this developmental progression. Although the role of orthographic awareness in early spelling remains controversial, there is in fact some evidence for orthographic awareness early in spelling (McBride-Chang, 1998). For 
instance, a role of orthographic awareness in young children's invented spellings was suggested in a recent study of Hebrew speaking 5-year olds (Aram \& Levin, 2002). These researchers assessed orthographic awareness by presenting children with a printed word paired with a nonword that either contained illegal characters (numerals, latin letters) or illegal letter sequences. The children were asked to indicate which one looked like a real word. A strong correlation was reported between performance on this task and a composite measure of invented spelling and word recognition $(r=.63)$. Unfortunately, invented spelling performance was not analyzed separately but only as part of a literacy composite including a measure of word reading.

Suggestive results have also been reported by Treiman and colleagues. In particular, children as young as 5-years old have been reported to be sensitive to illegal consonant doubling at the beginning of nonwords, even if they are not fully aware of the phonological consequences (Cassar \& Treiman, 1997; Treiman, 1993; see also Wright and Ehri, 2006). Similar results were recently reported for 6 and 7-year old Finnish(Lehtonen \& Bryant, 2005) and French-speaking children (Pacton \& Fayol, 2004). Children can thus apparently use orthographic sources of information early in spelling acquisition. Cassar and Treiman have accordingly challenged the view that invented spelling initially reflects only phonologically based processes. Recently, several researchers have also stressed that orthographic awareness, apart from letter-sound knowledge, warrants further attention in the study of early literacy-skill acquisition (Caravolas, Kessler, Hulme, \& Snowling, 2005; Dixon et al., 2002; Lehtonen \& Bryant, 2005). 


\section{Oral Language}

Invented spelling has been described as a complex developmental skill, in that it arguably integrates many skills and areas of knowledge such as phonemic awareness, letter-sound knowledge and possibly working memory and orthographic awareness (McBride-Chang, 1998; Richgels, 1995). Yet, other areas of oral language that have been studied and found to be important components of other aspects of early literacy have gone relatively unexplored with respect to invented spelling. Given their established role in literacy skill acquisition, these areas are of theoretical interest in exploring the component processes that underlie invented spelling and are outlined next.

\section{Vocabulary}

Recent developmental literacy research has highlighted the important role of oral vocabulary to early word reading and reading comprehension (Dickinson, McCabe, Anastasopoulos, Peisner-Feinberg, \& Poe, 2003; NICHD Early Child Research Network, 2005; Ouellette, 2006; Scarborough, 2005; Sénéchal, Ouellette, \& Rodney, 2006).

Vocabulary knowledge has been proposed to predict word reading through its association with phonemic awareness and decoding (e.g., Whitehurst \& Lonigan, 1998), as well as through a less specified complex relation between oral and written language (Dickinson et al., 2003; Nation \& Snowling, 2004; Ouellette, 2006). Despite this growing acknowledgment of an important multi-faceted involvement of oral-language vocabulary in literacy skill acquisition, its role has not been explored in connection to invented spelling. Multivariate developmental studies do provide some tentative evidence of a relation between vocabulary and invented spelling, as where correlations are available they indicate a moderate association. For instance, Sénéchal and LeFevre (2002) reported 
a correlation coefficient of .24 between invented spelling sophistication and receptive vocabulary in a sample of kindergarten and grade-1 students and Caravolas et al. (2001) reported a coefficient of .37 between the constructs in kindergarten. Whether these correlations indicate a unique role of oral vocabulary in early spelling, however, has not been fully explored.

\section{Morphological Processing}

Awareness and knowledge of morphology has been shown to be associated with learning conventional spellings in older children (Berninger, 2000; Bryant, Nunes, \& Bindman, 1997; Deacon \& Bryant, 2005; Nagy, Berninger, \& Abbott, 2006). More sophisticated spelling emerges across time as children learn more about letter patterns in printed words and they come to understand that morphemes are often spelled in a consistent fashion (Treiman, 1998). If invented spelling is regarded as a precursor to conventional spelling, then the role of morphological knowledge in invented spelling also warrants attention. This hypothesis was highlighted by Treiman, Cassar, and Zukowski (1994) who reported that kindergarten children were sensitive to morphological factors in that they showed an awareness of word stems in their spelling attempts. For instance, these young children were more likely to correctly spell the $T$ in the word DIRTY than they were in a word that contained no stem (e.g., CITY). In both of these words the $T$ is actually pronounced more like a $/ \mathrm{d} /$, yet knowledge of the word stem DIRT appears to facilitate the correct spelling of DIRTY. Morphological awareness may thus be involved earlier than presumed by purely phonological accounts of invented spelling. A thorough evaluation of the component processes pertinent to invented spelling must accordingly take into consideration the child's morphological development. 
Component Processes of Invented Spelling: A Summary and the Present Research

There now exists considerable empirical evidence that invented spelling reflects both phonemic awareness and letter-sound knowledge. The involvement of these developmental skills also makes intuitive sense: in representing a word in print using phonological strategies, the child must analyze the word and then convert the segments into letters. Invented spelling, however, may also encompass other cognitive-linguistic skills as discussed to this point. To date, no single study has evaluated the shared and unique contributions of these skills with respect to invented spelling proficiency. This was precisely the goal of the first component of the present research.

The first part of the present research, herein referred to as Study 1, was a correlation study of the component processes underlying invented spelling. Early in kindergarten, children were assessed on a battery of tasks that evaluated invented spelling, phonemic awareness, letter-sound knowledge, working memory, orthographic awareness, oral vocabulary, and morphological processing. Measures of word reading, analytic intelligence, and parental education were also included as control variables. This experimental design allows for a concurrent analysis of shared and unique contributions of various cognitive-linguistic skills, as identified on theoretical and empirical grounds, to invented spelling proficiency. Study 1 is presented next. 


\section{Study 1: Component Processes of Invented Spelling}

Descriptions of young children's attempts at spelling prior to formal instruction have led to detailed phase theories of early spelling acquisition. Despite the interest in children's early spellings, a comprehensive investigation of the component processes underlying invented spelling has yet to be reported. Specifically, the role of cognitive and linguistic skills beyond phonemic awareness and letter-sound knowledge in invented spelling are not well established. A better understanding of the component processes involved in invented spelling has direct relevance to theories of early literacy acquisition as well as applied significance in explaining individual differences and in guiding instructional approaches to literacy teaching and stimulation. The present research begins with a single-age group correlation study of invented spelling sophistication and cognitive-linguistic skills identified earlier on the basis of theoretical and empirical grounds. Given that invented spelling emerges prior to reading in development, the intention was to evaluate the cognitive-linguistic underpinnings of invented spelling in children who had yet to acquire word-reading skills. By focusing only on nonreaders, the component processes of invented spelling can be evaluated without any confounding influence of reading ability and practice on language and literacy skills.

\section{Hypotheses}

It was hypothesized that in accordance with previous research, phonemic awareness and letter-sound knowledge would each predict significant unique variance in invented spelling. Further, representing a word in print also appears to rely upon auditory working memory capacity. That is, working memory is implicated in allowing the child to analyze an auditorally presented word, and was thus hypothesized to be predictive of 
invented spelling. Given that working memory is also a necessary requisite for successful performance on phonemic awareness tasks, however, a unique contribution of working memory beyond phonemic awareness was not expected. In accordance with recent proposals, it was also hypothesized that orthographic awareness would be found to be an important- yet often overlooked- component of early literacy and hence invented spelling. Finally, there has been little empirical attention directed towards the relations between other components of oral language and invented spelling, despite the growing acknowledgement of the association between oral language and literacy. In particular, it was hypothesized that oral vocabulary and morphology would be pertinent to the emergence of more sophisticated phases of invented spelling, given their already documented associations with phonemic awareness, reading, and conventional spelling. Whether these areas of oral language make unique contributions to the complexity of invented spelling expected at the start of kindergarten, however, remains uncertain.

\section{Method}

\section{Participants}

Of the 165 kindergarten children who participated, 115 were included in the analyses presented here. Given the focus on identifying component processes to early invented spelling, it was important to control for pre-existing reading skills. Thus, children who could read more than 1 word from a list of 5 simple CVC decodable words and/or more than 1 word from a list of 5 high frequency sight-words, were dropped from the analyses $(n=30)$. Importantly, these stringent criteria control for any influence that pre-existing reading skills may have on the areas under study here. That is, reading may well influence the cognitive-linguistic skills hypothesized here to underlie invented 
spelling; by focussing only on nonreaders, any such confounding influences can be controlled. In addition, 14 children were excluded because English was not the language spoken most at home, 4 children were excluded because of incomplete testing related to behavior and/or processing concerns, 1 child was excluded because of a clinical diagnosis of ADD, and 1 child was excluded because their age fell outside of the expected range.

The final sample consisted of 115 kindergarten children ( 67 girls and 48 boys) between the ages of 58 and 71 months $(M=64.17, S D=3.83)$. All participating children used English as their primary language, and English was the only language spoken in the homes of 102 children, with English and one or more other languages spoken in the homes of 13 children. The mean level of education of the parent completing the permission form was a college or undergraduate university degree, and parental education ranged from not having completed high school to having completed post-graduate studies. Children were recruited from four English schools in a large Canadian city. Tests and Measures

Screening for word reading. A non-standardized measure of 10 words was used to assess word reading: 5 high frequency irregularly spelled sight-words taken from lists provided by both Fry, Kree, and Fountoukidis (2000) and Fountas and Pinnell (1996), and 5 high frequency decodable words that were also used in the training component (Study 2) of the present research. All words (irregular and decodable) were between 2 and 4 letters in length and are presented in Appendix A, along with their respective lexical characteristics of word frequency and phonotactic (biphone) probability. The decodable words were also chosen based on their concreteness so that they could be easily drawn, as well as to represent various syllable structures. These words included a 
VC and a CVC closed syllable, a CV and a CVV open syllable, and a CVCV twosyllabic word. Words were presented one at a time in a fixed random order, on separate index cards in 48-point font. The irregular words were shown first and the children asked to say what they thought the word was. For the decodable items, the children were encouraged to look at the letters, to sound them out, and to give their best guess. All children who could read more than one decodable or sight word, were excluded from the present analyses. There was thus insufficient variability within the final sample to statistically evaluate reliability of the word-reading task.

Control variables. The parental consent form included one question pertaining to parental education and one question concerning family income. In 33 cases, however, the family income question was not completed, and therefore this measure was not included in any analyses. Analytic intelligence was also assessed to avoid potential confounds between other cognitive-linguistic processes and intelligence. Children were assessed with the Animal Pegs subtest of the Wechsler Preschool and Primary Scale of Intelligence-Revised (WPPSI-R, 1989), in which the child places colored pegs in holes according to a key. Performance is timed and the number of errors recorded. A combination of time and the number of errors results in a scaled score for each participant as per the test-scoring instructions.

Invented spelling. Children were dictated 10 words and encouraged to try their best to spell each one with provided paper and pencil. To alleviate stress, children were told that it did not matter if their words were spelled the same as an adult might spell them, and that there were no right or wrong ways to print the word. For each item spoken by the experimenter, a corresponding picture was shown to avoid confounds with 
memory. Each word was spoken three times, twice at a standard rate and once in an exaggerated fashion in which each phoneme was stretched (yet still blended together). Of the 10 words dictated, 3 were original words used by Tangel and Blachman $(1992,1995)$, and all were composed of a limited set of 13 letters taught in a subsequent training study (Study 2 of the present research). Given that children's invented spellings are influenced by the articulatory characteristics of the words (Read, 1971, 1975), the additional words were chosen to include characteristics that were absent in Tangel and Blachman's original stimulus set: voiced stop consonants, back vowels, and a diphthong. Together, the 10 words contained a range of vowels and consonant types (with respect to characteristics of manner, place and voicing). Spelling may also be influenced by syllable patterns and hence these words included open and closed syllables as well as mono- and multi-syllabic words. All words were considered high frequency ones, and contained chiefly high probability phonemic sequences. The words were thus chosen to fulfill several criteria and are presented along with their lexical characteristics in Appendix A.

The dependent variable of interest was the children's invented spelling sophistication. To reflect invented spelling sophistication, the scoring system described by Tangel and Blachman (1992) was implemented. This scoring procedure evaluates each spelling attempt on a 7-point scale (0-6). The scale takes into account both the number of phonemes represented and the level of orthographic representation and has excellent reported reliability (Tangel \& Blachman, 1995, 1992). Typically a score of 0 is given for a random string of letters, a score of 1 for a phonetically related letter used to mark a salient part of the word, a score of 2 for the correct initial grapheme, a score of 3 for representing more than one phoneme with phonetically related or conventional letters (in 
the proper sequence), a score of 4 for all phonemes represented with phonetically related or conventional letters, a score of 5 for all consonant phonemes represented with conventional letters and vowel presence marked, and a score of 6 for proper conventional spelling. Multi-syllabic words and those with consonant clusters have slightly different criteria for scoring; a detailed breakdown of the scoring levels for each stimulus item is presented in Appendix B.

To assess reliability of the invented spelling measure, the methodology reported by Tangel and Blachman $(1995,1992)$ and Treiman and Bourassa (2000) was adopted. This procedure requires that two separate raters score all spelling attempts, and then the inter-rater reliability is considered in two ways. The first reliability measure involved simply calculating the percentage agreement between the two raters on all 1150 items (115 children X 10 words), which was $85.83 \%$. The second measure of reliability considered the Pearson correlation between the total score given to each child by the two raters $(r=.981)$. Unlike in previous studies, however, each individual item score that was not congruent across raters was reviewed and discussed by the raters and a consensus score reached. This is an important step to ensure accuracy, as 119 of the 163 discrepancies were found to be scorer error, while the remaining 44 discrepancies were related to interpretation of the child's intended target letter. Using the final agreed upon scores, the interitem reliability was also calculated and found to be excellent $(\propto=.908)$.

Phonemic awareness. Three subtests of The Comprehensive Test of Phonological Processing (CTOPP: Wagner, Torgesen, \& Rashotte, 1999) assessed children's awareness of phonemes in the word-initial and word-final positions, as well as their ability to delete a syllable or phoneme from a spoken word, and to blend individually presented phonemes 
into words. In the Sound Matching subtest, children were shown 4 pictures on each trial, and asked to indicate which picture either started the same or ended the same as the first picture. Each picture was also named by the experimenter upon presentation. There are 20 items in all (10 first sound matching; 10 final sound matching) but testing is stopped when the child misses 4 out of 7 items. In the Elision subtest the child repeats a word after the experimenter and is then asked to say the word again but leaving certain sounds out. For example, to say cup without saying $/ \mathrm{k} /$. There are 20 items in all with testing stopped following 3 consecutive errors. The Blending Words subtest requires the participant to listen to a recorded CD of a female voice, saying words phoneme by phoneme. The child is then asked to say what the intended word was. This subtest was presented via a personal CD player and headphones. There are 20 items in all with testing stopped following 3 consecutive errors. Following the recommended scoring procedures of the CTOPP, scores on these 3 subtests were converted to standard scores with a mean of 10 , then combined to create a phonemic awareness composite.

Letter-sound knowledge. Children were presented with index cards containing both individual upper and lower case letters of the alphabet (except for X, Q) in addition to 3 digraphs ( $\mathrm{CH}, \mathrm{SH}, \mathrm{TH})$ in a fixed random order (72-point Arial font). The children were asked to both name the letters and give the sound they make thus yielding 2 scores: letter names and letter sounds. Interitem reliability on these measures was excellent $(\alpha=$ $.934, .914$ respectively).

Working memory. To assess phonological working memory, the standardized Memory for Digits and Nonword Repetition subtests of The CTOPP (Wagner, Torgesen, \& Rashotte, 1999) were administered. These tests assess the ability to repeat series of 
numbers ranging from 2 to 8 digits and nonwords ranging from 3 to 15 sounds, respectively. There are 21 digit sequences and 18 nonwords, with testing stopped in each subtest following 3 consecutive errors. Performance on these subtests was converted to standard scores $(M=10)$, and then combined to create a phonological working memory composite score, as per the directions of the CTOPP.

Orthographic awareness: legal characters. Following the conceptualization of orthographic awareness reflecting visual recognition of legal characters and of permissible sequences within words, these two aspects of orthographic knowledge were assessed separately. This distinction is supported empirically by recent principle components analyses (PCA) reported by Levy, Gong, Hessels, Evans, and Jared (2006). These investigators tested young children on a forced choice task, where the participant was required to pick the word that looked the best from a conventional word and an incorrect alternative that had an orthographic violation. In all, 13 different types of violations were included and 7 of these orthographic distinctions were not at floor or ceiling for their sample of 5-year olds $(\mathrm{N}=166)$. A PCA on these 7 distinctions identified 2 components. These components were termed word elements and spelling by Levy et al., but are referred to here more accurately as legal characters and permissible sequences. The present study thus assessed these two identified areas of orthographic awareness, adapting the forced choice task of Levy et al..

Awareness of legal characters was assessed through two tasks adapted from Levy et al. (2006), named Numbers and Variety. Real-word stimuli of Levy et al. were first converted to nonwords by changing one letter, so as to not confound performance here with any logographic reading. Further, given that orthographic awareness can be defined 
as awareness of rules, the use of nonwords allows for a more stringent evaluation of this implicit knowledge. The final stimuli consisted of 10 nonword pairs where one of the items contained an embedded illegal character (a number), and 10 nonword pairs where one of the items simply contained the same letter repeated (while the other item contained a variety of letters). In all cases, the procedure from Levy et al. was followed; each card containing a stimuli-pair was shown to the child, and they were then asked which item looked best or which item their teacher would like to read the most. All stimuli were presented in a fixed-random order on individual index cards in 72-point Arial capitalized font. The stimuli are presented in Appendix A in the order of presentation. Interitem reliability was very good ( $\propto=.850, .802$ for Numbers and Variety respectively).

Orthographic awareness: permissible sequences. Awareness of permissible sequences within words was assessed through two further forced choice tasks, presented in the same fashion and context as just outlined above. The first task, referred to as Vowels, was again adapted from Levy et al. (2006), and contrasted nonwords containing a medial vowel with nonwords lacking a vowel (10 stimuli pairs). The final task, named Double Consonants, was adapted from Cassar and Treiman (1997), and contrasted nonwords where one item contained an allowable consonant doubling at the final position and the other contained an illegal consonant doubling in the onset position. All stimuli are presented in Appendix $\mathrm{A}$ in the order of presentation. Performance here was close to chance, thus preventing accurate estimation of interitem reliability.

Oral vocabulary. Children's receptive-vocabulary knowledge was assessed with the standardized Peabody Picture Vocabulary Test -Revised (PPVT-R, 1993), in which children are required to point to the picture (out of a choice of 4 ) that matched a word 
spoken by the examiner. Words are organized according to difficulty, and testing discontinued when the child misses 6 out of 8 items.

Morphological processing. Morphological processing was assessed with the standardized Grammatical Morphemes subtest of the Test for Auditory Comprehension of Language-Third Edition (TACL-3: Carrow-Woolfolk, 1999). This subtest requires the student to choose from 3 pictures the one that best matches a phrase or sentence spoken by the examiner. The relevant information for the correct answer lies in the meaning of grammatical morphemes such as prepositions, noun-verb agreement, derivational suffixes, and pronouns (Carrow-Woolfolk, 1999). There are 46 items with testing stopped following 3 consecutive errors.

\section{Procedure}

Participants were obtained for the present study as per the appropriate guidelines of the local school boards. With the permission of both the Principal and classroom teacher, parents were sent an introductory letter, and consent form for participation. They were asked to return the material to the school in a provided envelope. Children were then withdrawn from class and assessed individually in a quiet room or hallway, within their school. Assessment took place over two sessions per child, the second of which occurred within 7 days of the first session. Assessment was conducted by one of five testers, one of whom was a Speech Language Pathologist and one of whom was a classroom teacher, both with extensive experience conducting childhood assessments. These individuals provided extensive training to the remaining three testers, all of whom had completed an undergraduate degree in Psychology. All sessions were completed in November and December, and individual sessions did not exceed 30 minutes in duration. 
Each child received the same order of experimental tasks, chosen to create two sessions of equal duration with varied task demands to maintain interest: in session 1 , morphological processing, letter-sound knowledge, phonemic awareness, word reading, analytic intelligence, and in session 2 , oral vocabulary, invented spelling, working memory, orthographic awareness.

\section{Results}

\section{Data Reduction}

The non-standardized letter-sound knowledge and orthographic awareness tasks were subjected to a principal components analysis to evaluate the validity of combining measures into theorized latent variables for subsequent analyses. As shown in Table 1, when all 6 measures were considered with oblique rotation to allow for correlated factors (Oblimin rotation), 3 components were formed with simple structure. These components accounted for $75.56 \%$ of the total variance and provide empirical justification for the separation of letter-sound knowledge and orthographic awareness, and for the further distinction between awareness of legal characters (Numbers and Variety tasks) and permissible sequences (Vowels and Double consonants) within the domain of orthographic awareness. These identified components (letter-sound knowledge, awareness of legal characters, awareness of permissible sequences) were used in all subsequent analyses, by combining the respective subtest scores. 
Table 1

Component Loadings of Letter-Sound and Orthographic Awareness Tasks From Principal Components Analysis

\begin{tabular}{lccc}
\hline & $\begin{array}{c}\text { Component 1 } \\
(\lambda=2.36)\end{array}$ & $\begin{array}{c}\text { Component 2 } \\
(\lambda=1.19)\end{array}$ & $\begin{array}{c}\text { Component 3 } \\
(\lambda=1.00)\end{array}$ \\
\hline Alphabet names & .923 & & \\
Alphabet sounds & 909 & .806 \\
Numbers & & .882 \\
Variety & .799 & \\
Vowels & .803 & \\
Double consonants & & \\
\hline
\end{tabular}

Note. Loadings of less than .300 are suppressed here for clarity.

\section{Descriptive Statistics}

The means and standard deviations are presented for all constructs in Table 2, along with zero-order correlations. Looking first at the means and standard deviations, it is apparent that the children were not spelling conventionally (which would yield a maximum score of 60). Recall that these children were all nonreaders and thus the rather low mean of 22.13 is not surprising. Also note the considerable standard deviation (11.40), indicative of the wide range of spelling levels observed, ranging from random strings of letters and/or non-alphabetic markings to close approximations representative of a transitional phase of spelling. Consistent with the conceptualization of developmental phases (rather than stages), children tended to exhibit qualities of more than one phase; it was therefore not possible to categorize the participants into distinct levels or stages of spelling acquisition. Consistent with spelling levels, there was also 
considerable variability amongst the children in their letter-sound knowledge.

Performance on all standardized measures (analytic intelligence, phonemic awareness, working memory, oral vocabulary, morphological processing) fell within an average (age-expected) range.

Table 2

Zero-Order Correlations Among Variables, With Means and Standard Deviations

\begin{tabular}{llllllllll}
\hline IS Age & P.Ed & AIQ & PA & L-S & WM & O.LC & O.PS & Voc & Mor
\end{tabular}

IS

Age $\quad .24^{*}$

P.Ed $\quad .18 * \quad .06 \quad-$

AIQ $\quad .20 * \quad .25 * * \quad .14 \quad-$

PA $\quad .46 * * * \quad .24 * \quad .21^{*} \quad .38 * * *$

L-S $\quad .66 * * * \quad .13 \quad .16 \quad .28 * * \quad .56 * * *$

WM $\quad .32 * * * \quad .10 \quad .17 \quad .25 * * \quad .52 * * * \quad .29 * * \quad-$

$\begin{array}{llllllll}\text { O.LC } & .44 * * * & .28 * * & .22 * & .13 & .30^{* * *} & .39 * * * & .28 * *\end{array}$

$\begin{array}{lllllllll}\text { O.PS } & .35 * * * & .20 * & .17 & .09 & .09 & .24 * * & .05 & .15\end{array}$

$\begin{array}{llllllllll}\text { Voc } & .39 * * * & .05 & .31^{* * *} & .23 * & .35^{* * *} & .31^{* * *} & .26 * * & .51 * * * & .10\end{array}$

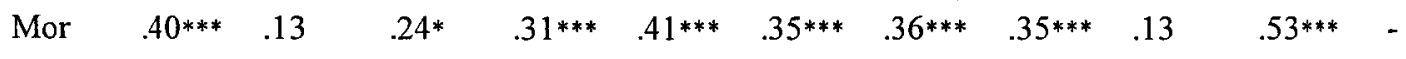

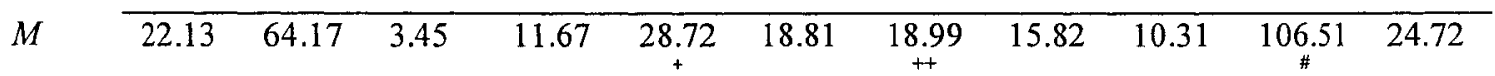

$\begin{array}{llllllllllll}S D & 11.40 & 3.83 & .98 & 2.35 & 3.85 & 5.53 & 3.66 & 4.59 & 2.65 & 12.83 & 7.04\end{array}$

Note. ${ }^{*} p<.05 ;{ }^{* *} p<.01 ; * * * p<.001$; IS = invented spelling; Age = age in months; P.Ed = parental education; $\mathrm{AIQ}=$ analytic intelligence scaled score; $\mathrm{WM}=$ working memory; PA = phonemic awareness; L-S = letter-sound knowledge; O.LC $=$ orthographic awareness-legal characters; O.PS = orthographic awareness-permissible sequences; Voc $=$ receptive vocabulary $;$ Mor $=$ morphological processing $;+=$ standard score, mean 30 ; $++=$ standard score, mean $20 ; \#=$ standard score, mean 100 
As also evident in Table 2, performance on the invented spelling measure correlated significantly with all other measures, thus confirming their hypothesized relevance to invented spelling. The greatest magnitude of correlation appears among invented spelling, letter-sound knowledge, and phonemic awareness, congruent with the theorized connections amongst these skills areas. Also noteworthy are the moderate correlations between invented spelling and all orthographic awareness and oral language variables, and the significant correlation between parental education and the oral language measures. Regression Analyses

To more fully evaluate the role of the hypothesized cognitive-linguistic components in invented spelling, a series of hierarchical regression analyses was conducted. These models, as guided by previous research and the present hypotheses, evaluate the shared and unique contributions that the various predictor variables make to invented spelling sophistication early in kindergarten. In all models, the control variables (age, analytic intelligence, and parental education) were entered in the first step. Preliminary analyses indicated that all control variables contributed to invented spelling when entered separately in the first step of the model.

Phonemic awareness and letter-sound knowledge. Previous research has established a clear link between invented spelling and phonemic awareness and lettersound knowledge, while the role of working memory has yet to be explored to the same extent. It was thus hypothesized here that phonemic awareness and letter-sound knowledge would each account for significant variance in invented spelling. The first 
series of regression models tested the hypothesized roles of these phonemically based skills, and is presented in Table 3.

Table 3

Hierarchical Regression Analyses With Phonemic Awareness and Letter-Sound Knowledge

\begin{tabular}{lcccc}
\hline \hline Order & $R^{2}$ & $\Delta R^{2}$ & $\Delta F$ & $\beta$ \\
\hline Model 1 & & & & \\
$\begin{array}{l}\text { 1. Control variables } \\
\text { 2. Phonemic awareness }\end{array}$ & .143 & .143 & $6.14^{* * * *}$ & - \\
3. Letter-sound knowledge & .513 & .106 & $23.83^{* * *}$ & .433 \\
\end{tabular}

\section{Model 2}

2. Letter-sound knowledge .462 .31

$65.52 * * *$ .433

3. Phonemic awareness

.513

.051

$11.34 * * * \quad .304$

\section{Model 3}

2. Letter-sound knowledge .462 .319 $65.52 * * * \quad .433$

3. Phonemic awareness .513 .051 $11.34 * * * \quad .304$

4. All other predictors .561 .048 $2.49^{*}$ $* p<.05 ;{ }^{* *} p<.01 ; * * * p<.001$

As presented in Model 1 (Table 3), phonemic awareness explained 26.4\% of statistically significant unique variance in invented spelling after controlling for age, 
analytic intelligence, and parental education (which together accounted for $14.3 \%$ of the variance). Letter-sound knowledge explained an additional $10.6 \%$ of the variance in invented spelling when entered last in the model, bringing the total variance accounted for to $51.3 \%$. This pattern of results is consistent with the present hypotheses as well as past reports of a significant role of phonemic awareness and letter-sound knowledge in explaining invented spelling sophistication.

A second regression was run with these predictor variables only, this time changing the order of the phonemic awareness and letter-sound knowledge measures. This was done to evaluate if the variance accounted for by phonemic awareness was shared with letter-sound knowledge, and is presented as Model 2 in Table 3. When entered after the control variables, letter-sound knowledge accounted for $31.9 \%$ of the variance in invented spelling, with phonemic awareness attributing an additional $5.1 \%$ of the total variance when entered last. There is thus considerable shared, as well as unique variance, in invented spelling predicted by phonemic awareness and letter-sound knowledge.

Having established a sizable role of phonemic awareness and letter-sound knowledge in predicting invented spelling sophistication, the last regression model was repeated, but with all of the other measured predictor variables entered together in the final step. This was done to evaluate if the other skill areas hypothesized as relevant would predict any unique variance as a set, beyond the impressive amounts already accounted for by phonemic awareness and letter-sound knowledge. This regression analysis is presented as Model 3 in Table 3, and shows that after the control variables, letter-sound knowledge, and phonemic awareness were entered into the model, these 
additional measures together predicted an additional $4.8 \%$ of the variance in invented spelling. This finding provides justification for further analyses, focusing on each skill area separately.

Working memory. The role of working memory in invented spelling has not received much empirical attention. Although working memory may seem to be relevant to the process of spelling, it is also implicated in tasks that measure phonemic awareness. It was thus hypothesized that the role of working memory in invented spelling may be redundant with phonemic awareness. This hypothesis was first tested through a series of regression analyses presented in Table 4.

Table 4

Hierarchical Regression Analyses With Working Memory

\begin{tabular}{lcccc}
\hline \hline Order & $R^{2}$ & $\Delta R^{2}$ & $\Delta F$ & $\beta$ \\
\hline Model 1 & & & & \\
1. Control variables & .143 & .143 & $6.14^{* * *}$ & - \\
2. Working memory & .190 & .047 & $6.43^{*}$ & .001 \\
3. Phonemic awareness & .409 & .219 & $40.47^{* * *}$ & .304 \\
4. Letter-sound knowledge & .513 & .104 & $23.08^{* * *}$ & .433 \\
& & & & \\
Model 2 & .407 & .264 & $49.01^{* * *}$ & .304 \\
2. Phonemic awareness & .513 & .106 & $23.83^{* * *}$ & .433 \\
3. Letter-sound knowledge & .513 & .000 & 0.00 & .001 \\
\hline 4. Working memory & & & & \\
\hline
\end{tabular}


As presented in Model 1 (Table 4) working memory explained $4.7 \%$ of statistically significant unique variance in invented spelling after controlling for age, analytic intelligence, and parental education. When entered next, phonemic awareness explained $21.9 \%$ of the variance in invented spelling, and letter-sound knowledge explained an additional $10.4 \%$ of the variance when entered last. Note that the total variance explained was the same as in the previous series of regressions that included only phonemic awareness and letter-sound knowledge. In addition, the nominal standardized coefficient for working memory suggests that working memory may not contribute to invented spelling beyond its influence on phonemic awareness. This is further highlighted in Model 2 (Table 3); moving working memory to the final position in the model rendered its contribution non-significant, whereas the variance predicted by phonemic awareness skill increased to $26.4 \%$. These results are consistent with the present hypothesis.

Orthographic awareness: legal characters and permissible sequences. The next set of analyses tested the hypothesis that orthographic awareness, specifically awareness of legal characters and of permissible sequences, is pertinent in invented spelling at the start of kindergarten. In these regression models, the contribution of orthographic awareness to invented spelling is evaluated first with only the control variables in the model, and then again after considering the significant unique contributions of phonemic awareness and letter-sound knowledge revealed in previous regressions. These alternate models are presented in Table 5.

Most striking within the abbreviated models are the significant contributions of both areas of orthographic awareness. In the first model presented, awareness of legal 
characters predicted $10.8 \%$ of statistically significant unique variance in invented spelling, again controlling for age, analytic intelligence, and parental education. Awareness of permissible sequences predicted an additional $5.9 \%$ of the total variance.

Table 5

Hierarchical Regression Analyses With Orthographic Awareness Measures

\begin{tabular}{|c|c|c|c|c|}
\hline Order & $R^{2}$ & $\Delta R^{2}$ & $\Delta F$ & $\beta$ \\
\hline \multicolumn{5}{|l|}{ Model 1} \\
\hline 1. Control variables & .143 & .143 & $6.14 * * *$ & - \\
\hline 2. Legal characters & .251 & .108 & $15.89^{* * *}$ & .343 \\
\hline 3. Permissible sequences & .310 & .059 & $9.31 * *$ & .254 \\
\hline \multicolumn{5}{|l|}{ Model 2} \\
\hline 2. Permissible sequences & .210 & .067 & $9.30 * *$ & .254 \\
\hline 3. Legal characters & .310 & .100 & $15.81^{* * *}$ & .343 \\
\hline \multicolumn{5}{|l|}{ Model 3} \\
\hline 2. Phonemic awareness & .407 & .264 & $49.01 * * *$ & .272 \\
\hline 3. Letter-sound knowledge & .513 & .106 & $23.83 * * *$ & .379 \\
\hline 4. Legal characters & .525 & .012 & 2.83 & .131 \\
\hline 5. Permissible sequences & .554 & .029 & $6.72 * *$ & .177 \\
\hline
\end{tabular}

The regression exploring the role of orthographic awareness in invented spelling was repeated changing the order of the measures. This was done to evaluate shared and unique contributions of these defined aspects of orthographic awareness, and is presented 
as Model 2 in Table 5. In this model, awareness of permissible sequences explained $6.7 \%$ of statistically significant unique variance in invented spelling performance after controlling for age, analytic intelligence, and parental education. Awareness of legal characters predicted an additional $10.0 \%$ of the total variance. There thus appears to be little shared variance between these defined aspects of orthographic awareness, and these results support the present hypothesis in establishing an important role for orthographic awareness, in invented spelling at the start of kindergarten.

A third regression was run to explore the role of orthographic awareness in invented spelling, this time also taking into account the substantial variance explained by phonemic awareness and letter-sound knowledge (Model 3, Table 5). After the control variables, phonemic awareness, and letter-sound knowledge were entered into the model, awareness of legal characters appeared redundant, as it no longer explained unique variance in invented spelling. ${ }^{1}$ Awareness of permissible sequences, however, still explained $2.9 \%$ of statistically significant unique variance in invented spelling when entered last.

Oral language: vocabulary and morphology. The final set of regression models evaluated the hypothesized relevance of morphological processing and oral vocabulary levels to invented spelling. In these regression models, the contribution of these oral language skills was evaluated first with only the control variables in the model, and then again after considering the significant predictors from the previous sets of regressions. These alternate models are presented in Table 6.

\footnotetext{
${ }^{1}$ If this last regression model is recreated, but with letter-sound knowledge removed, the contribution of awareness of legal characters regains significance.
} 
As evident in the abbreviated models, both oral language measures explained unique variance in invented spelling early in kindergarten, thus supporting the present hypotheses. In the first model presented, vocabulary levels predicted $6.2 \%$ of statistically significant unique variance in invented spelling, again controlling for age, analytic intelligence, and parental education. Morphological processing predicted an additional $3.5 \%$ of the total variance.

Table 6

Hierarchical Regression Analyses With Oral Language Measures

\begin{tabular}{|c|c|c|c|c|}
\hline Order & $R^{2}$ & $\Delta R^{2}$ & $\Delta F$ & $\beta$ \\
\hline \multicolumn{5}{|l|}{ Model 1} \\
\hline 1. Control variables & .143 & .143 & $6.14^{* * *}$ & - \\
\hline 2. Receptive vocabulary & .205 & .062 & $8.52 * *$ & .179 \\
\hline 3. Morphological processing & .240 & .035 & $5.02 *$ & .228 \\
\hline \multicolumn{5}{|l|}{ Model 2} \\
\hline 2. Morphological processing & .219 & .076 & $10.71 * * *$ & .228 \\
\hline 3. Receptive vocabulary & .240 & .021 & $2.95^{*}$ & .179 \\
\hline \multicolumn{5}{|l|}{ Model 3} \\
\hline 2. Phonemic awareness & .407 & .264 & $49.01 * * *$ & .261 \\
\hline 3. Letter-sound knowledge & .513 & .106 & $23.83 * * *$ & .392 \\
\hline 4. Permissible sequences & .541 & .028 & $6.58 * *$ & .184 \\
\hline 5. Morphological processing & .548 & .007 & 1.64 & .059 \\
\hline 6. Receptive vocabulary & .555 & .007 & 1.74 & .108 \\
\hline
\end{tabular}


The regression exploring the role of oral language components was repeated changing the order of the measures. This was done to evaluate shared and unique contributions of these defined areas of oral language, and is presented as Model 2 in Table 6 . In this model, morphological processing explained $7.6 \%$ of statistically significant unique variance in invented spelling performance after controlling for age, analytic intelligence, and parental education. Oral vocabulary predicted an additional $2.1 \%$ of the total variance. There thus appears to be both shared and unique contributions to invented spelling, from these components of oral language.

A third regression was run to explore the role of oral language skills in invented spelling, this time also taking into account the significant unique variance explained by predictors in previous regression models: phonemic awareness, letter-sound knowledge, awareness of permissible sequences (Model 3, Table 6). When entered after the control variables, phonemic awareness, letter-sound knowledge, and awareness of permissible sequences (orthographic awareness), neither oral language measure still accounted for unique variance in invented spelling. ${ }^{2}$

\section{Mediation Models}

When the table of correlations (Table 2) is considered along with the regression results presented thus far, several mediation relations are implicated. Care must be taken, however, in evaluating mediational hypotheses based solely on changing statistical significance or $R^{2}$ values (Baron \& Kenny, 1986). Rather, Baron and Kenny have

\footnotetext{
${ }^{2}$ Supplementary analyses revealed that neither oral language measure was significant when entered last in the model; this result did not change if the two measures were combined to create an oral language composite score. Further, this pattern of results was not changed by removing orthographic awareness and letter-sound knowledge from the model.
} 
discussed four steps to establish mediation, where the focus is on the unstandardized regression coefficients in a series of three regression equations. That is, the steps to establish mediation are: the predictor variable must be shown to be predictive of the response variable (regression \#1), the predictor variable must be shown to be predictive of the mediator variable (regression 2), the mediator variable must affect the response variable, with the original predictor variable held constant (regression 3), and the effect of the predictor variable on the response variable must be altered by the inclusion of the mediator (also regression 3).

This procedure was followed to test specific mediation models that were derived from the patterns of relations reported in the data analyses presented thus far. These models extend and clarify the original hypotheses that were based on previous research and theory, and their rationale is discussed in detail below. Restated in terms of mediation then, the following hypotheses were directly evaluated:

1. The influence of working memory on invented spelling is mediated by phonemic awareness skill.

2. The influence of oral language on invented spelling is mediated by phonemic awareness skill.

3. The influence of parental education on invented spelling is mediated by oral language.

Working memory, phonemic awareness, and invented spelling. The first sets of regression models reported in the present study demonstrated that working memory and phonemic awareness explained common variance in invented spelling. Further, when the working memory score was moved to the final position in the model, its contribution lost 
statistical significance while the variance explained by phonemic awareness increased. It thus appears that the influence of working memory on invented spelling is mediated by phonemic awareness skill. This would explain the pattern of relations observed in the present study, and clarify the original hypothesis that working memory does not predict invented spelling beyond its influence on phonemic awareness skill. The hypothesized mediation model is shown in Figure 1, along with the coefficients derived from the recommended procedures of Baron and Kenny (1986).

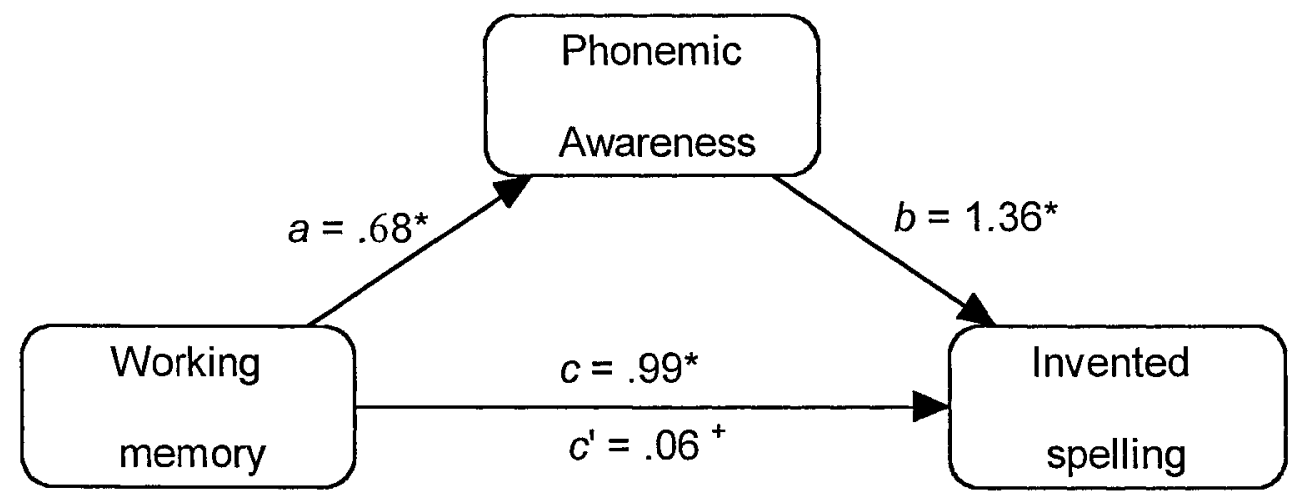

\section{Figure 1}

Mediation Model of Working Memory, Phonemic Awareness, and Invented Spelling. Note. ${ }^{*} \mathrm{p}<.001 ;{ }^{+} p>.10, \mathrm{n} . \mathrm{s} ; a$ is the unstandardized coefficient from the regression predicting phonemic awareness from working memory, $b$ is the unstandardized coefficient from the regression predicting invented spelling with phonemic awareness, holding working memory constant, $c$ is the unstandardized coefficient from the regression predicting invented spelling from working memory alone, and $c$ ' is the unstandardized coefficient from this regression but holding phonemic awareness constant. The extent of mediation is defined as $c-c^{\prime}$, which is the reduction in the influence of working memory on invented spelling brought about by holding phonemic awareness constant (which is also equal to $a b$ ). 
As evident in Figure 1, all conditions for mediation were met, and the recommended Sobel test (MacKinnon, Lockwood, Hoffman, West, \& Sheets, 2002) was significant $(z=4.05, p<.001)$, thus confirming the mediational hypothesis. Note that the unstandardized regression coefficient for working memory ( $\left.c^{\prime}\right)$ was close to zero and not statistically significant when phonemic awareness was also entered into the regression predicting invented spelling. This satisfies the conditions for complete statistical mediation, confirming that the influence of working memory on invented spelling is explained in full by the influence of working memory on phonemic awareness.

Oral language, phonemic awareness, and invented spelling. The series of regression models reported here that explored the role of oral language, revealed that both oral language measures explained unique variance in invented spelling. These measures lost their significant role, however, when phonemic awareness was first entered into the model. It thus appears that the influence of oral language on invented spelling may also be mediated by phonemic awareness skill. This would account for the pattern of results reported here, be consistent with previous reports of an association between oral language and phonemic awareness, and extend the present hypothesis that questioned whether oral language would contribute directly to invented spelling in this age group. The hypothesized mediation model is shown in Figure 2, along with the coefficients derived from the recommended procedures of Baron and Kenny $(1986)^{3}$. All conditions for mediation were met, and the Sobel test was significant $(z=3.18, p<.01)$, thus confirming the mediational hypothesis. Note here, however, that the unstandardized regression coefficient for the oral language composite $\left(c^{\prime}\right)$ remained significant (and different from

\footnotetext{
${ }^{3}$ For these and the subsequent analyses, the two oral language measures were combined into a composite score by simply adding the raw scores together and dividing by 2 .
} 
zero) when phonemic awareness was held constant in the regression predicting invented spelling. This is a case of partial mediation, where the extent of mediation can be calculated as $c-c^{\prime} \cong a b=.156$. Contrary to the previous regression results then, oral language skills appear to have a direct predictive role on invented spelling performance, beyond their relation with phonemic awareness. This valuable result exemplifies the importance of thorough statistical evaluation of hypothesized relations.

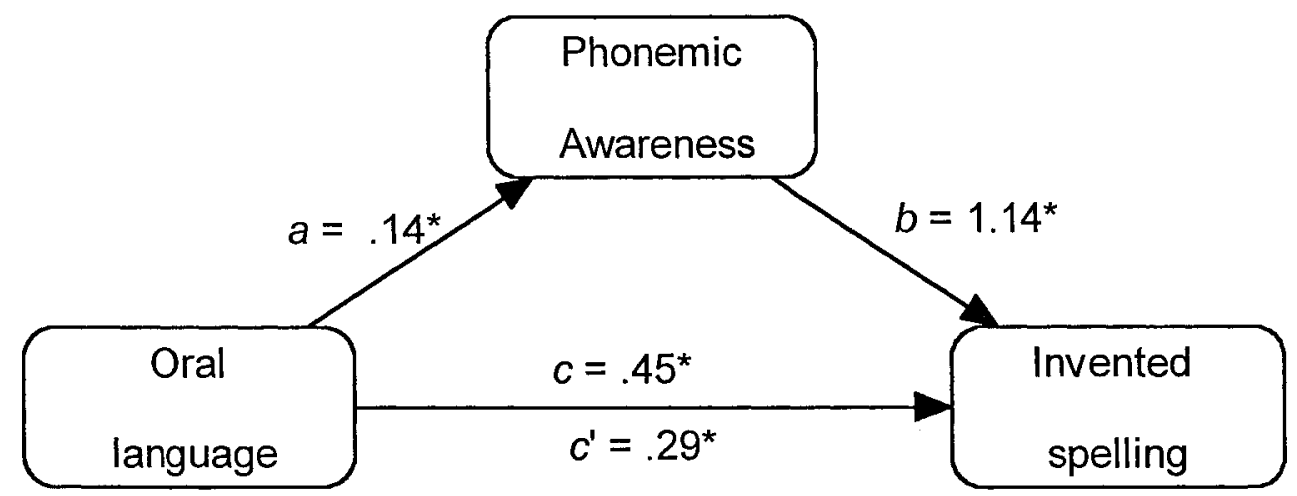

\section{Figure 2}

Mediation Model of Oral Language, Phonemic Awareness, and Invented Spelling. Note. ${ }^{*} p<.001 ;{ }^{+} p>.10, \mathrm{n} . \mathrm{s} ; a$ is the unstandardized coefficient from the regression predicting phonemic awareness from oral language, $b$ is the unstandardized coefficient from the regression predicting invented spelling with phonemic awareness, holding oral language constant, $c$ is the unstandardized coefficient from the regression predicting invented spelling from oral language alone, and $c$ 'is the unstandardized coefficient from this regression but holding phonemic awareness constant. The extent of mediation is defined as $c-c^{\prime}$, which is the reduction in the influence of oral language on invented spelling brought about by holding phonemic awareness constant (which is also equal to ab).

Parental education and oral language. A measure of parental education was included here as a control variable. This control variable was significantly correlated with 
both oral language and invented spelling, and its inclusion in the regression models previously reported may have accordingly served to minimize the variance in invented spelling explained by the oral language measures. This becomes especially relevant given the above reported direct influence of oral language on invented spelling beyond its effect on phonemic awareness. It was thus of interest to more carefully examine the pattern of relations among parental education, oral language, and invented spelling. Based on hypothesized pathways of influence, it was predicted that the relation between parental education and invented spelling would in fact be explained by the effect of parental education on oral language. This mediation model, as shown in Figure 3, was directly tested.

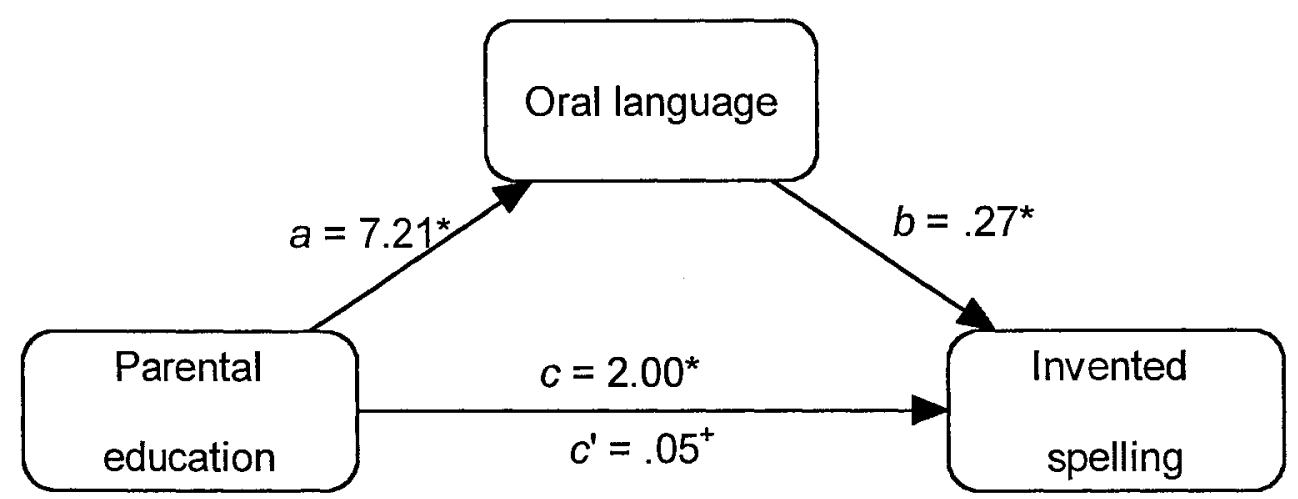

Figure 3

Mediation Model of Parental Education, Child Oral Language, and Invented Spelling. Note. ${ }^{*} p<.001 ;{ }^{+} p>.10, \mathrm{n.s} ; a$ is the unstandardized coefficient from the regression predicting child oral language from parental education, $b$ is the unstandardized coefficient from the regression predicting invented spelling with oral language, holding parental education constant, $c$ is the unstandardized coefficient from the regression predicting invented spelling from parental education alone, and $c^{\prime}$ is the unstandardized coefficient from this regression but holding oral language constant. The extent of mediation is defined as $c-c^{\prime}$, which is the reduction in the influence of parental education on 
invented spelling brought about by holding child oral language constant (which is also equal to $a b$ ).

Note that once more, all conditions for mediation were met and the Sobel test was significant $(z=2.88, p<.01)$, thus confirming the mediational hypothesis. The unstandardized regression coefficient for parental education was close to zero and not statistically significant $\left(c^{\prime}\right)$ when oral language was held constant in the regression predicting invented spelling, thus indicating complete statistical mediation where parental education influences oral language, which in turn influences invented spelling.

\section{Interim Discussion}

The present results both validate the constructs assessed, and clarify the cognitivelinguistic skills pertinent to invented spelling sophistication. A principal components analysis validated the distinction among the nonstandardized measures of letter-sound knowledge and two levels of orthographic awareness, and the reported correlations and regression models clearly demonstrated important roles for all of the proposed cognitivelinguistic skills in invented spelling proficiency: phonemic awareness, letter-sound knowledge, working memory, orthographic awareness, oral vocabulary, and morphological processing.

Unique and shared contributions of the cognitive-linguistic skills hypothesized as relevant to invented spelling success, were explored here through hierarchical regression model building with specific mediation models tested directly. This approach revealed a sizable contribution of the phonologically based skills of working memory, phonemic awareness, and letter-sound knowledge, to invented spelling sophistication. Further, working memory was found to predict invented spelling only through a hypothesized causal influence on phonemic awareness. These results support previous contentions of a 
significant role for phonology in invented spelling (e.g., Read, 1971; 1975), and also extend previous findings in clarifying the role of working memory. The amount of variance accounted for by phonemic awareness and letter-sound knowledge was comparable to that reported previously by Caravolas et al. (2001) and thus the demonstrated importance of these skills was not unexpected. Invented spelling requires the child to analyze a spoken word at a sublexical level, thus requiring phonemic awareness. Letter-sound knowledge is then required for the child to begin to represent the word in print. Phonemic awareness skill and letter-sound knowledge can thus either facilitate or constrain the sophistication of invented spellings (Ehri et al., 2001; Griffith, 1991; Stahl \& Murray, 1998).

The present results also demonstrated that invented spelling involves more than phonology, and is clearly not a proxy for phonemic awareness as previously suggested (Mann, 1993; McBride-Chang \& Ho, 2005). In particular, the present results are novel in that they provide direct evidence for the importance of orthographic awareness in the invented spelling sophistication of children who have yet to learn how to read. Although awareness of legal characters was redundant with letter-sound knowledge in regression analyses, awareness of permissible sequences in print predicted invented spelling beyond the sizable contributions of phonemic awareness and letter-sound knowledge. These findings provide empirical support for the recent suggestions that orthographic awareness may be relevant in literacy acquisition earlier than previously thought (Caravolas et al., 2005; Cassar \& Treiman, 1997; Dixon et al., 2002; Lehtonen \& Bryant, 2005; Wright \& Ehri, 2006). 
Invented spelling was also influenced by oral language skills other than phonemic awareness, and by receptive vocabulary and morphological processing in particular. Although these areas of oral language did not predict unique variance in invented spelling when entered into regression models after the control variables and phonemic awareness, mediation models were tested that clarified their important contribution. In particular, the data supported a hypothesized influence of parental education on child oral language, which in turn influenced invented spelling through an association with phonemic awareness as well as through a hypothesized direct path. This valuable finding provides initial evidence for an importance of oral language development in the early literacy skill of invented spelling, and is congruent with previous reports of an association between oral language and phonemic awareness (Sénéchal et al., 2006; Whitehurst \& Lonigan, 1998), as well as with proposals of direct links between oral vocabulary and written language skills (Dickinson et al., 2003; Nation \& Snowling, 2004; Ouellette, 2006), and morphological knowledge and early spelling (Treiman et al., 1994).

Towards a Cognitive Model of Invented Spelling: The Role of Internal Representations

Whereas previous research has offered qualitative descriptions of young children's spellings, the present findings highlight the cognitive-linguistic skills that underlie this early literacy skill. In doing so, the present study depicts invented spelling as a complex developmental skill. While working memory, phonemic awareness, and letter-sound knowledge are all intricately involved, so too are areas of orthographic awareness, receptive vocabulary, and morphological processing. Invented spelling thus appears to reflect a marriage of phonology, orthography, and other components of oral language in 
development. In this respect, the present study makes a significant contribution in clarifying important cognitive-linguistic skills that underlie successful invented spelling.

The present results can be extended towards a cognitive model of invented spelling, by postulating that invented spelling incorporates mental representations from the domains studied here. Mental representations can be considered cognitive structures that stand for or represent what is perceived (Martinez, 1999). For instance, representations can be seen as neural codes resulting from transformed sensory input (Aslin \& Smith, 1988). With respect to literacy skill acquisition, phonological representations have been proposed to underlie decoding, and orthographic/lexical representations required for visual-word recognition. The present results suggest that invented spelling involves representations at the phonological and orthographic level, and importantly integrates representations across these domains. It is this integration of mental representations that is proposed here to underlie successful acquisition of invented spelling.

A model of invented spelling is thus proposed as an integration of phonological and orthographic representations, with underlying involvement of working memory and oral language. A direct role of oral language is also possible, but the nature of this role has yet to be fully explained. A cognitive picture of invented spelling then, is one in which representations are created, stored, and accessed. Importantly, practice of invented spelling integrates these internal representations across domains; this integration of representations is seen as fundamental to successful literacy skill acquisition.

It is important to reiterate that the children involved in this study could not read. The next question that can be addressed then, is whether invented spelling helps children 
learn how to read. This question deals intrinsically with the relation between spelling and reading in children's acquisition of early literacy. The results of Study 1 indicate that invented spelling integrates knowledge (and representations) from different areas, specifically, phonology, orthography, and other components of oral language. In this respect, invented spelling is seen as a complex developmental skill that integrates important skill areas, and potentially provides a valuable context in which children can further hone these skill areas. Previous research has suggested bi-directional relations among invented spelling and phonemic awareness (Martins \& Silva, 2006; Treiman, 1993); practice with invented spelling may then promote phonemic awareness skills. Invented spelling may also potentially promote other areas of oral language and orthographic awareness. If these skills are also pertinent when it comes to learning how to read, this learning process may place children at an advantage. Practice of invented spelling may also help children to integrate internal representations that are utilized in learning to read, thus facilitating a cycle of bi-directional relations amongst spelling, phonological processing, orthographic awareness, oral language, and reading. The facilitative effects of invented spelling on these skill areas and the relations between spelling and reading are the focus of the next component of the present research. 
V. Literature Review: The Connection Between Spelling and Reading

Word reading and spelling together constitute basic literacy skills, and are closely linked throughout our literate lives: In reviewing the empirical literature, Ehri (2000) reported correlation coefficients between reading and spelling ranging from .68 to .86 from grade 1 to college. Although these two aspects of literacy are clearly related and appear to rely upon many of the same underlying knowledge sources and cognitive processes, they are nonetheless regarded by most as distinct areas (Fitzgerald \& Shanahan, 2000; Rieben et al., 2005, but cf., Carver, 2003). In this respect Gill (1992) conceptualized spelling and reading as distinct yet related areas, and Berninger (2000) defined reading and spelling as distinct language systems that interact in development.

Evidence for the distinctness of spelling and reading is garnered through reported dissociations in development: there have been reports of strong readers who are not strong spellers (Frith, 1980), young children who cannot read what they themselves have spelled (Read, 1971; Sulzby, 1988), specific words that can be spelled but not read and vice versa (Fletcher-Flinn et al., 2004), and correlations between reading and spelling that are significantly lower for readers with disabilities than for readers without. In addition, spelling is often described as a more difficult task than reading (Caravolas et al., 2001; Ehri, 2000; Fletcher-Flinn et al., 2004), as English contains more phonetically plausible ways to misspell than to misread a word.

\section{Parallels in Development}

As outlined in previous sections, early spelling can be evaluated along a progression starting with pre-conventional or invented spelling. Invented spelling itself progresses in sophistication as children become more adept at representing sounds and 
words in print. Initial descriptions of invented spelling focused on phonology, yet the results of Study 1 reported here portray invented spelling as a complex interplay between phonology, other areas of oral language, and orthography. Although the earliest phases of invented spelling may reflect a reliance on phonologically based processes where the child attempts to represent phonological structure in print, orthographic knowledge may become increasingly important as invented spellings increase in sophistication. This apparent progression from phonology to orthography in early spelling acquisition has interesting parallels with models of early word recognition in reading acquisition.

The acquisition of word-recognition skills has been described in detail by Ehri $(2000,2005)$, who outlines phases of acquisition that have clear similarities to those proposed for invented spelling. According to Ehri, once children begin to associate letters with sounds they only use some of the letters in print to read a word. For instance, children may only remember and use the $B$ and $R$ to read $B E A V E R$; these children would then confuse words with similar letters. This is termed phonetic-cue reading (Ehri \& Wilce, 1987) and has clear parallels with the semi-phonetic phase of invented spelling proposed by Gentry (1982) and Gentry and Gillet (1993). As students master graphemephoneme correspondences including vowels, they enter into a full-alphabetic level of reading where unfamiliar words can be decoded. This level of reading seems to correspond to a phonetic stage of invented spelling. Finally, just as spelling progresses through a transitional phase to reach conventional levels, Ehri proposes that word reading goes through a consolidated-alphabetic phase, where chunks of letters and corresponding phonemes are stored in memory, eventually leading to orthographic representations at the lexical level and sight-word reading (Bhattacharya \& Ehri, 2004). Word reading then, has 
proposed phases of acquisition that like those for invented spelling, reflect a progression from phonological to orthographic processes. Further, in accordance with the results reported here in Study 1, Wright and Ehri (2006) have recently suggested that orthographic awareness may be important earlier in development than is suggested by phase theory of word reading. Once more, the acquisition of spelling and reading has clear parallels. A key issue given this parallelism pertains to how reading and spelling are coordinated in development. In particular, knowledge concerning pathways of influence between the two areas is fundamental to both theoretical models of literacy acquisition and teaching practices.

\section{Coordination in Development: Directions of Influence}

The interplay between phonology and orthography suggested by research into both early spelling and word reading is also reflected in Share's $(1995,1999)$ selfteaching-mechanism account of word-reading acquisition. Share proposes that early reading relies upon grapheme-phoneme conversion and it is this early decoding practice that provides knowledge about spellings, eventually leading to the storage of wordspecific orthographic representations. Both this theory and Ehri's phases of word recognition suggest that it is exposure to words through reading that leads to the storage of orthographic information that would then be available for spelling. ${ }^{4}$ Ehri (2000) cautions, however, that learning to read does not necessitate that words will be spelled perfectly, rather more accurately from a developmental perspective. This view of reading influencing spelling coincides with the proposal that reading is an easier task than

\footnotetext{
${ }^{4}$ While Share $(1995,1999)$ proposes that practice with decoding leads to orthographic representations, recently Wright and Ehri (2006) have suggested that mere exposure to printed words may suffice.
} 
conventional spelling and thus would be expected to be acquired first in development. Empirical support for the directional influence of reading experience on spelling accuracy comes from studies with students in grade 2 and beyond that demonstrate that exposure to word-specific orthographic information during reading influences subsequent spelling performance (Ehri, 1980; Ehri \& Wilce, 1987; Maki, Voeten, Vauras, \& Poskiparta, 2001).

Other studies, however, have reported bi-directional influences between reading and spelling in the elementary school years. For instance, Berninger, Abbott, Abbott, Graham, and Richards (2002) assessed 100 children at each grade, first through sixth, on a number of literacy measures. Using structural equation modeling, causal paths were proposed to exist from spelling to word recognition, and from word recognition to spelling, in all grades. Similarly, Shanahan and Lomax (1986) assessed 256 grade-2 students and 251 grade- 5 students on measures of reading and conventional spelling and through structural equation modeling found that the data were best explained by an interactive relation in which spelling influenced word reading and word reading influenced spelling, at both grade levels.

One goal of the present research is to highlight the relevance of invented spelling in early literacy acquisition. When invented spelling is recognized in exploring the pathways of influence between reading and spelling, a different picture emerges than that outlined above. That is, if invented spelling is acknowledged as an early form of spelling, then it is spelling that emerges in development prior to reading. Recall that the original descriptions of invented spelling involved young children who could not read (Read, 1971); thus it seems plausible that the direction of influence in development would 
initially be from spelling to reading. This description is in accordance with Frith (1985) who proposed that early spelling attempts provide children with insight into the role of the alphabet in representing sounds in words, and this knowledge is later transferred to word reading. In fact, when invented spelling is included in empirical investigations, correlations suggest this hypothesis to be the case. For instance, Morris and Perney (1984) reported that invented spelling sophistication at the start of grade 1 correlates well with reading at the end of the school year $(r=.68)$. Similarly, Mann (1993) reported a correlation coefficient of .54 between invented spelling in kindergarten and word attack skills in grade 1 (see also, Bryant \& Bradley, 1980; Cataldo \& Ellis, 1988; Ehri, 1989; Mann, Tobin \& Wilson, 1987; McBride-Chang, 1998).

Further support for a pathway of influence from invented spelling to word reading comes from a word-learning study conducted by Richgels (1995). In this experiment, kindergarten children with strong alphabetic knowledge but who were still nonreaders were classified as good or poor invented spellers. These children $(n=16)$ were then taught to read phonetically simplified words through a paired-associate learning task. The good invented spelling-group significantly outperformed the poor invented-spelling group in terms of the number of words learned over a 2-day period. Richgels thus concluded that there is a strong relation between invented spelling and learning to read at the start of schooling.

Thus far, evidence has been presented that supports an influence from reading to spelling, spelling to reading, and bi-directional influences in development. The key to understanding the seemingly complex relations between reading and spelling lies in acknowledging invented spelling as an early phase of spelling and in taking the timeline 
of influence into consideration. That is, if findings from existing research are consolidated over a wide range of spelling levels, the pathways of influence appear to be transient. The results presented thus far suggest that invented spelling involves phonological and orthographic knowledge, areas that are pertinent to learning how to read. Given that invented spelling emerges prior to word reading, it is thus hypothesized here to have a direct influence on early word reading. Subsequent word reading would then conceivably influence conventional spelling, as exposure to words in reading would lead to storage of word-specific orthography and more efficient sight-word reading and spelling. This descriptive picture of changing pathways of influence is supported by path analyses that suggest that although invented spelling influences reading initially, the pathway of influence appears to switch to one of reading influencing conventional spelling in or around the third year of schooling (Caravolas et al., 2001; Cataldo \& Ellis, 1998; Ellis \& Cataldo, 1990).

Although structural equation models and path analyses provide a means of analyzing relations over time, they must be interpreted with caution (Stevens, 2002). Primarily, they are construed from correlation data, researchers have considerable control over which variables are entered into the model, and there remains controversy concerning the interpretation and evaluation of a models' fit (MacCallum, 1995). Further, despite their common (mis)interpretation in the literature, structural equation models should not be interpreted as models of causation (Everitt \& Dunn, 1991). To verify hypothesized pathways of influence in development, direct training studies provide far more rigorous evidence. 


\section{Training Studies}

Training studies offer stringent tests of causal relations in development. That is, if training in one area can be shown to transfer to or facilitate growth in another, hypothesized pathways of influence can be confirmed. Following the proposed directional influence of invented spelling on word reading, training invented spelling would be hypothesized to benefit children in subsequently learning how to read. In this respect, both Treiman (1998) and Frith (1985) have proposed that early spelling practice improves reading, although direct empirical evidence for this contention is at present lacking.

There are two studies frequently cited as providing evidence that training invented spelling improves reading: Ehri and Wilce (1987) and Uhry and Sheppard (1993). Despite the important contributions made by these studies, arguably neither actually involved training invented spelling. Each study is described in detail next.

Ehri and Wilce (1987) trained kindergarten children to spell phonetically simplified words (for example, SEAT spelled as SET) and then found these children learned to read similarly simplified words in fewer trials than did a control group of children. Although these researchers did train kindergarten children to spell phonetically simplified words similar to those seen in invented spelling, this instruction was not tailored to the individual child's developmental level nor did training involve spontaneous spelling attempts which are fundamental to the definition of invented spelling; Key to the concept of invented spelling is that it results from an individual's own experimentation with representing words in print and it occurs naturally (Burns \& Richgels, 1989; Richgels, 1995). In addition, the experimental group may have been 
more adept at learning to read simplified words because they were more familiar with similar stimuli. That is, participants in the experimental group were exposed to simplified spellings that were taught as words during the training component whereas the control group was not. As highlighted by Troia (1999), failure to expose participants in a control group to similar materials used for experimental interventions - especially when those materials are involved in post-testing - can threaten internal validity as the novelty/familiarity of the stimuli is not controlled. Internal validity was also threatened by a discrepancy in instructional time for the experimental and control participants, as the experimental group received more instructional time than did the control group.

In a lengthy training program, Uhry and Sheppard (1993) taught grade-1 students to phonemically analyze words. They then introduced letters into a segmenting task as an introduction to conventional spellings. Impressively, these children demonstrated transfer to word decoding and outperformed a control group of children on post-test measures of word reading. Although this study highlights the importance of analytic phonemic awareness and spelling instruction in grade 1, it does not directly deal with the potential pathway of influence between invented spelling at the start of schooling and subsequent word reading. In particular, invented spelling was not implemented in the training procedure and it is not clear whether it was the spelling component or the phonemic awareness training that was most responsible for the reported growth in word-reading skill.

Neither the frequently cited study of Ehri and Wilce (1987), nor the impressive intervention study of Uhry and Sheppard (1993), actually provide direct evidence that training invented spelling has benefits for learning to read. In fact, an extensive review of 
the literature revealed only two training studies in which naturally occurring invented spelling was encouraged or involved in a teaching paradigm, and word reading was evaluated as a post-test measure. These two studies are outlined next.

In a naturalistic-educational study, Clarke (1988) compared two grade-1 classroom programs - one that included invented spelling and one that included conventional spelling instruction. Over the school year, the classes in which invented spelling was encouraged showed the greatest improvements in both decoding and irregular word recognition. This important study establishes the relevance of invented spelling in the classroom, yet the natural classroom context of the research comes at the expense of experimenter control and internal validity. In particular, such studies preclude random assignment to conditions and in this case there is a confounding of treatment with schools and teachers (teachers were not counterbalanced across conditions): These are all limitations that threaten internal validity (Troia, 1999). In addition, phonemic awareness was not measured and thus it is not known if group differences were attributable to any pre-existing differences in this already established influential skill.

Rieben et al. (2005) recently reported a carefully controlled multiple-group intervention study with 5-year old French-speaking children. This study contrasted the effects of training invented spelling, invented spelling with corrective feedback, and copied spelling. Unfortunately, a large number of post-test measures complicated the analyses and planned comparisons on post-test measures yielded somewhat confusing results; the invented spelling group was not significantly different from a control group (picture drawing) in reading, but the invented spelling group with feedback scored significantly higher than the control group and all other experimental groups for reading 
practiced words only. No between-group differences were evident for reading of words not used in the training program and more surprisingly, no group differences were reported for measures of phonemic awareness and invented spelling complexity. Thus, encouraging invented spelling had no obvious beneficial effects, while combining invented spelling with corrective feedback resulted in improved reading but for previously practiced words only. In contrast to the researchers' own conclusions, these data suggest that encouraging invented spelling may be of questionable educational value. It should be noted, however, that the 18 training sessions given to each group were spread out over six months, which may not have been intensive enough to promote learning. Participants' letter knowledge was also very low which may have constrained learning across all conditions and precluded those in the invented spelling groups from benefiting from the intervention, especially given the complexity of the reading-test stimuli used.

It is also important to note that although Rieben et al. (2005) assessed word reading to evaluate any transfer of spelling skills to reading, post-testing immediately after the training component may not have allowed sufficient time for skills to transfer from one task (i.e., spelling) to the other (i.e., reading). That is, positive transfer of training occurs when learning one task benefits the learning of a second task, and thus the facilitatory effects of training may not be immediately evident. In this respect, the question is whether training invented spelling will aid children in learning to read words, a question that is not necessarily addressed by a simple post-test measure of word reading. At present then, it not clearly established whether training in invented spelling facilitates the subsequent learning of how to read words. 
The Connection Between Spelling and Reading: Summary and the Present Research

The connections between spelling and reading appear transient across development. When invented spelling is recognized as an early literacy skill, there is suggestive evidence that this early level of spelling may influence subsequent reading. Yet direct training evidence is lacking and thus the transfer and/or facilitation from spelling to reading and vice versa remains unresolved (Caravolas et al., 2001; FletcherFlinn et al., 2004). As recently highlighted by Rieben et al. (2005), there is still a lack of direct evidence that encouraging invented spelling will benefit reading acquisition. To date, there are no documented experimental training studies that incorporated invented spelling with English-speaking kindergarten children and examined facilitative effects on learning to read words. 
VI. Study 2: An Invented Spelling Training Study

Training studies offer a powerful means to assess hypothesized pathways of influence in development, yet to date there has not been a single experimental study published that has trained invented spelling in English-speaking kindergarten students and then examined facilitative effects on learning to read words. Such an experimental design would be both novel and important in establishing pathways of influence in early literacy acquisition. This knowledge is relevant to both theoretical models of the interplay between reading and spelling and in directing approaches to early childhood stimulation and education.

Study 2 of the present research evaluated the benefits of training kindergarten students to be better invented spellers through a pre-test, post-test, comparison-group design. In addition to a group trained in invented spelling and a control group, there was also a comparison group trained in phonemic awareness. This last group allowed for a direct comparison between children trained on invented spelling and children trained on phonemic awareness, a comparison that is relevant given past assertions that invented spelling represents self-directed phonemic awareness training (e.g., Mann et al., 1987). This design allowed for a clear evaluation of group differences on key skills that were post-tested, following the different interventions. In addition, a word-learning task was given to all participants following the intervention to assess any facilitative effects of the training on learning to read words.

\section{Method}

\section{Participants}

Children assessed in the first study of the present research served as the pool from 
which participants were chosen for this training component. Based upon performance on the word reading assessment from Study 1, children who could read more than one word on either measure (regular and irregular word reading tasks) were excluded from consideration. Including only nonreaders allowed for the focus to be on the transfer of skills from spelling to reading without the influence of pre-existing reading skills. From the identified nonreaders, children from each class were randomly assigned to one of three intervention groups if they could be matched with two other students from the same class, on invented spelling, phonemic awareness and sound-letter knowledge. In all, this matching procedure allowed 69 children (39 female, 30 male, mean age 67.2 months), to be assigned to one of three training groups, creating three equivalent groups of 23 students (spread over four schools, with teachers and schools counterbalanced across conditions).

It is important to note that this matching procedure produced three groups with equivalent levels of skills for invented spelling, phonemic awareness, and sound-letter knowledge. A multivariate analysis of variance confirmed that there were no statistically significant group differences on the set of these measures (Wilks' lambda, $F(6,128)=$ $.942, p=.689$ ), nor were there any univariate group differences on any of the measures from Study 1 (see Appendix C). Note that because matching was done across groups, the range of skills within each group was also equivalent. That is, within each group there were children with a wide range of skills as assessed in Study 1. The end result was three carefully matched groups, each with a wide range of ability. Including children of varying pre-existing skills created groups more representative of the regular classroom, 
thus increasing external validity. Also note that the matching was done within each class, thus counterbalancing the classroom/teacher across groups.

\section{Experimental Design}

The experimental design involved 9 training sessions followed by a post-test, all completed within a 4-week block prior to the mid-point of senior kindergarten. The experimental group of interest received training intended to increase the complexity of their invented spellings. A control group was included to avoid Hawthorne effects (Troia, 1999) and an additional comparison group received training on phonemic awareness.

\section{Intervention Groups}

In addition to the specific training that defined each group, all students were taught 13 letter-sound associations. This training was done to avoid any constraint of low letter-sound knowledge on post-test measures in addition to controlling for a possible confounding influence of increased exposure to letters in the invented spelling group. All training words were composed from this limited set of letters, as were all regular words in the spelling and reading assessments (pre- and post-tests). These letters included a variety of articulatory manners: voiced and voiceless stops $(B, P, D, T)$, liquids $(L, R)$, a nasal (N), fricative (S), glide (Y) and 4 common vowels (A, E, I, O). Both short and long vowel sounds were taught. Letter-sound teaching was carried out through a group activity, in which the children were taught a rhythmic chant for each letter, with a sequence of clapping and knee slapping, which gave both the name and sound of the letter. This activity occurred for approximately 3 minutes at the start of each group session, with 4 sounds practiced each session and recycled in the same order throughout 
the duration of the training program. The sequence followed and the exact wording of the task, are presented in Appendix D.

To control for a possible confound of familiarity with syllable/word forms used in training, all groups were exposed to the same words and at the same frequency (see below). There were 20 regularly spelled words used in this training study and all were made from the 13 letters also taught to each group. The words were chosen to represent different syllable structures and vowel sounds. They included 4 words that started with a vowel, 2 of which contained short vowel sounds and 2 with long vowel sounds. There were also 4 words that were open syllables (CV(V)), 4 words that were closed syllables with a long vowel sound ( 2 marked by a silent $e, 2$ with vowel teams), 6 words that were closed syllables with short vowel sounds, and 2 multi-syllabic words. All words are presented in Appendix E, along with the order that they were used.

Invented spelling group. This group was trained to increase the sophistication of their naturally occurring invented spellings. The training words were presented, one at a time, in both picture form and orally by the instructor. A picture was included to reduce demands on auditory memory (Caravolas et al., 2001). Each word was spoken out loud by the instructor at a normal speech rate. It was then repeated in a stretched manner with exaggerated articulation but with no pausing between the phonemes. The instructor said the word a third time (at a normal speech rate), and the children were asked to repeat the word out loud in unison. The word was said a fourth time and the children instructed to each print the word in a provided notebook. Instructions were similar to those reported by Rieben et al. (2005) in that they were embedded in the context of asking the children's help in making materials for a game that required many examples of how boys and girls 
in kindergarten thought words were spelled. Children were instructed to print the word how they thought it would look. They were repeatedly encouraged to do their best and told that their spellings did not have to be the same as an adult might write or even be the same as the spellings produced by the other children in their group.

After each word was printed, the instructor went around the table offering individually tailored feedback in which each invented spelling was contrasted with an instructor-generated invented spelling representative of a minimal increase in sophistication as per the phases of invented spelling outlined earlier. This feedback was provided in the context of praising the child's invented spelling and then showing another way to write the word; the corrected form typically contained one additional correct letter as per the developmental progression outlined by Gentry and Gillet (1993). A similar procedure was recently used successfully with Portuguese-speaking kindergarten children by Martins and Silva (2006). Following the fourth session, feedback also included drawing the child's attention to any extra letters within their invented spelling. This was done to coincide with the phonemic awareness group's switch to phoneme counting, as well as to offer additional help to the weaker spellers by focusing their attention on the correspondence between sounds within a word and the letters in their spellings. The specific guidelines used in responding to the individual spellings are presented in Appendix F. Note that the procedure of providing feedback in the form of a model with one additional element of complexity resulted in providing the conventional spelling only when the child's production was one element away from being (conventionally) correct. Again, this is in accordance with phase theory of spelling acquisition that describes invented spelling as a progression of complexity that eventually leads to conventional 
spelling. In this respect, conventional spelling is seen as the end goal of evolving invented spelling skills; and thus was only provided as a model if the child's own spelling attempt was one element shy of being conventionally correct.

Following the individualized feedback, children turned to a clean page in their notebooks, and the procedure was repeated using the same word. After the word had been spelled (and feedback given) twice, the procedure was repeated with the next word from the list. Within each session, 5 words were spelled (two times each); these words were repeated for two consecutive sessions (yielding the total of 20 words over eight sessions; the ninth and final session repeated 5 of these words; see Appendix E).

Phonemic awareness group. This group was taught to analyze words into smaller segments. Following the developmental progression of phonemic awareness tasks proposed by Ehri et al. (2001) and previous research on analytic phoneme awareness training with children of this age (Ball \& Blachman, 1991; Bradley \& Bryant, 1985; Tangel \& Blachman, 1992), two segmentation related tasks were taught. Children in this group were first taught to match pictures based on shared initial and final sounds, using the first 10 of the 20 training words (in picture form), in the same order and at the same frequency as in the invented spelling group (i.e., 5 words per session, each repeated twice and used for 2 consecutive sessions). Each child was given a sheet with the appropriate picture along with 3 others. All pictures were named by the instructor in the same fashion as for the invented spelling group: one time at a normal speech rate, one time with stretched speech, and two more times at a normal rate with the children repeating the word out loud in unison once. Thus the frequency and manner of exposure to the training stimuli was carefully controlled across groups. For each word, the children were asked to 
circle the pictures that started or ended the same. The instructor then went around the table offering individually tailored corrective feedback, modeling the correct answer as necessary. Each trial was then repeated.

For the final 10 words (i.e., final 5 sessions), the children were taught a phonemic segmenting task based on Elkonin's (1973) original say-it and move-it activity. In this task, children learned to represent each sound within a word by stamping a marker, once for each phoneme in a word, into squares below a picture of that word. Again, the instructor said each word four times as before, and the procedure modeled as necessary. For each word, the children were asked to repeat the word out loud in unison and to make the appropriate number of stamps as they did so. Individually tailored feedback was given and the trial repeated. Training in these types of analytic phoneme awareness tasks has repeatedly been shown to be effective with this age group (e.g., Ball \& Blachman, 1991; Bradley \& Bryant, 1985; Tangel \& Blachman, 1992) and a progression from initial and final sound comparisons to phoneme counting and segmenting is common in educational phonemic awareness teaching programs and guidelines (e.g., Chard \& Dickson, 1999). Once more, the same words were used in the same order and at the same frequency as with the other groups.

Control group. This group of children received similar instructions as the invented spelling group except that instead of writing each word, they were asked to draw what it represented. The same words were used as in the other groups, in the same order and with the same frequency of exposure: Once again, the children heard each word four times (one of which was with stretched speech) and were required to repeat the word out loud in unison once. 


\section{Procedure}

Children received the assigned intervention in small groups. Group size depended upon the logistics of the number of children participating from each school, and ranged from 3 to 6 children. Interventions were delivered in 9 sessions scheduled over a 3 -week period midway through the senior kindergarten school year. Each session lasted approximately 25 minutes, with equivalent instructional time given to all groups and conditions.

Interventions were delivered by one of three highly qualified instructors, including a speech language pathologist with past experience delivering intervention programs to groups of children. The other instructors were a licensed classroom teacher and an experienced research assistant. To avoid potential instructor effects, Troia's (1999) recommendation that instructors be counter-balanced across conditions was followed. Each instructor therefore taught all conditions, with the same number of groups in all three conditions assigned to each instructor (i.e., each instructor taught two invented spelling groups, two phonemic awareness groups, and two control groups).

\section{Post-Test Measures}

Post-testing was completed over two individual assessment sessions, completed within 7 days of the last intervention session. Children were post-tested in pseudorandom order, such that the same number of children from each intervention condition was tested each day. Post-testing included the areas hypothesized to be influenced by the types of training proposed here: invented spelling, phonemic awareness, letter-sound knowledge, orthographic awareness, and word reading. All children received the same 
order of tasks, arranged to make for two sessions of equal length with varying task demands and response requirements.

Invented spelling. Children were dictated the same 10 words used in Study 1, in the same order and with the same methodology. Note once more, that these words were all composed from the set of 13 letters taught to all intervention groups (see Appendices D, E). All spellings were scored by two raters, using the same scoring system as in Study 1 (see Appendix B). The inter-rater reliability was $91.5 \%$. As per Study 1, all discrepant scores were reviewed and a consensus reached, to further increase the reliability of the scoring procedure.

Phonemic awareness. Three subtests of The Comprehensive Test of Phonological Processing (CTOPP: Wagner, Torgesen, \& Rashotte, 1999) were re-administered to assess children's awareness of phonemes in the word-initial and word-final positions, as well as their ability to delete a syllable or phoneme from a spoken word, and to blend individually presented phonemes into words. In the Sound Matching subtest, children were shown 4 pictures on each trial, and asked to indicate which picture either started the same or ended the same as the first picture. Each picture was also named by the experimenter upon presentation. There are 20 items in all (10 first sound matching; 10 final sound matching) but testing is stopped when the child misses 4 out of 7 items. In the Elision subtest the child repeats a word after the experimenter and is then asked to say the word again but leaving certain sounds out. For example, to say cup without saying $/ \mathrm{k} /$. There are 20 items in all with testing stopped following 3 consecutive errors. The Blending Words subtest requires the participant to listen to a recorded $\mathrm{CD}$ of a female voice, saying words phoneme by phoneme. The child is then asked to say what the 
intended word was. This subtest was presented via a personal CD player and headphones. There are 20 items in all with testing stopped following 3 consecutive errors. Following the recommended scoring procedures of the CTOPP, scores on these subtests were converted to standard scores with a mean of 10 , and then combined to create a phonemic awareness composite.

Letter-sound knowledge. Children were presented with index cards containing both individual upper and lower case letters of the alphabet (except for X, Q) in addition to 3 digraphs $(\mathrm{CH}, \mathrm{SH}, \mathrm{TH})$ in a fixed random order (72-point Arial font). The children were asked to provide the sound that the letter(s) made.

Orthographic awareness: permissible sequences. Awareness of permissible sequences within words was re-assessed using the two forced choice tasks from Study 1 (awareness of legal characters was not re-assessed as performance on those tasks was predicted to be near ceiling). The first task, referred to as Vowels, was again adapted from Levy et al. (2006), and contrasted nonwords containing a medial vowel with nonwords lacking a vowel (10 stimuli pairs). The final task, named Double Consonants, was adapted from Cassar and Treiman (1997), and contrasted nonwords where one item contained an allowable consonant doubling at the final position and the other contained an illegal consonant doubling in the onset position. All stimuli are presented in Appendix $A$ in the order of presentation.

Word reading. Word reading was assessed with a repetition of the ten-word reading assessment from Study 1 with five additional words added. Note that the five decodable words from the reading pre-test were stimuli used in the interventions, thus as a post-test they offer a measure of regular word reading for practiced words. Five 
additional decodable words were added to provide a measure of regular word reading for novel words. These additional words were of the same syllable structure, composed from the same limited letter set, and contained the same vowel types as the practiced words, and are presented along with all assessment stimuli in Appendix A.

Facilitative effects: A word-learning task. Following intervention training it is important to consider potential facilitative effects on other areas. For the present study, it was the intention to evaluate the influence of invented spelling training on the participants' ability to learn to read words. Given that these children were nonreaders, a transfer of skills may not be readily apparent in immediate post-testing. That is, sufficient time may not have elapsed between training and post-testing for any transfer of skills to be evident. Thus, the post-testing phase of Study 2 concluded with a word-learning task modeled after that developed by Ehri and Wilce (1987), which evaluated participants' learning proficiency with respect to word reading. In this word-learning task, the participant was taught to read 10 decodable words in a paired-associate fashion. This allowed for an evaluation of learning proficiency with respect to word reading. Unlike the stimuli used by Ehri and Wilce, the proposed study used conventionally spelled words rather than simplified spellings. This was done for two reasons: children are not typically taught to read simplified spellings, thus using correctly spelled words more closely resembled the task at hand for children learning to read words, and using conventional spellings here minimizes any stimuli familiarity that would favor the invented spelling group. The words were all composed from the same letter set taught to all intervention groups and are listed in Appendix A: note that 5 started with $B$ and 5 with $P$, thus requiring the children to pay attention to more than just the initial consonant. For each 
initial consonant, there was 1 closed CVC word with a short vowel, 1 open syllable word (CVV), 1 closed syllable with a long vowel sound, 1 closed syllable with a consonant cluster, and 1 bi-syllabic word. These words thus represented a range of common syllable types used in early- reading instruction, and included words of varying difficulty with the inclusion of a consonant blend and bi-syllabic word. Children therefore had to attend to all letters in the words, and this small set of words allowed for their learning proficiency to be evaluated over a range of syllable types and complexity.

The procedure used was adapted from that outlined by Ehri and Wilce (1987). This task began with a study trial in which children were told that they were going to learn to read some words and that the words contained the letters that they had practiced in their groups. Each word was shown to the child and read by the instructor in a sounding out and blending fashion, as s/he ran her/his finger under the word: The word was said phoneme by phoneme with the sounds stretched and still connected, to encourage the children to use decoding skills yet not disrupting coarticulatory effects. The word was then repeated at a typical speaking rate. A sentence was also read that provided a meaningful context for the word. The child was then asked to say the word in a similar fashion while running their finger under it. This was repeated for all 10 words. A recall trial was then completed in which each word was shown individually and the child asked to read it by sounding out the letters; if incorrect, the answer was given and the child asked to repeat the word out loud stretching the sounds while again running their finger under the word. Trials were repeated with the word order varied randomly, until all 10 words were read correctly on two consecutive trials (to a maximum of 5 trials). 


\section{Hypotheses}

It was hypothesized that the training procedures implemented would prove to be efficient in that the invented spelling group would show improved spelling sophistication relative to the other groups, while the phonemic awareness group would show improved phonemic awareness post-test relative to the control group. Given that invented spelling practice also involves phonemic awareness, it was hypothesized that the invented spelling group would show a post-test advantage over the control group for phonemic awareness as well. No between-group differences on letter-sound knowledge were expected. It was also hypothesized that the invented spelling group would show a post-test advantage over both other groups on orthographic awareness, but only for the vowel task. There was no exposure to consonant doubling in any of the training stimuli; therefore this aspect of orthographic awareness was not expected to be influenced by the training provided to each group. Transfer of skills to the post-test reading measure were predicted to be obscured by floor effects given the age group under study, yet the invented spelling group was hypothesized to outperform the other groups on the word-reading learning task.

\section{Results}

\section{Post-Test Measures}

All post-test measures that were repeated from Study 1 were entered into a multivariate analysis of variance. This between-group test was statistically significant (Wilks' lambda $F(12,122)=1.90, p<.05)$. Performance between groups on individual measures was then analyzed in a series of univariate analysis of variance, followed by planned orthogonal contrasts (Helmert) to address the above hypotheses; these contrasts first compared the invented spelling group to both of the comparison groups, and then the 
two comparison groups to each other. These analyses are presented next, followed by the results of the word-learning task.

Invented spelling. The mean performance of each group on the invented spelling post-test is depicted in Figure 4. An ANOVA on these scores revealed a statistically significant group difference $(F(2,66)=3.39, p<.05)$.



Figure 4. Mean performance (and standard deviation) of each training group on invented spelling (Note. Maximum score possible $=60$ ). 
As evident in Figure 4, the invented spelling group appears superior to both of the comparison groups; in support of the present hypothesis, planned orthogonal contrasts confirmed the significance of this difference. The invented spelling group was found to have higher scores relative to the other two groups $(t(66)=2.48, p<.01)$, whereas there was no statistically significant difference between the phonemic awareness and control groups $(t(66)=.79, p=.433)$. The higher scores observed within the invented spelling group reflect the increased sophistication in the self-generated spellings of these children. Qualitatively, there was an apparent increase in their ability to match a word's phonology with appropriate (phonetically or conventionally) letter sequences.

Phonemic awareness. The mean performance of each group on the phonemic awareness post-test is depicted in Figure 5. An ANOVA on these scores revealed a statistically significant group difference $(F(2,66)=3.15, p<.05)$. As evident in Figure 5, the invented spelling group appears superior to both of the comparison groups. Contrary to the present hypothesis, planned orthogonal contrasts confirmed the significance of this difference: The invented spelling group was found to have higher scores relative to the other two groups $(t(66)=1.98, p<.05)$. In accordance with the hypothesized benefit of phonemic awareness training on subsequent phonemic awareness skill, the phonemic awareness group did perform significantly better than the control group on this post-test measure (contrast $2: t(66)=1.68, p<.05)$.

Letter-sound knowledge. Figure 6 shows the mean of each group for knowledge of the 13 letter sounds taught to all groups. In accordance with the present hypothesis, an ANOVA revealed no statistically significant group difference $(F(2,66)=0.42, p=.660)$. 
There were also no group differences if the dependent variable in the ANOVA was switched to knowledge of all letter sounds $(F(2,66)=0.35, p=.704)$.

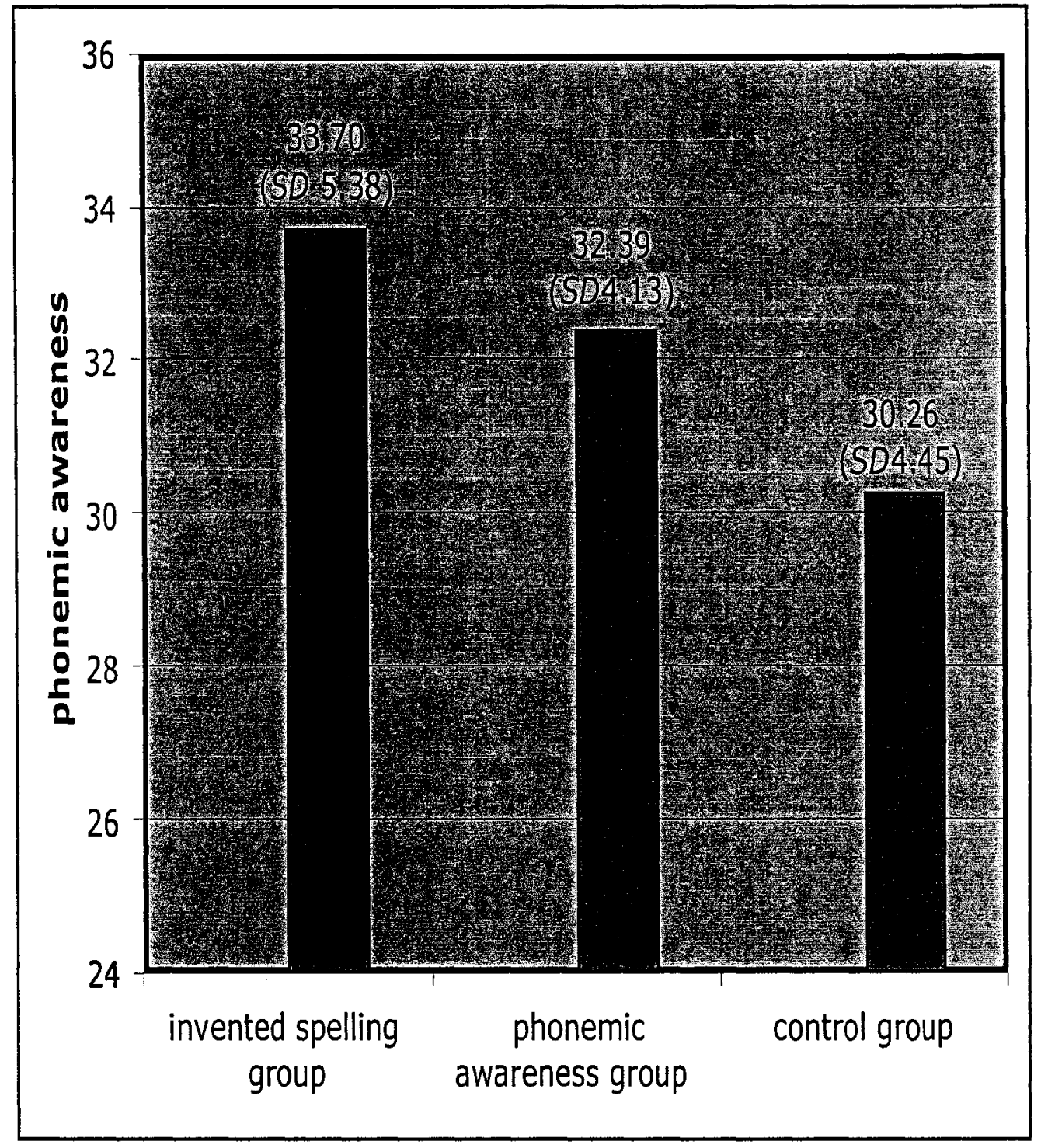

Figure 5. Mean performance (and standard deviation) of each training group on phonemic awareness (Note. Standard score composite with Mean $=30$ ). 


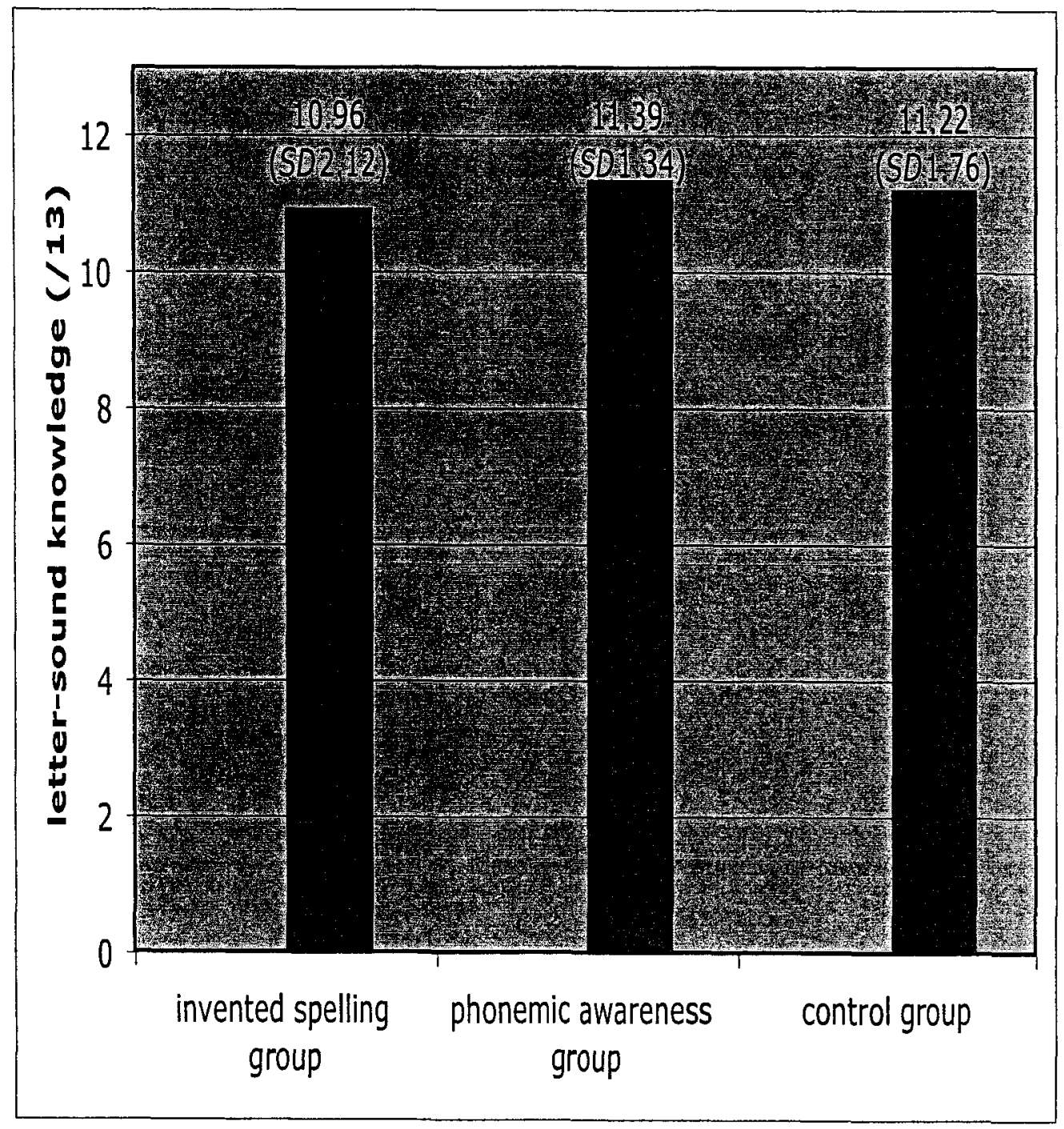

Figure 6. Mean performance (and standard deviation) of each training group on letter-sound knowledge (Note. For the set of 13 letters taught to all groups). 
Orthographic awareness: permissible sequences. Due to the stimuli characteristics, the invented spelling training was hypothesized to benefit awareness of vowels but not awareness of consonant doubling. Accordingly, performance on the two orthographic awareness tasks was analyzed separately. An ANOVA revealed no statistically significant group difference for awareness of consonant doubling $(F(2,66)=$ $0.32, p=.729)$, but there was a significant difference for awareness of vowel presence $(F(2,66)=3.79, p<.05)$. The mean performance of each group on these measures is shown in Figure 7. In accordance with the present hypotheses, planned contrasts confirmed that the invented spelling group performed significantly better than the other two groups on the vowel presence task $(t(66)=2.59, p<.01)$, whereas there was no statistically significant difference between the phonemic awareness and control groups $(t(66)=.94, p=.351)$.

Word reading. The mean performance of each group on the word reading posttest is depicted in Figure 8. Consistent with the present hypothesis, an ANOVA on these scores revealed no statistically significant group differences $(F(2,66)=1.71, p=.189)$. Yet, when the dependent variable in the ANOVA was switched to reading for only the 5 words that were also part of the training stimuli, a statistically significant between group difference emerged $(F(2,66)=5.52, p<.01)$. Mean performance on this reduced set of 5 words is also shown in Figure 8. The invented spelling group appears superior to both of the comparison groups; planned orthogonal contrasts confirmed the significance of this difference. The invented spelling group was found to have higher scores relative to the other two groups $(t(66)=3.32, p<.001)$, whereas there was no statistically significant difference between the phonemic awareness and control groups $(t(66)=.00, p=1.000)$. 

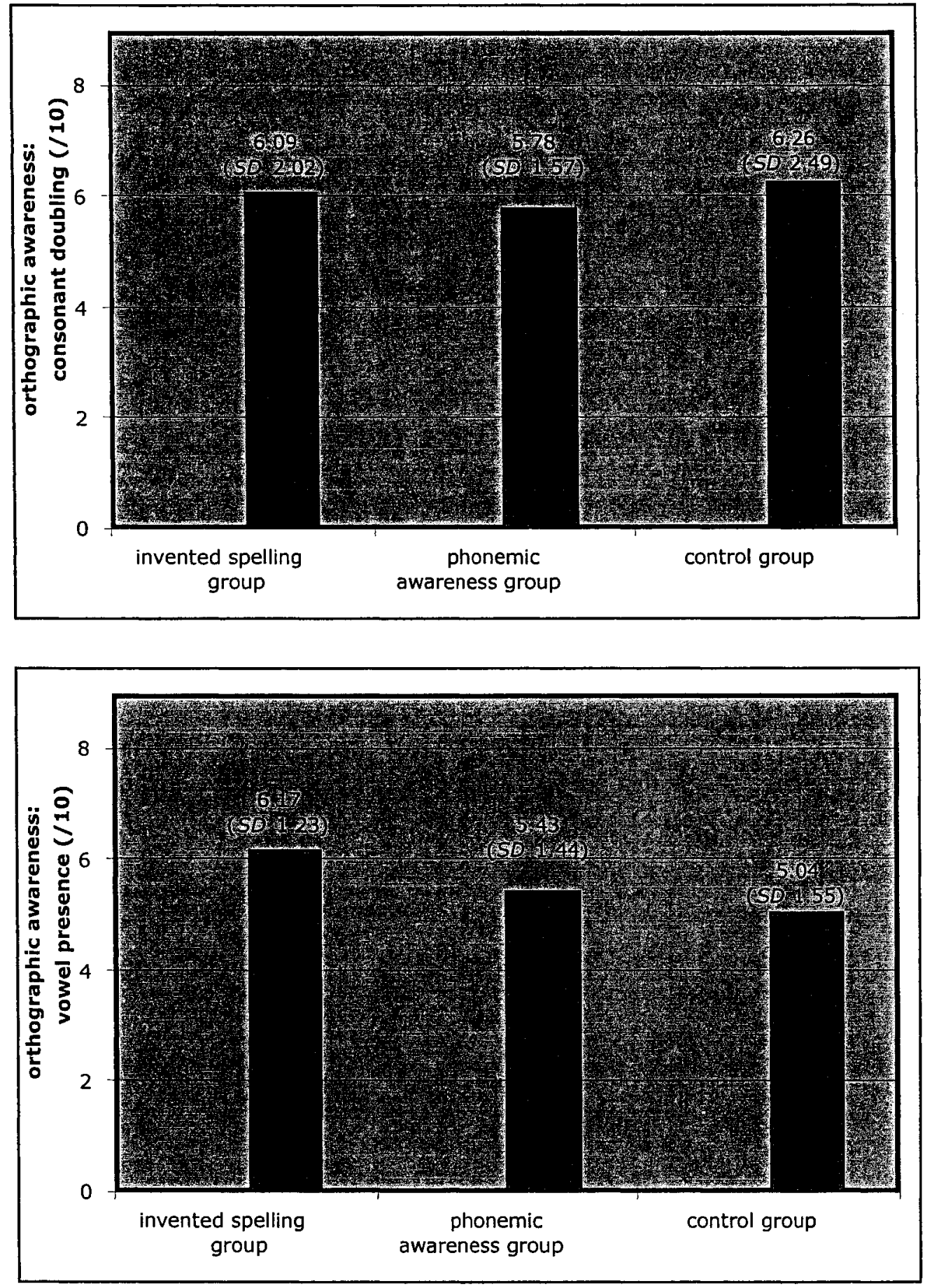

Figure 7. Mean performance (and standard deviation) of each training group on orthographic awareness measures (consonant doubling; vowel presence). Note. Maximum score 10. 

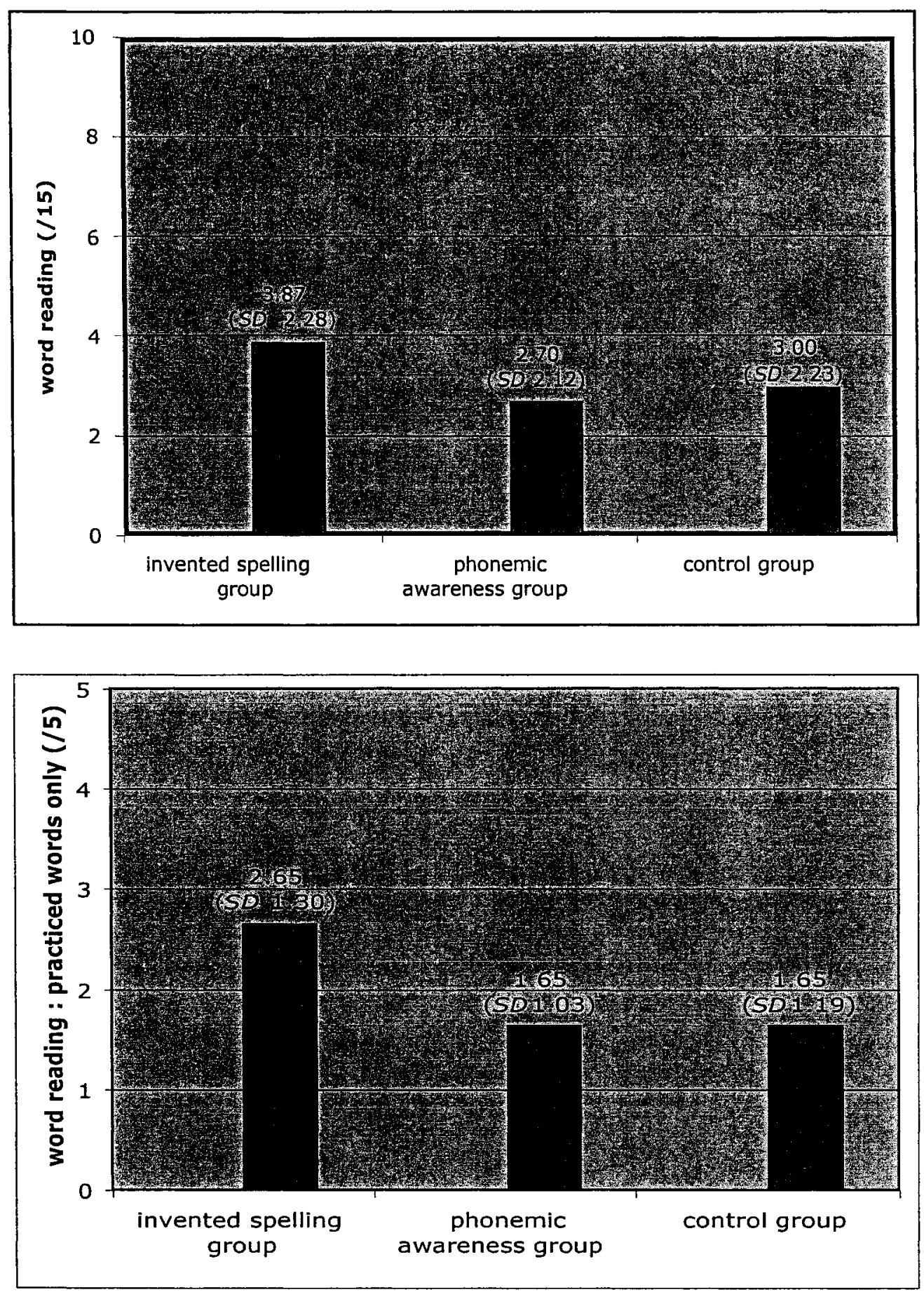

Figure 8. Mean performance (and standard deviation) of each training group on word reading measures (full 15 word post-test; 5 practiced words only). 
Facilitative Effects: A Word-Learning Task.

Mean group performance on each of the five recall trials is depicted in Figure 9.

As evident in this presentation, the invented spelling group appears to have outperformed the other groups on all trials. This was confirmed through a multivariate approach to repeated measures analysis, which revealed a statistically significant between-group difference on the series of trials as a set $(F(2,66)=3.92, p<.05)$, with a moderate effect size $\left(\eta^{2}=.106\right)$. There was no significant interaction between group and trial $(F(8,264)=$ $.75, p=.645$ ). Planned orthogonal contrasts (Helmert) on the series of trials confirmed the observed superior performance of the invented spelling group over the two comparison groups (contrast estimate 1.509, S.E. $=.539, p<.01$ ), whereas there was no statistically significant difference between the phonemic awareness and control groups (contrast estimate .078, S.E. $=.623, p=.90$ ).

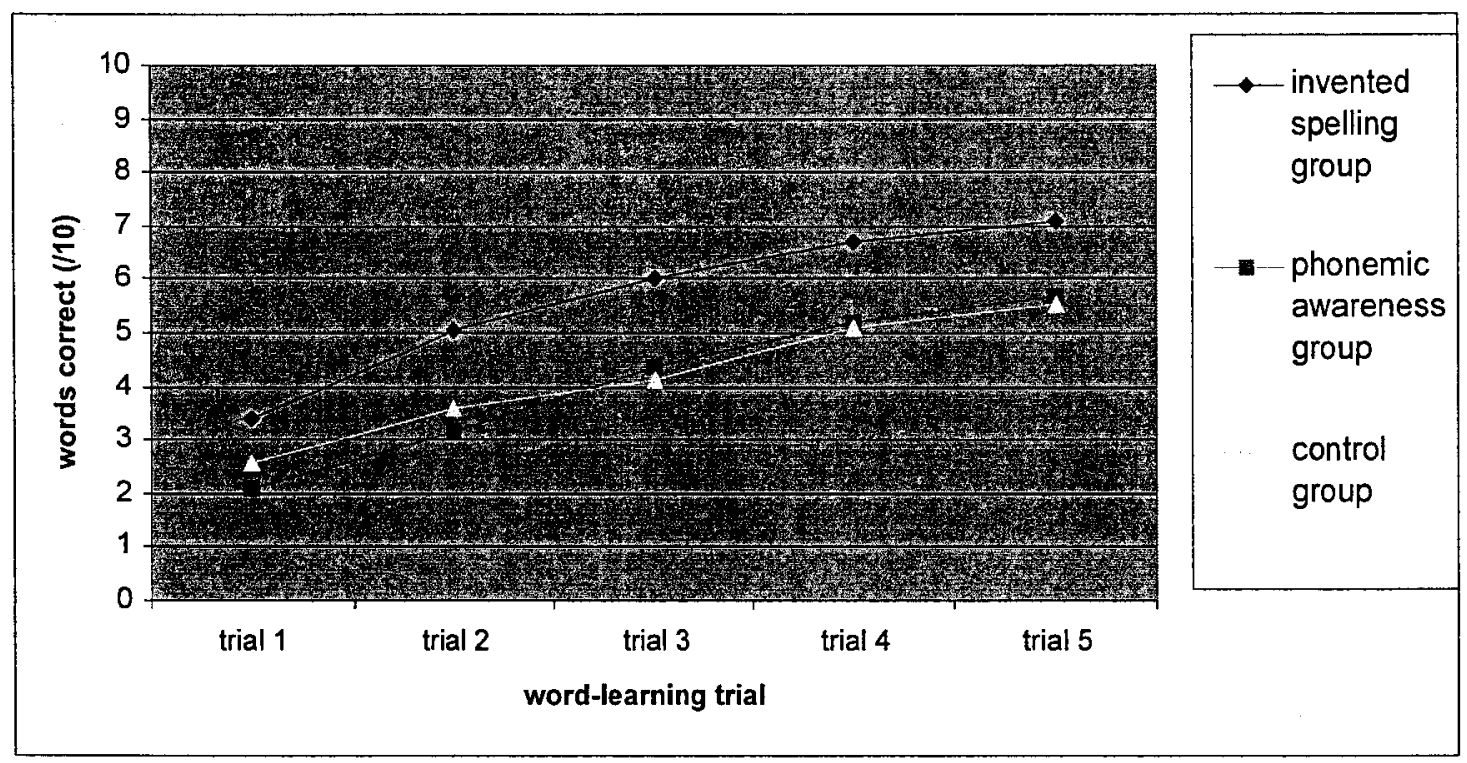

Figure 9. Mean performance on each trial of the word-learning task

Note. Maximum score $=10$. 
Planned orthogonal contrasts were also carried out separately for each trial, and these test results are summarized in Table 7. As evident in this presentation, the invented spelling group significantly outperformed the other two groups at all test points, whereas there were no statistically significant differences between the phonemic awareness and control groups at any point. These results provide direct support for the hypothesized role of invented spelling in learning to read words.

Table 7

Word-Learning Task: Results and Orthogonal (Helmert) Contrasts By Trial

\begin{tabular}{ccccc} 
Trial 1 & Trial 2 & Trial 3 & Trial 4 & Trial 5 \\
\hline & & & & \\
$t(66)=2.30$ & $t(66)=3.04$ & $t(66)=2.63$ & $t(66)=2.40$ & $t(66)=2.15$ \\
$p<.05$ & $p<.01$ & $p<.01$ & $p<.05$ & $p<.05$
\end{tabular}

$\begin{array}{cccccc}\text { Contrast } 2 & t(66)=-.90 & t(66)=-.61 & t(66)=.28 & t(66)=.12 & t(66)=.22 \\ p=.37 & p=.54 & p=.78 & p=.91 & p=.83\end{array}$

Note. Contrast 1 : Invented spelling group relative to both comparison groups

Note. Contrast 2 : Phonemic awareness group relative to control (drawing) group

\section{Supplementary Analyses}

Recall that the training groups were conducted by three different instructors. It was therefore of interest to re-analyze performance on all post-test measures to assess whether there were any significant instructor effects. This question was addressed through a series of univariate analysis of variance tests with the instructor as the independent variable. These analyses revealed statistically significant differences 
between instructors on the post-test measures of invented spelling $(F(2,66)=10.42, p$ $<.001)$, letter-sound knowledge $(F(2,66)=8.57, p<.001)$, and phonemic awareness $(F(2,66)=9.17, p<.001)$. It should be noted, however, that participants were drawn from four different schools. Due to scheduling logistics it was impossible to counterbalance instructors across schools, and thus the apparent instructor effects reported here may in fact be attributable to differences amongst the schools. To further evaluate this possibility, all time-1 measures were re-analyzed in a series of univariate analysis of variance with school as the independent variable. These analyses revealed significant preexisting differences between schools on phonemic awareness $(F(3,65)=4.95, p<.01)$, and analytic intelligence $(F(3,65)=3.06, p<.05)$, as well as an apparent discrepancy in oral vocabulary that approached statistical significance $(F(3,65)=2.51, p=.067)$. The direction of these pre-existing school effects was congruent with the observed post-test instructor effects. Note that participants were matched across intervention conditions within each school. Schools were thus counterbalanced across conditions, as were instructors. This counterbalancing minimizes any threat to the validity of the present findings, and serves to highlight the importance of careful counterbalancing in experimental design. The pre- and post-test means and standard deviations are presented for each school, for reference in Appendix G.

\section{Interim Discussion}

The results of the present training study both validate the training procedures used and highlight the importance of invented spelling in early literacy skill acquisition. Although all groups learned letter-sound knowledge, the invented spelling group demonstrated more advanced invented spellings than did the other groups, and the 
phonemic awareness group outperformed the control group on phonemic awareness. Invented spelling training also benefited phonemic awareness, orthographic awareness, and reading of words used in the training protocol. Further, the invented spelling group outperformed both comparison groups on the word-learning task, thus establishing an importance of invented spelling in learning how to read.

One serendipitous finding in the present study was that the invented spelling group scored higher on post-tested phonemic awareness, relative to both comparison groups (although importantly, the phonemic awareness group did outperform the control group). Invented spelling may thus offer a powerful context in which children learn valuable phonemic awareness skills. This interpretation is consistent with Treiman (1993) and Mann et al. (1987), who proposed that invented spelling fosters phonemic awareness growth, and is in accord with the training study reported by Martins and Silva (2006).

It should be noted that the invented spelling training offered in the present study differed considerably from the combined phonemic awareness-spelling training common in the phonemic awareness intervention literature. That is, studies that combine word segmentation training with letters (e.g., Uhry \& Sheppard, 1993) explicitly teach phonemic segmentation, typically through say it and move activities, and then introduce letter tiles to directly combine phonemic awareness and spelling. Children are then directly taught to spell words in the accepted conventional form. In the present study, however, there was no direct teaching of phonemic segmentation with letters, and no explicit instruction bridging segmentation with conventional letter-sound mapping. Rather, children's own invented spellings were elicited and served as the basis for each child's individual instruction. Teaching was thus tailored to each individual, and the 
children were encouraged to analyze and represent each word in their own way. This exploratory approach to spelling appears to have greatly benefited the children's phonemic awareness. There was consistent feedback implemented that focused the child's attention on unnecessary letters within their spelling, and this component of the feedback may have contributed to the impressive phonemic awareness skills learned within the invented spelling group. In addition, the exploratory and interactive nature of invented spelling provides for an excellent learning environment.

The invented spelling training implemented here also resulted in improved orthographic awareness as measured by a task that evaluated knowledge of the rule that words must contain a vowel. This finding suggests that the process of invented spelling, with feedback, directly influenced the children's orthographic awareness. Invented spelling then, offers a meaningful context from which children can deduce rules, gain orthographic knowledge, and thus store orthographic representations. This result is especially relevant given recent contentions in the literature that children appear to learn orthographic information earlier than previously ascribed by phase theory of literacy acquisition (Wright \& Ehri, 2006). Further, it is of interest to note that where Share's (1995, 1999) self-teaching theory proposes that children must first decode to learn orthographic knowledge, Wright and Ehri have suggested that mere exposure to printed words may suffice. Indeed if orthographic information is learned early, it would seem that learning would be incidental (Caravolas et al., 2005; Wright \& Ehri, 2006). The interactive exposure to word forms in invented spelling may facilitate this learning, offering an excellent milieu for children to deduce orthographic rules and store representations. Also note that the invented spelling group outperformed the others when 
it came to reading the words that they were exposed to during training. Rieben et al. (2005) also reported superior reading only for practiced words for one of their invented spelling training groups, and Clarke (1988) reported improved irregular word reading in classrooms that encouraged invented spelling. Together these findings support the conclusion here that orthographic information is learned through invented spelling practice.

Importantly, the present results provide direct evidence for a causal role of invented spelling in learning to read, thus confirming the hypotheses of Frith (1985) and Treiman (1993). In particular the invented spelling group learned to read more words in the word-learning task administered here. These children learned more words on the first trial, and maintained this advantage over the five learning trials. These findings are congruent with Richgels (1995), who reported an advantage on a similar task for children classified as superior invented spellers, and helps explain the correlations previously reported between invented spelling and subsequent word reading skill (e.g., Morris \& Perny, 1984; Mann, 1993). That is, the skills and knowledge learned through invented spelling appear to put children at an advantage when it comes to learning how to read words. This conclusion also supports and extends Clarke's (1988) findings of an association between invented spelling practice and reading levels within grade-1 classrooms.

The present finding of an important role of invented spelling in learning how to read, may seem at odds with the recent training study reported by Rieben et al. (2005). In that study, French-speaking children were provided practice with invented spelling but no clear post-test advantages were reported for invented spelling, phonemic awareness, or 
word reading. There were important methodological differences between the studies, however, that may account for the discrepant findings. In particular, the present study offered far more concentrated training, included letter-sound instruction to avoid possible constraining effects of low knowledge in this important area, included carefully selected stimuli representing various articulatory features and syllable types, and included a posttest learning task. In addition, the feedback offered in the present study was tailored to increase invented spelling sophistication by modeling a spelling that was only nominally more complex than the child's own attempt. In contrast, Rieben et al. did not offer feedback at all or corrected the children by showing them the conventional spelling. The method of feedback used in the present study may be more likely to improve invented spelling sophistication, as it presents a model that is closer to the child's own developmental level.

The present results offer the first direct training evidence that improvements in invented spelling bring about an advantage in learning how to read. As previously discussed, invented spelling offers a powerful milieu in which to learn critical phonemic awareness skills. Invented spelling, however, involves more than phonemic awareness. The growth seen in orthographic knowledge following invented spelling training, suggests that both phonemic and orthographic representations are important in learning how to spell. The results of Study 1 portray invented spelling as a complex developmental skill in which phonology, orthography, and oral language all play roles. The present training results are thus interpreted as evidence that practice with invented spelling helps children to hone and integrate a host of important skills that are potentially involved in learning how to read. In particular, invented spelling leads to increased 
phonemic and orthographic awareness, and as proposed by Frith (1985), provides valuable insight and practice with the alphabetic code. The exploratory nature of invented spelling also encourages children to use an analytical approach and integration of knowledge (and representations) in the areas of phonology and orthography. This in turn, may benefit children when it comes to learning how to read. 
VII. Invented Spelling: General Discussion and Conclusions

There has been theoretical and applied interest in children's invented spellings since they were brought to the forefront by Read (1971). Although original descriptions of invented spellings focused exclusively on the phonology of the language, the present research has depicted invented spelling as a more complex developmental skill than perhaps indicated by early phase theory of spelling acquisition. In particular, invented spelling has been described here as a union of letter-sound knowledge, phonemic awareness, and orthographic awareness, with an underlying importance of working memory, oral language vocabulary and morphology. The present discussion has also argued for the importance of invented spelling in subsequent literacy skill acquisition. Foremost, it has been presented that invented spelling emerges prior to word reading and as such offers a valuable glimpse into the acquisition and refinement of skills that underlie literacy acquisition. Further, invented spelling has been presented not only as an early emerging literacy skill, but one that has important implications for learning how to read. The results of the training program detailed here have provided direct evidence that growth in invented spelling puts children at an advantage when it comes to learning how to read.

The results from Study 1 portrayed invented spelling as a complex developmental skill. The pattern of relations uncovered in this component process evaluation revealed that working memory exerts its influence on invented spelling indirectly, through its involvement in phonemic awareness; phonemic awareness and letter-sound knowledge are critical to invented spelling sophistication. In addition, parental education was found 
to influence oral vocabulary and morphological processing, which in turn have indirect (through phonemic awareness) and possibly direct pathways of influence to invented spelling. Importantly, orthographic awareness was also found to contribute uniquely to explaining invented spelling. These results highlight both the complexity of invented spelling and the importance of diverse developmental skills in literacy acquisition These results further suggest that phase theory of invented spelling may be an oversimplification, with too much emphasis on phonology alone.

The results of Study 2 offered the first direct training evidence that invented spelling plays a causal role in learning how to read. Combined with the complex portrayal of invented spelling from Study 1, these findings suggest that invented spelling fosters growth in areas critical in learning how to read. In particular, invented spelling appears an excellent context in which children learn phonemic awareness. Importantly, invented spelling also brought about improved orthographic awareness, suggesting that invented spelling does more than promote phonemic awareness. In addition, the exploratory and interactive nature of invented spelling makes for a self directed learning process that encourages an analytical approach and integration of phonemic and orthographic representations that puts children at an advantage in learning how to read.

Many of the same skills that were found to underlie invented spelling also benefited from practice in invented spelling. Invented spelling is thus seen as an important literacy activity in that it integrates important skill areas, and provides a learning context in which children further hone these skills. In this respect, practice of invented spelling integrates and promotes skill areas that are utilized in learning to read, 
thus starting a cycle of bi-directional relations amongst spelling, phonological processing, orthographic awareness, oral language, and reading.

In the present training study, the invented spelling group outperformed the comparison groups on phonemic awareness, orthographic knowledge, and in learning how to decode words. It should be cautioned, however, that despite the statistical significance of the planned contrasts (favoring the invented spelling group), the magnitude of the between-group differences may be considered modest. Still, the present research does provide tentative empirical support for the proposal originally brought forth by Chomsky (1971), and reiterated by Clarke (1988), that invented spelling can be incorporated into early literacy instruction. In particular, invented spelling, combined with feedback that offers models just above the child's developmental level, has been shown here to promote growth in invented spelling, phonemic and orthographic awareness, and importantly may place children at an advantage learning how to read. The present results also highlight the importance of teaching letter-sound correspondence. Further, early childhood educational programming should also take care not to minimize opportunities for oral language stimulation and growth.

With respect to teaching applications, invented spelling had been criticized in the past as exposing children to erroneous orthography (Clarke, 1988). The feedback offered in the present study, however, and the general context of the training, made it clear to the children that their spellings were not the same as an adults. Invented spellings were therefore never reinforced as correct in a conventional sense. It should also be noted that Clarke (1988) found improved irregular word reading in grade 1 classrooms where invented spelling was encouraged, and in the present research, invented spelling training 
actually increased the children's orthographic awareness. Together then, these findings should go along way in alleviating fears that encouraging invented spelling will impede acquisition of conventional spelling.

The present results highlight parallels between word reading and spelling. Both of these literacy skills, although heavily dependent on phonologically based processes and awareness, also incorporate other important areas of oral language, as well as orthographic awareness. There thus seems to be complex interactions of phonology, other areas of language, and orthography in early phases of both word reading and invented spelling. Once more, phase theory of literacy skill acquisition that focuses on phonology alone may prove to be an oversimplification of complex developmental skills.

It is of interest to note that in the present study, training invented spelling benefited learning to read, despite the lack of direct training on phonemic blending. Previously, it had been proposed that invented spelling may not benefit reading for this very reason; that is, direct instruction in blending may be necessary to learn how to read, and this is not taught through invented spelling (Castiglioni-Splaten \& Ehri, 2003). Alternatively, it has been suggested that blending may actually be mediated by reading (Stahl \& Murray, 1994, 1998). It may well be that early spelling and early word reading are learned without direct blending instruction, and practice in both may bring about improved phonemic blending. In this respect, it is interesting to note that Uhry and Sheppard (1993) reported greater gains in word reading for a small group of children trained with conventional spelling relative to children trained directly in phonemic blending, and Torgesen and Davis (1996) found invented spelling to be a strong predictor of subsequent phonemic blending. 


\section{Future Research}

The present results suggest several avenues for important future research. Specifically, it would be of interest to evaluate the interplay between invented spelling and the underlying skills targeted in Study 1, at different times in development. Likewise, the interplay between invented spelling and word reading may well depend upon the grade level under study. In particular, it is of interest to track the influence of invented spelling training on subsequent decoding skills and sight-word reading ability through the first few years of formal schooling. The present findings make an important contribution in highlighting the role of orthographic awareness in early literacy acquisition and demonstrating a link between invented spelling and subsequent orthographic knowledge. It would thus be of interest to evaluate long term outcomes associated with invented spelling, of sight-word reading and reading fluency.

In the present training study, impressive phonemic awareness outcomes were associated with invented spelling. Note, however, that the post-test used was a general measure of phonemic awareness and not one that specifically targeted the (13) letter set from which all training stimuli were composed. A more restricted post-test measure may reveal phoneme specific skills, and possibly be more sensitive to uncovering the growth expected within the phonemic awareness training group. Phoneme-specific measures may prove informative in future training studies. In addition, recall that the matching procedure followed here in composing the experimental groups resulted in each group containing children with varying pre-existing skills. Although the resulting variability within the groups contributed to ensuring external validity, it may have also obscured the true extent that invented spelling training benefited those with lesser pre-existing skill 
levels. That is, given that strong students may do well regardless of the training program to which they are assigned, their progress within the comparison groups may have lessened the extent of the between-group differences (post-training). In this respect, future research is warranted to specifically evaluate the utility of training at risk or reading disordered children to be better invented spellers. Finally, the role of other areas of oral language in early literacy skill acquisition has yet to be fully explained. It would thus be of interest to evaluate the effects of training invented spelling in language delayed/ disordered populations.

In closing, it is proposed here that invented spelling refines phonemic and orthographic awareness, and promotes an analytical approach and integration of phonological and orthographic representations that facilitates learning to read. Learning to read is also reliant upon other areas of oral language that also underlie invented spelling. Practice in early word reading would then hone blending skills while exposing children to orthographic information, leading to further growth in orthographic awareness and storage of word specific representations. This in turn would benefit both reading and spelling, thus explaining the bidirectional relation typically reported between spelling and reading after grade 1 (e.g., Berninger et al., 2002; Shanahan \& Lomax, 1986). This proposal, although not irreconcilable with phase theory of word reading and Share's (1995, 1999) self-teaching theory, does purport an increased relevance of skills outside of phonology early in the acquisition process. 


\section{References}

Aslin, R.N. \& Smith, L. (1998). Perceptual development. Annual Review of Psychology, $39,435-474$.

Baddeley, A.D. (1986). Working memory. Oxford: Oxford University Press.

Ball, E., \& Blachman, B. (1991). Does phoneme awareness training in kindergarten make a difference in early word recognition and developmental spelling? Reading Research Quarterly, 26, 49-66.

Baron, R. M., \& Kenny, D. A. (1986). The moderator-mediator variable distinction in social psychological research: Conceptual, strategic and statistical considerations. Journal of Personality and Social Psychology, 51, 1173-1182.

Berninger, V.W. (2000). Development of language by hand and its connections with language by ear, mouth, and eye. Topics in Language Disorders, 20(4), 65-84.

Berninger, V.W., Abbott, R.D., Abbott, S.P., Graham, S., \& Richards, T. (2002). Writing and reading: Connections between language by hand and language by eye. Journal of Learning Disabilities, 35(1), 39-56.

Bhattacharya, A., \& Ehri, L. (2004). Graphosyllabic analysis helps adolescent struggling readers read and spell words. Journal of Learning Disabilities, 37, 331-348.

Bradley, L. \& Bryant, P. (1985). Rhyme and reason in reading and spelling. International academy for research in learning disabilities monograph series, No. 1. Ann Arbor, MI: University of Michigan Press.

Brooks, A., Vaughan, K., \& Berninger, V. (1999). Tutorial interventions for writing disabilities: Comparison of transcription and text generation processes. Learning Disabilities Quarterly, 22, 183-190. 
Bryant, P., \& Bradley, L. (1980). Why children sometimes write words which they do not read. In U. Frith (Ed.), Cognitive processes in spelling (pp. 355-370). NY: Academic Press.

Bryant, P., Nunes, T., \& Bindman, M. (1997). Children's understanding of the connections between grammar and spelling. In B. Blachman (Ed.), Foundations of reading acquisition and dyslexia (pp.219-240). Mahwah, NJ: Erlbaum.

Burns, J., \& Richgels, D. (1989). An investigation of task requirements associated with invented spellings of 4-year-olds with above average intelligence. Journal of Reading Behavior, 21, 1-14.

Bus, A., \& VanIJzendoorn, MN. (1999). Phonological awareness and early reading: A meta-analysis of early training studies. Journal of Educational Psychology, 91, 403-414. 1

Caravolas, M., Bruck, M., \& Genesee, F. (2003). Similarities and differences between English-and French-speaking poor spellers. In, N. Goulandris (Ed.), Dyslexia in different languages: Cross-linguistic comparisons (pp.157-180). London, England: Whurr.

Caravolas, M., Kessler, B., Hulme, C., \& Snowling, M. (2005). Effects of orthographic consistency, frequency, and letter knowledge on children's vowel spelling development. Journal of Experimental Child Psychology, 92, 307-321.

Caravolas, M., Hulme, C., \& Snowling, M.J. (2001). The foundations of spelling ability: Evidence from a 3-year longitudinal study. Journal of Memory and Language, 45, 751-774.

Carver, R.P. (2003). The highly lawful relationships among pseudoword decoding, word 
identification, spelling, listening, and reading. Scientific Studies of Reading, $72(2), 127-154$.

Cassar, M. \& Treiman, R. (1997). The beginnings of orthographic knowledge: Children's knowledge of double letters in words. Journal of Educational Psychology, 89, 296300.

Castiglioni-Spalten, M.L., \& Ehri, L.C. (2003). Phonemic awareness instruction: Contribution of articulatory segmentation to novice beginners' reading and spelling. Scientific Studies of Reading, 7(1), 25-52.

Cataldo, S., \& Ellis, N. (1988). Interactions in the development of spelling, reading, and phonological skills. Journal of Research in Reading, 11(2), 86-109.

Chard, D.J., \& Dickson, S.V. (1999). Phonological awareness: Instructional and assessment guidelines. Intervention in School and Clinic, 34(5), 261-270.

Chomsky, C. (1971). Write first, read later. Childhood Education, 47, 296-300.

Clarke, L.K. (1988). Invented versus traditional spelling in first graders' writings: Effects on learning to spell and read. Research in the Teaching of English, 22, 281-309.

Clay, M. (1972). Reading: The patterning of complex behavior. London: Heinemann.

Deacon, S.H. \& Bryant, P. (2005). The strength of children's knowledge of the role of root morphemes in the spelling of derived words. Journal of Child Language, $32(2), 375-389$.

Dickinson, D.K., McCabe, A., Anastasopoulos, L., Feinberg, E.S., \& Poe, M.D. (2003). The comprehensive language approach to early literacy: The interrelationships among vocabulary, phonological sensitivity, and print knowledge among preschool-aged children. Journal of Educational Psychology, 95(3), 465-481. 
Dixon, M., Stuart, M., \& Masterson, J. (2002). The relationship between phonological awareness and the development of orthographic representations. Reading and Writing: An Interdisciplinary Journal, 15, 295-316.

Ehri, L. (1980). The development of orthographic images. In U. Frith (Ed), Cognitive processes in spelling (pp.311-338). London: Academic Press.

Ehri, L. (1989). Development of spelling knowledge and its role in reading acquisition and reading disabilities. Journal of Learning Disabilities, 22, 356-365.

Ehri, L.C. (2000). Learning to read and learning to spell: Two sides of a coin. Topics in Language Disorders, 20(3), 19-36.

Ehri, L. (2005). Learning to read words: Theory, findings, and issues. Scientific Studies of Reading,9(2), 167-188.

Ehri, L.C., Nunes, S.R., Willows, D.M., Schuster, B.V., Yaghoub-Zadeh, Z., \&

Shanahan, T. (2001). Phonemic awareness instruction helps children learn to read:

Evidence from the National Reading Panel's meta-analysis. Reading Research Quarterly, 36(3), 250-287.

Ehri, L.C., \& Wilce, L.S. (1987). Does learning to spell help beginners learn to read words? Reading Research Quarterly, 20, 47-65.

Ellis, N.C., \& Cataldo, S. (1990). The role of spelling in learning to read. Language and Education, 41, 1-28.

Everitt, B.S., \& Dunn, G. (1991). Applied multivariate data analysis. London: Edward Arnold.

Ferreiro, E. (1991). Psychological and epistemological problems on written representation of language. In M. Carretero, M. Pope, R. Simons, \& J. Pozo 
(Eds.), Learning and instruction: European research in an international context (Volume 3, pp.157-173). New York: Pergamon Press.

Ferreiro, E., \& Teberosky, A. (1982). Literacy before schooling. Portsmouth, NH: Heinemann.

Fitzgerald, J. \& Shanahan, T. (2000). Reading and writing relations and their development. Educational Psychologist, 35(1), 39-50.

Fletcher-Flinn, C.M., Shankweiler, D., \& Frost, S.J. (2004). Coordination of reading and spelling in early literacy development: An examination of the discrepancy hypothesis. Reading and Writing: An Interdisciplinary Journal, 17, 617-644.

Fountas, I. C. \& Pinnell, G. S. (1996). Guided Reading: Good First Teaching for All Children. Portsmouth, NH: Heinemann.

Frith, U. (1985). Beneath the surface of developmental dyslexia. In, K. Patterson, M. Coltheart, \& J. Marshall (Eds.), Surface dyslexia. London: Lawrence Erlbaum. Fry, E., Kress, J., and Fountoukidis, D. (2000). The Reading Teacher's Book of Lists. Paramus, New Jersey: Prentice Hall.

Gathercole, S.E., \& Baddeley, A.D. (1989). Evaluation of the role of STM in the development of vocabulary in children: A longitudinal study. Journal of Memory and Language, 28, 200-213.

Gathercole, S.E., \& Baddeley, A.D. (1993). Phonological working memory: A critical building block for reading development and vocabulary acquisition? European Journal of Psychology and Education, 8(3), 259-272.

Gentry, J.R. (1982). An analysis of developmental spelling in GNYS at WRK. The Reading Teacher, 36, 192-200. 
Genty, J.R., \& Gilet, J.W. (1993). Teaching kids to spell. Portsmouth, NH: Heinemann. Gill, J.T. (1992). The relationship between word recognition and spelling. In S.Templeton \& D.R. Bear (eds.), Development of Orthographic Knowledge and the Foundations of Literacy: A Memorial Festschrift for Edmund H. Henderson. Hillsdale, NJ: Lawrence Earlbaum Associates.

Goulandris, N. (1994). Teaching spelling: Bridging theory and practice. In, G.D.A. Brown \& N.C. Ellis (Eds.), Handbook of spelling: Theory, processes, and intervention (pp.407-423). Chichester: Wiley.

Griffith, P. (1991). Phoneme awareness helps first graders invent spellings and third graders remember correct spellings. Journal of Reading Behavior, 23, 215-233.

Henderson, E.H. (1981). Learning to read and spell: A child's knowledge of words. Dekalb: N. Illinois University Press.

Laing, E., \& Hulme, C. (1999). Phonological and semantic processes influence beginning readers' ability to learn to read words. Journal of Experimental Child Psychology, $73,183-207$

Lehtonen, A., \& Bryant, P. (2005). Active players or just passive bystanders? The role of morphemes in spelling development in a transparent orthography. Applied Psycholinguistics, 26, 137-155.

Levin, I., Share, D., \& Shatil, E. (1996). A qualitative-quantitative study of pre-school writing:It's development and contribution to school literacy. In M. Levy \& S. Ransdell (Eds.), The science of writing (pp. 271-293). Mahwah, NJ: Erlbaum.

Liberman, I., Rubin, H., Duques, S., \& Carlisle, J. (1985). Linguistic abilities and spelling proficiency in kindergarteners and adult poor spellers. In, D. Gray, \& J. 
Kavanagh (Eds.), Biobehavioral measures of dyslexia (pp.163-176). Parkton, MD: York Press.

MacCallum, R.C. (1995). Model specificati0on: Procedures, strategies and related issues: In R.H. Hoyle (Ed.), Structural equation modeling: Concepts, issues, and applications (pp.16-36). CA: Sage.

MacKinnon, D. P., Lockwood, C. M., Hoffman, J. M., West, S. G., \& Sheets, V. (2002). A comparison of methods to test the significance of the mediated effect. Psychological Methods, 7, 83-104.

Maki, H.S., Voeten, M.J.M., Vauras, M.M.S., \& poskiparta, E.H. (2001). Predicting writing skill development with word recognition and preschool readiness skills. Reading and Writing: An Interdisciplinary Journal, 14, 643-672.

Mann, V.A. (1993). Phoneme awareness and future reading ability. Journal of Learning Disabilities, 26, 259-269.

Mann, V., Tobin, P., \& Wilson, R. (1987). Measuring phonological awareness through the invented spellings of kindergarten children. Merrill Palmer Quarterly, 33, 365-391.

Martin, F., Claydon, E., Morton, A., Binns, S., \& Pratt, C. (2003). The development of orthographic and phonological strategies for the decoding of words in children. Journal of Research in Reading, 26(2), 191-203.

Martinez, M.E. (1999). Cognitive representations: Distinctions, implications, and elaborations. In I.E. Siegel (Ed.), Development of mental representation: theories and applications (pp.13-31). Mahwah, NJ: Erlbaum. 
Martins, M.A., \& Silva, C. (2006). The impact of invented spelling on phonemic awareness.Learning-and-Instruction, 16, 41-56.

McBride-Chang, C. (1998). The development of invented spelling. Early Education and Development, 9, 147-160.

McBride-Chang, C., \& Ho, C.S.H. (2005). Predictors of beginning reading in Chinese and English: A 2-year longitudinal study of Chinese kindergartners. . 117-144.

Morris, D., \& Perney, J. (1984). Developmental spelling as a predictor of first grade reading achievement. The Elementary School Journal, 84(4), 440-457.

Nagy, W., Berninger, V. W., \& Abbott, R. D. (2006). Contributions of morphology beyond phonology to literacy outcomes of upper elementary and middle school students. Journal of Educational Psychology, 98, 134-147.

NICHD Early Child Care Research Network. (2005). Pathways to reading: The role of oral language in the transition to reading. Developmental Psychology, 41 (2), 428442.

Ouellette, G.P. (2006). What's meaning got to do with it: The role of vocabulary in word reading and reading comprehension. Journal of Educational Psychology, 98, 554-566.

Rack, J., Hulme, C., Snowling, M., \& Wightman, J. (1994). The role of phonology in young children learning to read words: The direct mapping hypothesis. Journal of Experimental Child Psychology, 57, 42-71.

Read, C. (1971). Pre-school children's knowledge of English phonology. Harvard Educational Review, 41, 1-34. 
Read, C. (1975). Children's categorizations of speech sounds in English. Urbana, IL: National Council of Teachers of English.

Rieben, L., Ntamakiliro, L., Gonthier, B., \& Fayol, M. (2005). Effects of various early writing practices on reading and spelling. Scientific Studies of Reading, 9(2), 145166.

Richgels, D.J. (1995). Invented spelling ability and printed word learning in kindergarten. Reading Research Quarterly, 30(1), 96-109.

Scarborough, H.S. (1998). Early identification of cgildren at risk for reading disabilities:

Phonological awareness and some other promising predictors. In B.K. Shapiro, P.J. Accardo, \& A.J. Capute (Eds.), Specific reading disability: A view of the spectrum (pp. 75-119). Timonium, MD: York Press.

Sénéchal, M. \& LeFevre, J. (2002). Parental involvement in the development of children's reading skill: A five-year longitudinal study. Child Development, 73, $445-460$.

Sénéchal, M., Ouellette, .G., \& Rodney, D. (2006). The misunderstood giant: On the predictive role of early vocabulary to future reading. In, S.B. Neuman \& D. Dickinson (Eds.), Handbook of early literacy research:Volume 2. NY: Guilford Press.

Shanahan, T., \& Lomax, R.G. (1986). An analysis and comparisonof theoretical models of the reading-writing relationship. Journal of Educational Psychology, 78, 116123. 
Shanahan, T., \& Lomax, R.G. (1988). A developmental comparison of three theoretical models of the reading-writing relationship. Research in the Teaching of English, $22,196-212$.

Share, D.L. (1995). Phonological coding and self-teaching: Sine qua non of reading acquisition. Cognition, 55, 151-2218.

Shatil, E., Share, D., \& Levin, I. (2000). On the contribution of kindergarten writing to grade one literacy: A longitudinal study in Hebrew. Applied Psycholinguistics, 21, $1-21$.

Share, D.L. (1999). Phonological recoding and orthographic learning: A direct test of the self-teaching hypothesis. Journal of Experimental Child Psychology, 72, 95-129.

Siegler, R. S. (2000). The rebirth of children's learning. Child Development, 71, 26-35.

Stage, S., \& Wagner, R. (1992). Development of young children's phonological and orthographic knowledge as revealed by their spellings. Developmental Psychology, $28,287-296$.

Stahl, S.A., \& Murray, B. (1998). Issues involved in defining phonological awareness and its relation to early reading (pp 65-87). In, J.L. Metsala \& L.C. Ehri (Eds.), Word Recognition in Beginning Literacy. Lawrence Earlbaum:Mahwah, N.J.

Stevens, J.P. (2002). Applied multivariate statistics for the social sciences (fourth edition). Mahwah, NJ: Erlbaum.

Sulzby, E. (1988). A study of children's early reading development. In A.D. Pellegrini (Ed.), Psychological basis of early education (pp.39-75). Chichester:Wiley. 
Tangel, D.M., \& Blachman, B.A. (1992). Effect of phoneme awareness instruction on kindergarten children's invented spelling. Journal of Reading Behavior, 24, 233261.

Tangel, D.M., \& Blachman, B.A. (1995). Effect of phoneme awareness instruction on the invented spelling of first grade children: A one-year follow-up. Journal of Reading Behavior, 27(2), 153-185.

Torgesen, J.K., \& Davis, C. (1996). Individual differences variables that predict response to training in phonological awareness. Journal of Experimental Child Psychology, $63,1-21$.

Treiman, R. (1993). Beginning to spell. New York: Oxford University Press.

Treiman, R. (1998). Why spelling? The benefits of incorporating spelling into beginning Reading instruction. In J.L. Metsala \& L.C. Ehri (eds.), Word Recognition in Beginning Literacy (pp.289-313). Lawrence Earlbaum: Mahwah, N.J.

Treiman, R., Cassar, M., \& Zukowski, A. (1994). What types of linguistic information do children use in spelling? The case of flaps. Child Development, 65, 1310-1329.

Troia, G. (1999). Phonological awareness intervention research: A critical review of the experimental methodology. Reading Research Quarterly, 34, 28-52.

Uhry, J.K. (1999). Invented spelling in kindergarten: The relationship with finger-point reading. Reading and Writing: An Interdisciplinary Journal, 11, 441-464.

Uhry, J.K., \& Shepherd, M.J. (1993). Segmentation/spelling instruction as part of a first grade reading program: Effects on several measures of reading. Reading Research Quarterly, 28(3), 218-233. 
Vitevitch, M.S. \& Luce, P.A. (2004). A web-based interface to calculate phonotactic probability for words and nonwords in English. Behavior Research Methods, Instruments, \& Computers, 36, 481-487.

Vitevitch, M.S. \& Luce, P.A. (2005). Increases in phonotactic probability facilitates spoken nonword recognition. Journal of Memory and Language, 52, 193-204.

Wright, D., \& Ehri, L. (2006). The case of doubled letters: Do beginners remember orthography when they learn to read words? Manuscript submitted. 
Appendix A: Assessment Stimuli

Word Reading Assessment

Study 1

\begin{tabular}{lcc} 
& word frequency* & phonotactic probability ${ }^{+}$ \\
\cline { 2 - 3 } to & 84.1 & .0021 \\
come & 68.9 & .0094 \\
have & 76.3 & .0071 \\
are & 77.9 & .0051 \\
here & 68.2 & .0092 \\
lap & 52.2 & .0093 \\
day & 69.8 & .0015 \\
no & 72.7 & .0034 \\
ape & 47.4 & .0030 \\
lady & 58.0 & .0079
\end{tabular}

Study 2

Same 10 words as above, with 5 additional words added.

\begin{tabular}{lcc} 
& word frequency* & phonotactic probability \\
\cline { 2 - 3 } lip & 49.9 & .0056 \\
bay & 56.0 & .0017 \\
so & 73.6 & .0027 \\
ate & 58.5 & .0030 \\
bony & 47.6 & .0083
\end{tabular}

Invented Spelling Assessment (for both Study 1 and Study 2)

\begin{tabular}{lcc} 
& word frequency* & phonotactic probability ${ }^{+}$ \\
\cline { 2 - 3 } lap & 52.2 & .0093 \\
sit & 60.2 & .0155 \\
rabbit & 56.0 & .0106 \\
pretty & 59.4 & .0440 \\
train & 59.4 & .0195 \\
day & 69.8 & .0015 \\
boot & 47.5 & .0039 \\
no & 72.7 & .0034 \\
lady & 58.0 & .0079 \\
ape & 47.4 & .0030
\end{tabular}




\begin{tabular}{lcc} 
& \multicolumn{2}{c}{$\begin{array}{c}\text { Study } 2 \\
\text { Word-Learning Task Stimuli }\end{array}$} \\
\cline { 2 - 3 } bed & Whonotactic probability & ${ }^{+}$ \\
bee & 62.5 & .0069 \\
bend & 51.9 & .0022 \\
bone & 53.7 & .0313 \\
baby & 56.5 & .0045 \\
pin & 60.6 & .0050 \\
pie & 51.3 & .0143 \\
pond & 51.0 & .0017 \\
peel & 56.4 & .0152 \\
pony & 47.2 & .0050 \\
& 52.7 & .0108
\end{tabular}

Note. * Word frequency is presented in terms of standard frequency index (SFI) values derived from Zeno, Ivens, Millard, and Duvvuri (1998). These values are logarithmic transformations of the word's frequency per million tokens, weighted by an index of dispersion. All word stimuli were at or above the $90^{\text {th }}$ percentile in terms of word frequency reported by Zeno et al..

Note. ${ }^{+}$Phonotactic probability is presented in terms of summed position specific, biphone probabilities. These values were derived from the online calculator described in Vitevitch and Luce (2004). There are no set criteria that classify phonotactic probabilities as high or low; Word recognition research typically classifies stimuli on a median or similar split. For example, Vitevitch and Luce (2005) reported a mean summed biphone probability value of .008 for their stimuli classified as high phonotactic probability, and .001 for the stimuli set classified as low probability. 
Orthographic Awareness Stimuli

Word Elements (Numbers and Variety; Study 1 only)

$\begin{array}{ll}\text { KOUBT - KO6BT } & \text { FFFF - FOUG } \\ \text { 4INGE5 - LINGEN } & \text { INPENT-IIIII } \\ \text { 9H8N1 - THONK } & \text { BBBBB - BEDIN } \\ \text { MAB - M3B } & \text { JJ - JE } \\ \text { FY - F5 } & \text { POLVUTE - PPPPPPP } \\ \text { 7OR6EA2 - FORBEAL } & \text { WHIB - WWWW } \\ \text { 6E9M - PEAM } & \text { SSSSS - SWARP } \\ \text { WINPOW - W7N2O4 } & \text { TOV - TTT } \\ \text { B8I1E - BLIDE } & \text { RRRRRR - REPONT } \\ \text { JILE - J7LO } & \text { MUSIB - MMMMM }\end{array}$

Character Sequencing (Vowels and Double Consonants; used in both Study 1 and 2)

$\begin{array}{ll}\text { GHW - GOW } & \text { ROPP - RROP } \\ \text { KNDWL - KNOWL } & \text { NEP - NEPP } \\ \text { VO - VC } & \text { PESS- PPES } \\ \text { GRLBR - GRIOR } & \text { SSEN - SENN } \\ \text { SEAB - SCGL } & \text { TTAS - TASS } \\ \text { JACKEF - JDCKCF } & \text { NALL - NNAL } \\ \text { CNPY - ENPY } & \text { RRAS - RASS } \\ \text { CROSP - CRGSP } & \text { RETT - RRET } \\ \text { NARBOW - NDRBCW } & \text { PPON - PONN } \\ \text { PVGHTCN - PIGHTEN } & \text { SALL - SSAL }\end{array}$




\section{Standardized Measures}

CTOPP: Comprehensive Test of Phonological Processing

Wagner, R.K., Torgesen, J.K., \& Rashotte, C.A. (1999). Comprehensive Test of Phonological Processing. Austin, TX: Pro-Ed.

PPVT-R: Peabody Picture Vocabulary Test-Revised

Dunn, L.M., Theriault-Whalen, C.M., \& Dunn, L.M. (1993). Peabody Picture Vocabulary Test-Revised. Toronto: PSYCAN

TACL-3: Test for Auditory Comprehension of Language-Third Edition

Carrow-Woolfolk, E. (1999). Test for Auditory Comprehension of LanguageThird Edition. Toronto: PSYCAN

WPPSI-R: Weschler Preschool and Primary Scale of Intelligence-Revised

Weschler, D. (1989). Weschler Preschool and Primary Scale of Intelligence Revised. San Antonio, TX: The Psychological Corporation. 
Appendix B: Invented Spelling Scoring Key

\section{Lap, Sit, Boot}

0 A random string of letters that do not meet the conditions for any other score.

1 The initial phoneme represented with a phonetically related letter. A random string of letters may follow.

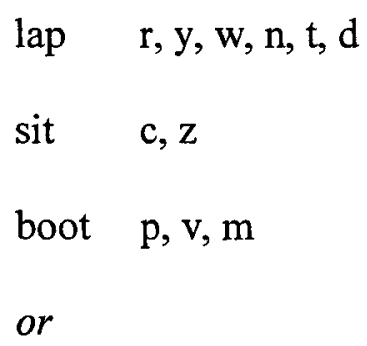

Some other salient part of the word represented. A random string of letters may also be present.

$\begin{array}{ll}\text { lap } & \mathrm{p}, \mathrm{a} \\ \text { sit } & \text { i t } \\ \text { boot } & \mathrm{u}, \mathrm{oo}, \mathrm{t}\end{array}$

2 The correct initial grapheme. A random string of letters may follow.

3 More than one phoneme represented but not all (phonetically related or conventional letters). Letters must be in proper sequence for credit to be given (once intrusions are removed).

lap e.g., lp, Itp (b, v, ,m, are acceptable for the final consonant)

sit e.g., st, cn, sib (n, $1, d$, are acceptable for the final consonant) 
boot e.g., bt, pt, bu (d, n, l, are acceptable for the final consonant)

4 All phonemes represented, phonetically or conventionally, in proper order. May include intrusions.

5 All consonants with conventional letters and vowels marked, in proper order. No intrusions or additional phonemes represented.

6 Correct conventional spelling.

Day, No

0 A random string of letters that do not meet the conditions for any other score.

1 The initial phoneme represented with a phonetically related letter. A random string of letters may follow.

day $\mathrm{n}, \mathrm{l}, \mathrm{t}$

no $\mathrm{m}, \mathrm{l}, \mathrm{t}, \mathrm{d}$

2 The correct initial grapheme or long vowel marked by letter name. A random string of letters may follow.

day d, a

no n, o

3 Both phonemes represented (not necessarily with phonetically related letters), with no intrusions.
day
e.g., fa
no
e.g., po 
4 Both phonemes represented (phonetically related or conventional letters).

Letters must be in proper sequence for credit to be given (once intrusions are removed).

day e.g., ta, tpa

no e.g., mo, mlo

5 All consonants with conventional letters and vowels marked. No additional letters present.

day e.g., da

no e.g., na

6 Correct conventional spelling.

$$
\text { Ape }
$$

0 A random string of letters that do not meet the conditions for any other score.

1 The initial phoneme represented with a vowel or the final phoneme represented by a phonetically related letter $(b, v, m)$. A random string of letters may also be present.

2 The correct initial grapheme (a) or final (p). A random string of letters may also be present.

3 Both phonemes represented (not necessarily with phonetically related letters), with no intrusions.

4 Both phonemes represented (phonetically related or conventional letters). Letters must be in proper sequence for credit to be given (once intrusions are removed). 
5 Initial vowel and final consonant correct (ap). No additional letters present.

6 Correct conventional spelling.

\section{Rabbit}

0 A random string of letters that do not meet the conditions for any other score.

1 The initial phoneme represented with a phonetically related letter (e.g., l, $\mathrm{y}, \mathrm{w})$. A random string of letters may follow. Or, some other salient part of the word represented by a single-letter response. A random string of letters may also be present (e.g., a, b, i, t).

2 The correct initial grapheme. A random string of letters may follow.

3 More than one phoneme represented but not all (phonetically related or conventional letters). Letters must be in proper sequence for credit to be given (once intrusions are removed). Note that phonetically related letters for (b) are (p, v, m), and for (t) are (n, l, d).

$4 \quad$ All phonemes from the first syllable represented, phonetically or conventionally, in proper order. May include intrusions. Or, all consonants represented (phonetically or conventionally) with no vowels present.

5 All consonants with conventional letters and vowels marked, in proper order. No intrusions or additional phonemes represented.

6 Correct conventional spelling. 
Pretty

0 A random string of letters that do not meet the conditions for any other score.

1 The initial phoneme represented with a phonetically related letter (e.g., b, $\mathrm{v}, \mathrm{m}$ ). A random string of letters may follow. Or, some other salient part of the word represented by a single-letter response (r, e, t, y). A random string of letters may also be present.

2 The correct initial grapheme. A random string of letters may follow.

3 More than one phoneme represented but not all (phonetically related or conventional letters). Letters must be in proper sequence for credit to be given (once intrusions are removed). Note that phonetically related letters for $(r)$ are $(1, y, w)$, and for $(t)$ are $(n, 1, d)$. An (i) is acceptable for the first vowel, and an (e) for the final (y).

4 All phonemes from the first syllable represented, phonetically or conventionally, in proper order. May include intrusions. Or, both syllables represented with either the blend or first syllable vowel absent (e.g., pre, pete).

5 All consonants with conventional letters and vowels marked, in proper order. No intrusions or additional phonemes represented.

6 Correct conventional spelling.

\section{Train}

0 A random string of letters that do not meet the conditions for any other score. 
1 The initial phoneme represented with a phonetically related letter (e.g., n, l, d, j, g, ch, h). A random string of letters may follow. Or, some other salient part of the word represented by a single-letter response (r, a, n). A random string of letters may also be present.

2 The correct initial grapheme. A random string of letters may follow.

3 More than one phoneme represented but not all (phonetically related or conventional letters). Letters must be in proper sequence for credit to be given (once intrusions are removed). Note that phonetically related letters for $(r)$ are $(1, y, w)$, and for $(n)$ are $(1, t, d, m)$. An (a) is acceptable for the vowel.

4 All consonants represented, phonetically or conventionally, in proper order, with any vowel. May include intrusions. Or, all consonants except the (r) represented with (a) or (ai) present.

5 All consonants with conventional letters and any vowel in proper order. No intrusions or additional phonemes represented.

$6 \quad$ Correct conventional spelling.

\section{$L a d y$}

0 A random string of letters that do not meet the conditions for any other score.

1 The initial phoneme represented with a phonetically related letter (e.g., r, $\mathrm{y}, \mathrm{w}, \mathrm{n}, \mathrm{t}, \mathrm{d})$. A random string of letters may follow. Or, some other salient part of the word represented by a single-letter response $(a, d, y, e) . A$ random string of letters may also be present. 
2 The correct initial grapheme. A random string of letters may follow.

3 More than one phoneme represented but not all (phonetically related or conventional letters). Letters must be in proper sequence for credit to be given (once intrusions are removed). Note that phonetically related letters for (d) are (n, 1, t). An (e) is acceptable for the final $(y)$.

4 All phonemes from the first syllable represented, phonetically or conventionally, in proper order. May include intrusions. Or, both syllables represented with first syllable vowel absent (e.g., lad, lde).

5 All consonants with conventional letters and vowels marked, in proper order. No intrusions or additional phonemes represented.

6 Correct conventional spelling. 
Appendix C : Pre-Test Scores and Univariate Tests for Training Groups

\begin{tabular}{|c|c|c|c|c|c|}
\hline & I.S. Group & P.A. Group & Cntrl Group & $F(2,66)$ & $P$ \\
\hline Age & 63.52 & 63.74 & 65.57 & 1.976 & .157 \\
\hline P.Ed & 3.57 & 3.26 & 3.61 & .832 & .440 \\
\hline AIQ & 12.39 & 12.17 & $\overline{11.61}$ & .728 & .487 \\
\hline IS & 24.87 & 24.48 & 23.83 & .047 & .954 \\
\hline $\mathrm{PA}^{+}$ & 29.39 & 30.17 & 29.13 & 1.35 & .282 \\
\hline L-S & 40.83 & 40.83 & 40.35 & .022 & .978 \\
\hline O.LC & 15.65 & 15.96 & 17.35 & .888 & .416 \\
\hline O.PS & 10.48 & 9.61 & 9.66 & .922 & .403 \\
\hline $\mathrm{Voc}^{++}$ & 107.91 & 109.17 & 107.17 & .131 & .878 \\
\hline Mor & 25.22 & 25.74 & 25.09 & .083 & .920 \\
\hline
\end{tabular}

Note. I.S. = Invented spelling; P.A. = Phonemic awareness; Cntrl = Control; Age = age in months; P.Ed = parental education; $\mathrm{AIQ}=$ analytic intelligence scaled score; $\mathrm{IS}=$ invented spelling; PA = phonemic awareness; L-S = letter-sound knowledge; O.LC = orthographic awareness-legal characters; O.PS = orthographic awareness-permissible sequences; Voc $=$ receptive vocabulary $;$ Mor $=$ morphological processing $;+=$ standard score, mean $30 ;++=$ standard score, mean 100 
Appendix D: Letter-Sound Instruction and Teaching Sequence

Letters Used

B, T, L, A, P, D, R, E, N, S, Y, I, O

\section{Task Directions/Presentation}

Instructor: Let's see our letters for today.

Here is a __ (letter name); __ (letter name) says __ (letter sound).

(for a vowel: Here is an __ (letter name); it can say different things. One of its sounds is___ (short vowel sound); it can also say its own name (long vowel sound)).

The letter is then used in a chant, with clapping coinciding with the letter name, and knee slapping with the letter sound.

Instructor:

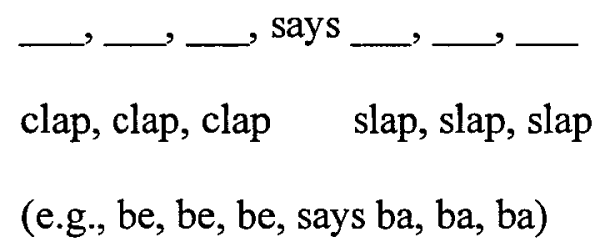

Everybody now - do the song with me

The chant is then repeated in unison two more times, and then the procedure repeated for the next letter in the teaching sequence. In all, four letters are presented each session. After all four letters have been presented in this manner, each is shown one additional time and the children asked to recite the chant without the instructor.

\section{Teaching Sequence}

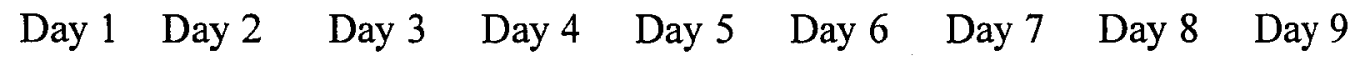

\begin{tabular}{lllllllll}
\hline B & P & N & O & A & E & I & L & R \\
T & D & S & B & P & N & O & A & E \\
L & R & Y & T & D & S & B & P & N \\
A & E & I & L & R & Y & T & D & S
\end{tabular}


Appendix E: Study 2 Training Stimuli For All Groups and Sequence of Presentation

Training Words

\begin{tabular}{lcc} 
& word frequency* & phonotactic probability $^{+}$ \\
\hline ape & 47.4 & .0030 \\
eel & 45.4 & .0027 \\
no & 72.7 & .0034 \\
on & 78.2 & .0005 \\
in & 82.8 & .0359 \\
day & 69.8 & .0015 \\
see & 71.4 & .0028 \\
pie & 51.0 & .0017 \\
soap & 53.8 & .0037 \\
nail & 51.4 & .0046 \\
line & 64.1 & .0047 \\
pole & 58.2 & .0103 \\
pen & 54.6 & .0195 \\
bib & 47.5 & .0064 \\
lap & 52.2 & .0093 \\
sad & 56.4 & .0070 \\
rip & 49.1 & .0220 \\
rod & 53.0 & .0036 \\
lady & 58.0 & .0079 \\
ladder & 53.4 & .0115
\end{tabular}

Note. ${ }^{*}$ Word frequency is presented in terms of standard frequency index (SFI) values derived from Zeno, et al. (1998). These values are logarithmic transformations of the word's frequency per million tokens, weighted by an index of dispersion. All word stimuli were at or above the $90^{\text {th }}$ percentile in terms of word frequency reported by Zeno et al.. Note. ${ }^{+}$Phonotactic probability is presented in terms of summed position specific, biphone probabilities. These values were derived from the online calculator described in Vitevitch and Luce (2004). There are no set criteria that classify phonotactic probabilities as high or low; Word recognition research typically classifies stimuli on a median or similar split. As a reference, Vitevitch and Luce (2005) reported a mean summed biphone probability value of .0080 for their stimuli classified as high phonotactic probability, and .0010 for the stimuli set classified as low probability. 
Presentation Sequence (for all groups)

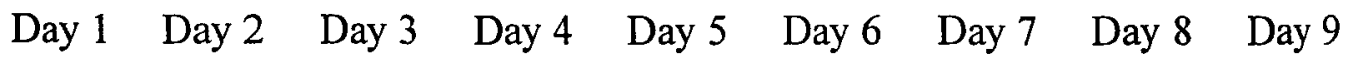

\begin{tabular}{lllllllll}
\hline Ape & ape & day & day & line & line & sad & sad & ape \\
Ape & ape & day & day & line & line & sad & sad & ape \\
Eel & eel & see & see & pole & pole & rip & rip & no \\
Eel & eel & see & see & pole & pole & rip & rip & no \\
No & no & pie & pie & pen & pen & rod & rod & nail \\
No & no & pie & pie & pen & pen & rod & rod & nail \\
On & on & soap & soap & bib & bib & lady & lady & lap \\
On & on & soap & soap & bib & bib & lady & lady & lap \\
In & in & nail & nail & lap & lap & ladder & ladder & lady \\
In & in & nail & nail & lap & lap & ladder & ladder & lady
\end{tabular}


Appendix F : Feedback Guidelines for Invented Spelling Training

The feedback for promoting invented spelling involved providing a model representative of a slight increase in sophistication over the spelling produced by each child. The guidelines below were intended to assist the instructor in determining the appropriate feedback. Following each spelling attempt, the instructor quickly determined the appropriate feedback by considering the defining characteristics of different levels of complexity, as based on Gentry and Gillet (1993).

\begin{tabular}{|c|c|c|}
\hline Target word & $\begin{array}{c}\text { Sessions } 1,2 \\
\text { Defining characteristic }\end{array}$ & Feedback model \\
\hline APE & $\begin{array}{l}\text { no A (may be a random } \\
\text { string or phonetically } \\
\text { related letters) } \\
\text { A present but no } P \text { after it } \\
\text { A and } P \text { in correct order but } \\
\text { with other letters present } \\
\text { AP }\end{array}$ & $\begin{array}{l}\text { add } A \text { to beginning or } \\
\text { replace first letter with } A \text { if } \\
\text { letter is a vowel } \\
\text { add } P \text { to the end or replace } \\
\text { last letter with } P \text { if letter is } \\
B \text { or V } \\
\text { remove extra letters } \\
\text { (except final } E \text { ) } \\
\text { APE }\end{array}$ \\
\hline EEL & $\begin{array}{l}\text { no } E \\
\text { E present but no } L \text { after it } \\
\text { E and } L \text { in correct order but } \\
\text { with other letters present } \\
\text { EL }\end{array}$ & $\begin{array}{l}\text { add } E \text { to beginning or } \\
\text { replace first letter with } E \text { if } \\
\text { letter is a vowel } \\
\text { add } L \text { to the end or replace } \\
\text { last letter with } L \text { if it is } Y \text {, } \\
W, R, N, T \text {, or } D \\
\text { remove extra letters } \\
\text { (except another E before } \\
\text { the } L \text { ) } \\
\text { EEL }\end{array}$ \\
\hline $\mathrm{NO}$ & $\begin{array}{l}\mathrm{N} \text { and } \mathrm{O} \text { in correct order } \\
\text { but with extra letters } \\
\text { NO }\end{array}$ & $\begin{array}{l}\text { add } \mathrm{N} \text { to beginning or } \\
\text { replace first letter with } \mathrm{N} \text { if } \\
\text { letter is } \mathrm{M}, \mathrm{T}, \mathrm{D} \text {, or } \mathrm{L} \\
\text { add } \mathrm{O} \text { to the end or replace } \\
\text { last letter with } \mathrm{O} \text { if letter is } \\
\text { a vowel } \\
\text { remove extra letters } \\
\text { NO }\end{array}$ \\
\hline
\end{tabular}




\begin{tabular}{|c|c|c|}
\hline $\mathrm{ON}$ & $\begin{array}{l}\mathrm{N} \text { but no } \mathrm{O} \text { before it } \\
\mathrm{O} \text { and } \mathrm{N} \text { in correct order } \\
\text { but with extra letters } \\
\mathrm{ON}\end{array}$ & $\begin{array}{l}\text { add } \mathrm{N} \text { to end or replace } \\
\text { last letter with } \mathrm{N} \text {, if it is a } \\
\mathrm{M}, \mathrm{T}, \mathrm{D} \text {, or } \mathrm{L} \\
\text { add } \mathrm{O} \text { to beginning or } \\
\text { replace first letter with } \mathrm{O} \text { if } \\
\text { letter is a vowel } \\
\text { remove extra letters } \\
\mathrm{ON}\end{array}$ \\
\hline $\mathrm{IN}$ & $\begin{array}{l}\mathrm{N} \text { but no I before it } \\
\text { I and } \mathrm{N} \text { in correct order but } \\
\text { with extra letters } \\
\text { IN }\end{array}$ & $\begin{array}{l}\text { add } N \text { to end or replace } \\
\text { last letter with } N \text { if it is a } \\
M, T, D \text {, or } L \\
\text { add I to beginning or } \\
\text { replace first letter with I if } \\
\text { letter is a vowel } \\
\text { remove extra letters } \\
\text { IN }\end{array}$ \\
\hline Target word & $\begin{array}{c}\text { Sessions 3, } 4 \\
\text { Defining characteristic }\end{array}$ & Feedback model \\
\hline DAY & $\begin{array}{l}\text { no D (may be a random } \\
\text { string or phonetically } \\
\text { related letters) } \\
\text { D present but no A after it } \\
\text { D and A in correct order but } \\
\text { with other letters present } \\
\text { DA }\end{array}$ & $\begin{array}{l}\text { add } D \text { to beginning or } \\
\text { replace first letter with } D \text { if } \\
\text { letter is } T, N \text {, or } L \\
\text { add } A \text { to the end or replace } \\
\text { last letter if it is a vowel } \\
\text { remove extra letters } \\
\text { (except final Y if present) } \\
\text { DAY }\end{array}$ \\
\hline SEE & $\begin{array}{l}S \text { present but no } E \text { after it } \\
S \text { and } E \text { in correct order but } \\
\text { with other letters present } \\
\text { SE }\end{array}$ & $\begin{array}{l}\text { add } S \text { to beginning or } \\
\text { replace first letter with } S \text { if } \\
\text { letter is a } Z \text { or } C \\
\text { add } E \text { to the end or replace } \\
\text { last letter if it is a vowel } \\
\text { remove extra letters } \\
\text { (except another } E \text { if } \\
\text { present) } \\
\text { SEE }\end{array}$ \\
\hline PIE & $P$ but no I after it & $\begin{array}{l}\text { add } P \text { to beginning or } \\
\text { replace first letter with } P \text { if } \\
\text { letter is } B, M \text {, or } V \\
\text { add I to the end or replace } \\
\text { last letter if it is a vowel }\end{array}$ \\
\hline & $\begin{array}{l}\mathrm{P} \text { and } \mathrm{I} \text { in correct order but } \\
\text { with other letters present } \\
\text { PI }\end{array}$ & $\begin{array}{l}\text { remove extra letters } \\
\text { (except for final E) } \\
\text { PIE }\end{array}$ \\
\hline
\end{tabular}




\begin{tabular}{|c|c|c|}
\hline SOAP & $\begin{array}{l}\mathrm{S} \text { but no } \mathrm{P} \text { after it } \\
\mathrm{S} \text { and } \mathrm{P} \text { in correct order but } \\
\text { no } \mathrm{O} \\
\mathrm{S}, \mathrm{O}, \mathrm{P} \text { in correct order but } \\
\text { with other letters present } \\
\text { SOP }\end{array}$ & $\begin{array}{l}\text { add } \mathrm{S} \text { to beginning or } \\
\text { replace first letter with } \mathrm{S} \text { if } \\
\text { letter is } \mathrm{Z} \text { or } \mathrm{C} \\
\text { add } \mathrm{P} \text { to end or replace last } \\
\text { letter if } \mathrm{B}, \mathrm{M} \text {, or } \mathrm{V} \\
\text { add } \mathrm{O} \text { between } \mathrm{S} \text { and } \mathrm{P} \text { or } \\
\text { replace existing medial } \\
\text { vowel with } \mathrm{O} \\
\text { remove extra letters } \\
\text { (except for medial } \mathrm{A} \text { ) } \\
\text { SOAP }\end{array}$ \\
\hline NAIL & $\begin{array}{l}\mathrm{N} \text { and } \mathrm{L} \text { in correct order } \\
\text { but no } \mathrm{A} \\
\mathrm{N}, \mathrm{A}, \mathrm{L} \text { in correct order but } \\
\text { with other letters present } \\
\text { NAL }\end{array}$ & $\begin{array}{l}\text { add } N \text { to beginning or } \\
\text { replace first letter with } N \text { if } \\
\text { letter is } M, T, D, L \\
\text { add } L \text { to ending or replace } \\
\text { last letter if } T, D, N, R, Y \text {, } \\
W \\
\text { add A between } N \text { and } L \text { or } \\
\text { replace existing medial } \\
\text { vowel with A } \\
\text { remove extra letters } \\
\text { (except for medial I) } \\
\text { NAIL }\end{array}$ \\
\hline Target word & $\begin{array}{c}\text { Sessions } 5,6^{*} \\
\text { Defining characteristic }\end{array}$ & Feedback model \\
\hline LINE & $\begin{array}{l}\text { no } \mathrm{L} \\
\mathrm{L} \text { but no } \mathrm{N} \text { after it } \\
\mathrm{L} \text { and } \mathrm{N} \text { in correct order but } \\
\text { no I } \\
\mathrm{L}, \mathrm{I}, \mathrm{N} \text { in correct order but } \\
\text { with other letters present } \\
\text { LIN }\end{array}$ & $\begin{array}{l}\text { add } L \text { to beginning or } \\
\text { replace first letter with } L \text { if } \\
\text { letter is } T, D, N, R, Y, W \\
\text { add } N \text { to end or replace } \\
\text { last letter if } M, T, D, L \\
\text { add I between } L \text { and } N \text { or } \\
\text { replace existing medial } \\
\text { vowel with I } \\
\text { remove extra letters } \\
\text { (except for final } E \text { ) } \\
\text { LINE }\end{array}$ \\
\hline POLE & $\begin{array}{l}\mathrm{P} \text { and } \mathrm{L} \text { in correct order but } \\
\text { no } \mathrm{O}\end{array}$ & $\begin{array}{l}\text { add } P \text { to beginning or } \\
\text { replace first letter with } P \text { if } \\
B, M, V \\
\text { add } L \text { to end or replace last } \\
\text { letter if it is a } T, D, N, R \text {, } \\
Y, W \\
\text { add } O \text { between } P \text { and } L \text { or } \\
\text { replace existing medial } \\
\text { vowel with } O\end{array}$ \\
\hline
\end{tabular}




\begin{tabular}{|c|c|c|}
\hline & $\begin{array}{l}\mathrm{P}, \mathrm{O}, \mathrm{L} \text { in correct order but } \\
\text { with other letters present } \\
\mathrm{POL}\end{array}$ & $\begin{array}{l}\text { remove extra letters } \\
\text { (except for final E) } \\
\text { POLE }\end{array}$ \\
\hline \multirow[t]{4}{*}{ PEN } & no $P$ & $\begin{array}{l}\text { add } P \text { to beginning or } \\
\text { replace first letter with } P \text { if } \\
B, M, V\end{array}$ \\
\hline & $\mathrm{P}$ but no $\mathrm{N}$ after it & $\begin{array}{l}\text { add } N \text { to end or replace } \\
\text { last letter if } M, T, D \text {, or } L\end{array}$ \\
\hline & $\begin{array}{l}\mathrm{P} \text { and } \mathrm{N} \text { in correct order but } \\
\text { no } \mathrm{E}\end{array}$ & $\begin{array}{l}\text { add } \mathrm{E} \text { between } \mathrm{P} \text { and } \mathrm{N} \text { or } \\
\text { replace existing medial } \\
\text { vowel with } \mathrm{E}\end{array}$ \\
\hline & $\begin{array}{l}\mathrm{P}, \mathrm{E}, \mathrm{N} \text { in correct order but } \\
\text { with other letters present }\end{array}$ & remove extra letters \\
\hline \multirow[t]{4}{*}{ BIB } & no $B$ & $\begin{array}{l}\text { add } B \text { to beginning or } \\
\text { replace first letter with } B \text { if } \\
P, M, V\end{array}$ \\
\hline & one $\mathrm{B}$ but no second $\mathrm{B}$ & $\begin{array}{l}\text { add } B \text { to end or replace last } \\
\text { letter if } P, M \text {, or } V\end{array}$ \\
\hline & $\mathrm{B}$ and $\mathrm{B}$ but no I & $\begin{array}{l}\text { add I between } B \text { and } B \text { or } \\
\text { replace existing medial } \\
\text { vowel with I }\end{array}$ \\
\hline & $\begin{array}{l}\text { B,I,B in correct order but } \\
\text { with other letters present }\end{array}$ & remove extra letters \\
\hline \multirow[t]{4}{*}{$\overline{\mathrm{LAP}}$} & no L & $\begin{array}{l}\text { add } \mathrm{L} \text { to beginning or } \\
\text { replace first letter with } \mathrm{L} \text { if } \\
\text { letter is } T, D, N, R, Y, W\end{array}$ \\
\hline & $L$ but no $P$ after it & $\begin{array}{l}\text { add } P \text { to end or replace last } \\
\text { letter if } M, B \text {, or } V\end{array}$ \\
\hline & $\begin{array}{l}\mathrm{L} \text { and } \mathrm{P} \text { in correct order but } \\
\text { no } \mathrm{A}\end{array}$ & $\begin{array}{l}\text { add } \mathrm{A} \text { between } \mathrm{L} \text { and } \mathrm{P} \text { or } \\
\text { replace existing medial } \\
\text { vowel with } \mathrm{A}\end{array}$ \\
\hline & $\begin{array}{l}\text { L,A,P in correct order but } \\
\text { with other letters present }\end{array}$ & remove extra letters \\
\hline
\end{tabular}

Sessions $7,8^{*}$

Target word Defining characteristic Feedback model

\begin{tabular}{|c|c|c|}
\hline \multirow[t]{2}{*}{$\mathrm{SAD}$} & $\mathrm{S}$ but no $\mathrm{D}$ after it & $\begin{array}{l}\text { add } S \text { to beginning or } \\
\text { replace first letter with } S \text { if } \\
\text { letter is } C \text { or } Z \\
\text { add } D \text { to end or replace } \\
\text { last letter if } N, T, L\end{array}$ \\
\hline & $\begin{array}{l}S \text { and } D \text { in correct order but } \\
\text { no } A\end{array}$ & $\begin{array}{l}\text { add } A \text { between } S \text { and } D \text { or } \\
\text { replace existing medial } \\
\text { vowel with } A\end{array}$ \\
\hline
\end{tabular}




\begin{tabular}{|c|c|c|}
\hline & $\begin{array}{l}\mathrm{S}, \mathrm{A}, \mathrm{D} \text { in correct order but } \\
\text { with other letters present }\end{array}$ & remove extra letters \\
\hline \multirow[t]{4}{*}{$\mathrm{RIP}$} & no $R$ & $\begin{array}{l}\text { add } R \text { to beginning or } \\
\text { replace first letter with } R \text { if } \\
\text { letter is } L, Y, W\end{array}$ \\
\hline & $\mathrm{R}$ but no $\mathrm{P}$ after it & $\begin{array}{l}\text { add } P \text { to end or replace last } \\
\text { letter if } B, M \text {, or } V\end{array}$ \\
\hline & $\begin{array}{l}\mathrm{R} \text { and } \mathrm{P} \text { in correct order but } \\
\text { no I }\end{array}$ & $\begin{array}{l}\text { add } I \text { between } R \text { and } P \text { or } \\
\text { replace existing medial } \\
\text { vowel with I }\end{array}$ \\
\hline & $\begin{array}{l}\mathrm{R}, \mathrm{I}, \mathrm{P} \text { in correct order but } \\
\text { with other letters present }\end{array}$ & remove extra letters \\
\hline \multirow[t]{4}{*}{ ROD } & no $R$ & $\begin{array}{l}\text { add } R \text { to beginning or } \\
\text { replace first letter with } R \text { if } \\
\text { letter is } L, Y, W\end{array}$ \\
\hline & R but no $\mathrm{D}$ after it & $\begin{array}{l}\text { add } D \text { to end or replace } \\
\text { last letter if } N, T \text {, or } L\end{array}$ \\
\hline & $\begin{array}{l}\mathrm{R} \text { and } \mathrm{D} \text { in correct order but } \\
\text { no } \mathrm{O}\end{array}$ & $\begin{array}{l}\text { add } O \text { between } R \text { and } D \text { or } \\
\text { replace existing medial } \\
\text { vowel with } O\end{array}$ \\
\hline & $\begin{array}{l}\mathrm{R}, \mathrm{O}, \mathrm{D} \text { in correct order but } \\
\text { with other letters present }\end{array}$ & remove extra letters \\
\hline \multirow[t]{4}{*}{ LADY } & no L & $\begin{array}{l}\text { add } L \text { to beginning or } \\
\text { replace first letter with } L \text { if } \\
\text { letter is } T, D, N, R, Y, W\end{array}$ \\
\hline & $\mathrm{L}$ but no $\mathrm{D}$ after it & $\begin{array}{l}\text { add } D \text { to end or replace } \\
\text { last letter if } T, N \text {, or } L\end{array}$ \\
\hline & $\mathrm{L}$ and $\mathrm{D}$ but no $\mathrm{A}$ & $\begin{array}{l}\text { add } A \text { between } L \text { and } D \text { or } \\
\text { replace existing medial } \\
\text { vowel with } A\end{array}$ \\
\hline & $\begin{array}{l}\mathrm{L}, \mathrm{A}, \mathrm{D} \text { in correct order but } \\
\text { with other letters present } \\
\text { and/or no final } \mathrm{Y}\end{array}$ & $\begin{array}{l}\text { remove extra letters and/or } \\
\text { add final } Y\end{array}$ \\
\hline \multirow[t]{5}{*}{ LADDER } & no $L$ & $\begin{array}{l}\text { add } L \text { to beginning or } \\
\text { replace first letter with } L \text { if } \\
\text { letter is } T, D, N, R, Y, W\end{array}$ \\
\hline & $\mathrm{L}$ but no $\mathrm{D}$ after it & $\begin{array}{l}\text { add } \mathrm{D} \text { to middle or replace } \\
\text { any medial } \mathrm{N}, \mathrm{T}, \mathrm{L}\end{array}$ \\
\hline & $\begin{array}{l}\mathrm{L} \text { and } \mathrm{D} \text { in correct order but } \\
\text { no } \mathrm{A}\end{array}$ & $\begin{array}{l}\text { add } A \text { between } L \text { and } D \text { or } \\
\text { replace existing medial } \\
\text { vowel with } A\end{array}$ \\
\hline & $\begin{array}{l}\mathrm{L}, \mathrm{A}, \mathrm{D} \text { in correct order but } \\
\text { with no final } \mathrm{R} \text { and/or extra } \\
\text { letters present }\end{array}$ & $\begin{array}{l}\text { remove extra letters and/or } \\
\text { add final } \mathrm{R}\end{array}$ \\
\hline & LADR & LADDER \\
\hline
\end{tabular}




\begin{tabular}{ll} 
Target word & \multicolumn{1}{c}{$\begin{array}{c}\text { Session } 9^{*} \\
\text { Defining characteristic }\end{array}$} \\
\hline APE & $\begin{array}{l}\text { no A (may be a random } \\
\text { string or phonetically } \\
\text { related letters) } \\
\text { A present but no P after it }\end{array}$ \\
& A and P in correct order but \\
& with other letters present \\
& AP \\
\hline NO & no N
\end{tabular}

Feedback model

add $A$ to beginning or

replace first letter with $A$ if

letter is a vowel

add $P$ to the end or replace

last letter with $P$ if letter is

$\mathrm{B}$ or $\mathrm{V}$

remove extra letters

(except final E)

APE

add $\mathrm{N}$ to beginning or

replace first letter with $\mathrm{N}$ if

$\mathrm{N}$ but no $\mathrm{O}$

letter is $\mathrm{M}, \mathrm{T}, \mathrm{D}$, or $\mathrm{L}$ add $\mathrm{O}$ to the end or replace last letter with $O$ if letter is a vowel

$\mathrm{N}$ and $\mathrm{O}$ in correct order

remove extra letters

but with extra letters

NO

NO

\begin{tabular}{ll} 
NO \\
\hline NAIL No N
\end{tabular}

$\mathrm{N}$ but no $\mathrm{L}$ after it

add $\mathrm{N}$ to beginning or replace first letter with $\mathrm{N}$ if letter is $M, T, D, L$ add $L$ to ending or replace last letter if T, D, N, R, Y, W

$\mathrm{N}$ and $\mathrm{L}$ in correct order but no $\mathrm{A}$ add $\mathrm{A}$ between $\mathrm{N}$ and $\mathrm{L}$ or replace existing medial vowel with $\mathrm{A}$

$\mathrm{N}, \mathrm{A}, \mathrm{L}$ in correct order but remove extra letters with other letters present (except for medial I) NAL NAIL

\begin{tabular}{ll}
\hline LAP no L & \\
& L but no P after it \\
& L and P in correct order but \\
no A
\end{tabular}
add $\mathrm{L}$ to beginning or replace first letter with $L$ if letter is T, D, N, R, Y, W add $P$ to end or replace last letter if $M, B$, or V add $A$ between $L$ and $P$ or replace existing medial vowel with $A$

$\mathrm{L}, \mathrm{A}, \mathrm{P}$ in correct order but remove extra letters with other letters present

LADY no L

add $\mathrm{L}$ to beginning or replace first letter with $L$ if letter is T, D, N, R, Y, W 
$\mathrm{L}$ but no $\mathrm{D}$ after it

$\mathrm{L}$ and $\mathrm{D}$ but no $\mathrm{A}$ add $D$ to end or replace last letter if $\mathrm{T}, \mathrm{N}$, or $\mathrm{L}$ add $A$ between $L$ and $D$ or replace existing medial vowel with $\mathrm{A}$

remove extra letters and/or add final $\mathrm{Y}$
L, A, D in correct order but with other letters present and/or no final Y

* Note. Beginning with session 5, the feedback for the second spelling of each word also involved removing all extra letters, regardless of the defining characteristics or level of the spelling attempt. 
Appendix G: Pre- and Post- Test Means By School

\begin{tabular}{|l|c|c|c|c|c|c|}
\hline & School 1 & School 2 & School 3 & School 4 & $F(3,65)$ & $p$ \\
\hline Age & 64.61 & 66.40 & 62.45 & 64.71 & 2.813 & .046 \\
\hline P.Ed & 3.44 & 3.80 & 3.55 & 3.29 & .643 & .590 \\
\hline AIQ & 12.72 & 10.70 & 12.75 & 11.48 & 3.060 & .034 \\
\hline IS- pre & 23.56 & 25.70 & 27.75 & 21.29 & 1.174 & .327 \\
\hline PA- pre & 28.94 & 27.50 & 31.65 & 28.00 & 4.950 & .004 \\
\hline L-S-pre & 40.67 & 40.30 & 43.90 & 37.76 & 1.718 & .172 \\
\hline O.LC & 14.44 & 15.60 & 16.75 & 17.86 & 2.010 & .121 \\
\hline O.PS- pre & 9.89 & 10.50 & 9.20 & 10.24 & .789 & .504 \\
\hline Voc ${ }^{++}$ & 107.56 & 99.10 & 108.35 & 112.57 & 2.507 & .067 \\
\hline Mor & 24.83 & 22.80 & 26.50 & 25.90 & 1.074 & .366 \\
\hline IS- post & 35.00 & 34.00 & 41.00 & 25.91 & 6.866 & .000 \\
\hline PA- post & 32.78 & 29.40 & 35.40 & 29.71 & 7.76 & .000 \\
\hline L-S- post & 46.78 & 43.00 & 49.85 & 41.91 & 6.644 & .001 \\
\hline O.PS- post & 10.00 & 11.20 & 13.30 & 11.52 & 7.60 & .000 \\
\hline
\end{tabular}

Note.; Age = age in months; $\mathrm{P} . \mathrm{Ed}=$ parental education; $\mathrm{AIQ}=$ analytic intelligence scaled score; IS- pre = invented spelling pre-test; PA-pre = phonemic awareness pre-test; L-S- pre = letter-sound knowledge pre-test; O.LC = orthographic awareness-legal characters; O.PS- pre = orthographic awareness-permissible sequences pre-test; Voc $=$ receptive vocabulary ; Mor = morphological processing; IS- post $=$ invented spelling post-test; PA- post $=$ phonemic awareness post-test; L-S- post $=$ letter-sound knowledge post-test; O.PS- post = orthographic awareness-permissible sequences post-test; + = standard score, mean $30 ;++=$ standard score, mean 100 